NUREG-0914

N3

\title{
Radiological Containment Handbook
}

NUREG--0914

DE83 900480

Manuscript Completed: October 1982

Date Published: October 1982

Division of Engineering Technology Office of Nuclear Regulatory Research U.S. Nuclear Regulatory Commission Washington, D.C. 20555

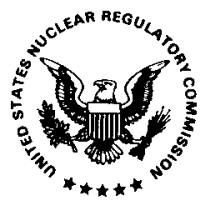




\section{DISCLAIMER}

This report was prepared as an account of work sponsored by an agency of the United States Government. Neither the United States Government nor any agency Thereof, nor any of their employees, makes any warranty, express or implied, or assumes any legal liability or responsibility for the accuracy, completeness, or usefulness of any information, apparatus, product, or process disclosed, or represents that its use would not infringe privately owned rights. Reference herein to any specific commercial product, process, or service by trade name, trademark, manufacturer, or otherwise does not necessarily constitute or imply its endorsement, recommendation, or favoring by the United States Government or any agency thereof. The views and opinions of authors expressed herein do not necessarily state or reflect those of the United States Government or any agency thereof. 


\section{DISCLAIMER}

Portions of this document may be illegible in electronic image products. Images are produced from the best available original document. 
NUREG-0914

\title{
RADIOLOGICAL CONTAINMENT HANDBOOK
}

\author{
Chemical Engineering Branch
}


I. INTRODUCTION ...................... I-

A.. General . . ..................... I-1

B. Selection of Containments .. . . . . . . . . . . . I-2

C. Design and Fabrication . . . . . . . . . . . . . . . . . . I-3

D. Training Program .................... I-4

II. INSTALLATION OF CONTAINMENTS . . . . . . . . . . . . II-1

A. Prefabrication Air Test Procedure . . . . . . . . . . . . . II-I

B. Fabrication of Containments . . . . . . . . . . . . . . . II-3

C. Onsite Glove Bag Installation . . . . . . . . . . . . . . . . . II-8

D. Installation of Secondary Containments . . . . . . . . . . . II-20

E. Installation of a Containment Tent. . . . . . . . . . . . . . II-24

III. INSPECTION OF CONTAINMENTS . . . . . . . . . . . . . III-I

A. General ....................... . III-1

B. Modification ................... . III-3

C. Inspection Frequency .................... . III-4

D. Inspection Criteria - After Installation . . . . . . . . . . III-4

E. Inspection Criteria - Routine . . . . . . . . . . . . . . . . III-5

F. Containment Tent Installation Inspection Criteria . . . . . . III-6

G. Containment Tent Inspection - Routine . . . . . . . . . . . III-7

IV. WORKING GUIDELINES ..................... IV-1

A. Prior To Working . . . . . . . . . . . . . . . . . . IV-1

B. During Work . . . . . . . . . . . . . . . . . . . . IV-1

C. Guidelines For Working Near Containments . . . . . . . . . . . IV-8

D. Guidelines For Securing the Containment After Work . . . . . . IV-9

V. OPERATING REQUIREMENTS ................ . .

A. Use of Polybottles . . . . . . . . . . . . . . . . . V-1

B. Removal of Polybottles . . . . . . . . . . . . . . . . V-8

C. Use of High Efficiency Filtered Vacuum Cleaners . . . . . . . . V-13

D. Grinding Welds Inside Containments . . . . . . . . . . . . . . V-17

E. Cutting Pipes Inside a Containment . . . . . . . . . . . V-20

F. Fitup and Welding of Pipes . . . . . . . . . . . . . V-22

G. Use of Lucite Shields . . . . . . . . . . . . . . . . V-26

H. Use of Drop Cloths . . . . . . . . . . . . . . . . V-26

I. Temporary Ventilation .................. . V-27

J. Decontamination During Work . . . . . . . . . . . . . V-31 
VI. EMERGENCY PROCEDURES ..................... . . VI-1

A. Spill Procedures . . . . . . . . . . . . . . . . . VI-1

B. Damaged Glove Removal and Replacement ............. VI-2

C. Cut Hand in a Glove Bag ................. . VI-7

VII. REMOVAL OF CONTAINMENTS ............... VII-I

APPENDIX A - Work chart ...............A-1

APPENDIX B - Glossary . . . . . . . . . . . . . B-1

APPENDIX C - Containment Examples .............. C-1 


\section{PREFACE}

The purpose of this NUREG is to be used as a reference text. It is meant to (a) be used by the working personnel as a guide for using temporary radiological containments. The installing group and health physics group may vary among organizations but responsibilities and duties will not change. 


\section{INTRODUCTION}

\section{A. GENERAL}

Control of radioactive contamination can be attained by:

1. Pre-job briefings between the cognizant groups before a job is started,

2. Training of personnel to adhere to established guidelines for work with radioactive materials, and/or

3. The use of containments.

What is a containment?

A temporary radiological containment as defined in this document is a partial or complete enclosure that is used as a temporary barrier to contain and/or prevent the spread of contamination. There are two kinds of temporary containments.

A primary containment is one that is used as the boundary for contamination control and work operations are performed inside it. When one or more of the following conditions are met, it is considered a primary containment:

1. The internal surface of the containment and/or the external surface of the component being contained is or has the potential for becoming contaminated above locally established surface contamination limits;

2. Contaminated liquid path surfaces could be exposed;

3. Contaminated solutions could be released within the containment; or

4. The containment is used for certain operations, as defined in the Work Chart (see Appendix A).

A secondary containment utilizes the system as the boundary for contamination control. These temporary containments are installed to control accidental releases from mechanical joints. The internal containment surfaces and external component areas are not expected to exceed established contamination limits.

The content of this manual is divided into six general areas:

1. The selection section which defines the various types of temporary containments, responsibilities, design and selection criteria, containment testing and training requirements;

2. The installation section which explains how various temporary containments are installed, the tests required for acceptance of temporary containment and responsibilities; 
3. The inspection section which sets forth the inspection criteria for various temporary containments;

4. The use section which details some precautions that should be taken when working in temporary containments, how to decontaminate temporary containments and the use of accessory equipment to control contamination during work;

5. The removal section which explains the procedure for removing or taking down a temporary containment after work has been completed; and

6. Emergency response section which explains the proper procedure for responding to emergency situations involving temporary containments.

\section{B. SELECTION OF CONTAINMENTS}

How do we know when a temporary containment is needed? When the operating procedure for a job is prepared, the cognizant engineering group, health physics group, and the operations staff will determine the need. This group should consider, as a minimum, the following factors:

1. The type of operation to be performed, using the Work Chart (Appendix $A$ ) as a guideline.

2. The radiological conditions:

- internal contamination levels, known or expected?

- open contaminated liquid surfaces?

- possible release of contaminated surfaces?

o history of activated metal?

3. The size and shape of the component/piping to be contained.

4. Interferences in the area.

5. Can a standard containment be used? If a special containment is needed, information will be gathered by the cognizant engineer.

How do we know what kind of temporary containment is needed? The guideline is that work done on potentially or actually contaminated systems is normally done inside a complete containment enclosure. When the operating procedure is being drawn up, this guideline should be used. Any decision to use other than a complete containment should be made by joint agreement between the health physics group, the engineering group, and the operations group. The operating procedure, when complete, should specify the following:

1. The general type of containment (e.g., glove bag, tent, drop cloth, etc. );

2. The level of containment (primary or secondary);

3. The amount of liquid expected, if any; 
4. The need for a HEPA-type ventilation system.

When a standard containment type is specified in the procedure, the user is responsible for determining the specific model to be used. If more than one working group will be using the containment, all the groups should be contacted and the most suitable model determined.

The standard containments depicted in this manual meet the needs and requirements of most work operations. The users can request modifications, such as the addition of sleeving, tie-offs, or access flaps, to the standard containments. Any alterations that physically change the body or configuration of a special or standard containment should require the approval of the health physics group.

The health physics group should have the following specific responsibilities with regard to containments:

1. Designing of and specifications for all radiological containments and associated equipment, including modifications, changes and alterations;

2. Resolving problems involving installation or use of containments in unusual or difficult situations;

3. Reviewing and approving containment training courses;

4. Evaluating containments which fail air leak tests, including repairs that may be done;

5. Inspection and approval of portable containment ventilation system, including alterations to the system;

6. Reviewing temporary shielding requirements; and

7. Reviewing containment effectiveness when notified by the cognizant management of changing work conditions.

\section{DESIGN AND FABRICATION}

There are several design criteria for temporary containments:

1. All flexible containments should be fabricated from polyvinylchloride (PVC) or a nylon reinforced laminated PVC sheeting. The use of polyethylene is prohibited unless specifically authorized in the procedure.

2. A specific color should be specified for contaminated or potentially contaminated material. The color purple was selected in this case because of its distinct color and undesignated universal use. PVC material must be transparent or translucent. Any deviation should require the approval of the health physics group. The exceptions are as follows: 
- When visibility is required, transparent PVC may be used, provided that purple PVC is used for those areas most susceptible to damage during use or removal, e.g., sleeves, skirts;

- Tubular rigid PVC or sheetmetal may be used for containment transfer sleeve collars; and

- Containment tents may be constructed of two (2) color reinforced sheets (i.e., white inside/purple outside) as an aid to light reflection and/or cleanliness control.

3. Weather protection for radiologically controlled areas/items should not be constructed of purple colored materials. "Caution! Potentially Contaminated" tape should be applied to the external surfaces of the cover to provide identification of covered material.

4. Containments installed around ur on components expected to exceed $60^{\circ} \mathrm{C}\left(140^{\circ} \mathrm{F}\right)$ on the surface should be thermally protected with an insulating material.

5. All complete primary enclosures should have a HEPA filter to protect the containment against billowing. If air tools are used and the exhaust is in the containment, the filter should have a minimum flow rate of $40 \mathrm{cfm}$.

6. Special containments should be utilized only for their intended purpose and only in areas specified in applicability listing.

\section{TRAINING PROGRAM}

A training program should be developed to instruct personnel on how to install, use, remove and inspect containments. It is recommended that three individual courses be developed, each tailored to the group of people who will be involved with the containment. These three courses should be for the health physics technicians, containment specialists, and the craftsman and/or transient worker.

All personnel involved in radiological containment installation should be required to receive specific training in methods of selection, installation, use, maintenance and removal. Workers who will be using containments should receive specific training in the use, maintenance and emergency procedures associated with radiological containments. When a containment tent or walk-in containment is used and mock-up training is being conducted, the training requirements should be satisfied for personnel not previously containment trained. The mockup training for them should be properly documented before the job is started. Training requirements may be waived for supervisory and technical personnel who:

1. are observing work in progress, or

2. must enter an enclosure to resolve technical difficulties, provided that on-the-job briefings are held prior to entry. 
Personnel performing pre-testing should receive specific training in the methods of testing and acceptance criteria, prefabrication and installation of containments.

Training records should be maintained with copies sent to the cognizant group managers. Questions regarding technical aspects of containments or techniques should be referred to the organizations Radiological Engineering or Health Physics Section for prompt resolution.

The course should have both theoretical and practical sections. The theoretical portion should provide the following:

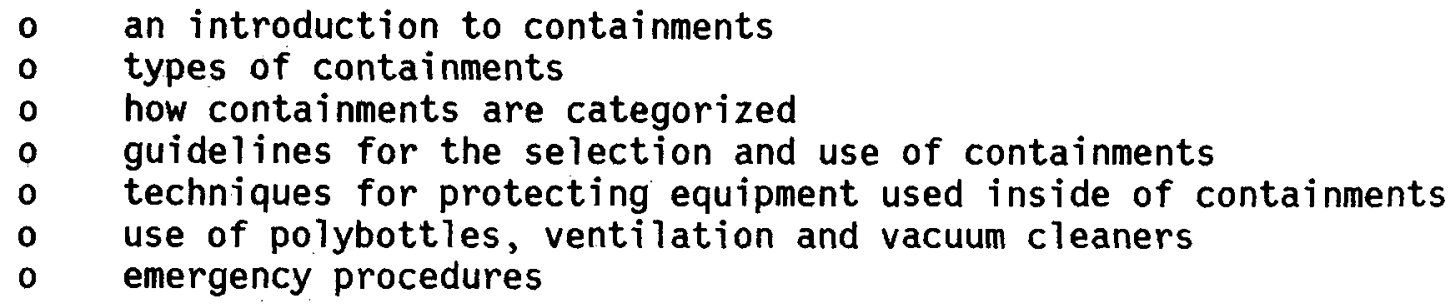

After this section is presented and discussed, the class should perform the practical section.

The practical section should take place in a mockup facility set-up with a walk-in containment and several types of glove bags. Mockups of typical operations should be set up in the containments with air and water services. Contamination can be simulated through the use of fluorescent powders and ultraviolet light.

The various groups who use containments should perform hands-on work in the following areas:

- installation of various containments, including service leads, polybottles and other accessory equipment

o inspection of containments, including the steps required to resolve any problems that may be found

- performing various operations, either as dry runs for a job or as initial training, using techniques developed for containment work

Every member of the class should participate in the practical phase and successfully demonstrate proficiency. Satisfactory completion of the class should permit the worker to work with containments.

If an operation requires dry runs because of unusual radiation and/or containment levels and the containment is of a complex nature, the personnel involved should be qualified for that operation, even though his containment qualification is still valid.

Successful completion of this course should be a prerequisite to conducting work with containments. 
All personnel who work with containments should be requalified every 24 months. Personnel who need the initial training should be fully qualified radiation workers whose retraining dates are still valid. 


\section{INSTALLATION OF CONTAINMENTS}

Containments should be prefabricated and assembled as much as possible prior to installation in order to reduce the exposure to the installer.

The Health Physics group should complete section 1 of the Radiological Containment Status Sheet (see Figure 2-A-1) after they have decided which particular model and modifications are needed. The status sheet is then sent to the installing group. Typical glove bag models are shown in Appendix $C$.

The installing group would preassemble the needed containment from stock. An air leak test is done by them to verify the integrity of the glove bag.

\section{A. PREFABRICATION AIR TEST PROCEDURE}

\section{CAUTION!}

\section{Only clean, dry oil-free air should} be used.

1. Attach the air supply to the test rig via quick disconnect.

2. Attach the supply/monitoring tube to a sleeve.

One test rig should be permanently assigned at the containment assembly facility to be used for the initial air test of the containment prior to issue, tape the sleeve to the tube (see Figure 2-A-2).

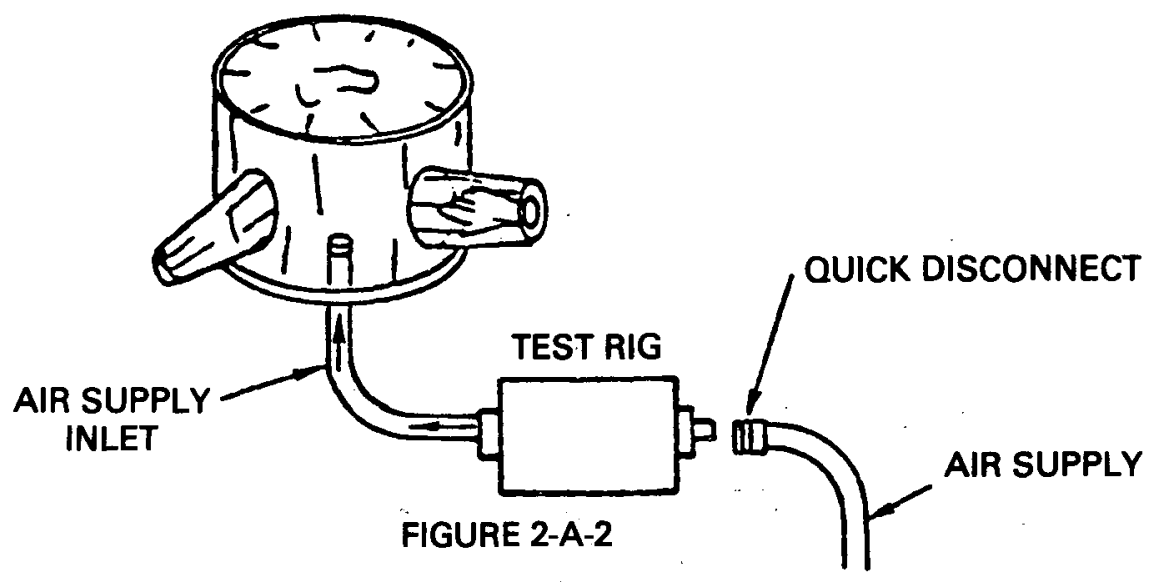

GLOVE BAG AIR TEST RIG

3. Tape any remaining open sleeves and zippers with 2-inch wide cloth-backed tape. 
RADIOLOGICAL CONTAINMENT STATUS SHEET

\begin{tabular}{lll}
\hline Area & Instal. Location Manager
\end{tabular}

I. REQUIREMENTS

- Model Type

Pump

Air Test

Containment Log No.

Containment Log No.

Operating Procedure No.

Gal. Poly Bottle

II. PRE-FABRICATION INSPECTION

\begin{tabular}{|c|c|}
\hline Fabricator/Tester & Date \\
\hline & \\
\hline
\end{tabular}

III. INSTALLATION INFORMATION

\begin{tabular}{|c|c|c|c|}
\hline User Approval* & Date & Installed By & Date \\
\hline & & & \\
\hline
\end{tabular}

\begin{tabular}{|c|c|c|c|}
\hline $\begin{array}{c}\text { Health Physics } \\
\text { Initial Acceptance }\end{array}$ & Date & Responsible Manager Approval & Date \\
\hline & & & \\
\hline
\end{tabular}

"Individual signing is assuring that the installer has been shown and knows where the containment is to be installed.

IV. ALTERATION/REPLACEMENT/MODIFICATION INFORMATION

\begin{tabular}{|l|l|l|l|l|l|l|l|}
\hline Att & Rep & Mod & Reason & $\begin{array}{c}\text { Resp. Manager } \\
\text { Approval }\end{array}$ & Date & $\begin{array}{c}\text { Health Physics } \\
\text { Approval }\end{array}$ & Date \\
\hline & & & & & & & \\
\hline & & & & & & & \\
\hline & & & & & & & \\
\hline & & & & & & & \\
\hline
\end{tabular}

V. AUTHORIZATION FOR REMOVAL

\begin{tabular}{|l|l|l|l|}
\hline Responsible Manager & Date & Health Physics Manager & Date \\
\hline & & & \\
\hline
\end{tabular}

REMOVAL COMPLETE

\begin{tabular}{|l|l|l|}
\hline Health Physics & Date & Swipe Survey \\
\hline & & \\
\hline
\end{tabular}

FIGURE 2-A-1

II -2 
4. Open the air supply slowly and allow the pressure to stabilize for about 2 minutes. The regulators should be set to provide 3 to 7 ounces while the protective relief is set at 7 ounces.

5. After the pressure has stabilized, apply a non-ionic detergent solution to all the seams. Any bubbles on the seams or failure due to stress constitutes a failure and the unit should be rejected.

6. Each sleeve which is isolated from the main body air test should be separately tested by inserting an air supply/monitoring tube into the open sleeve end and sealing with tape. Testing should be accomplished in the same manner as in steps 4 and 5 above.

\section{CAUTION!}

All tape and test solution residue must be removed after the testing.

7. If the containment satisfactorily passes the air test, complete the fabrication in accordance with the Radiological Containment Status sheet drawing. Verify by signature that the air test is satisfactory in section II of the Radiological Containment Status Sheet. This is for primary containments only. If the containment is a secondary type, attach a "Pre-Use Test" sticker to it (see Figure 2-A-3).

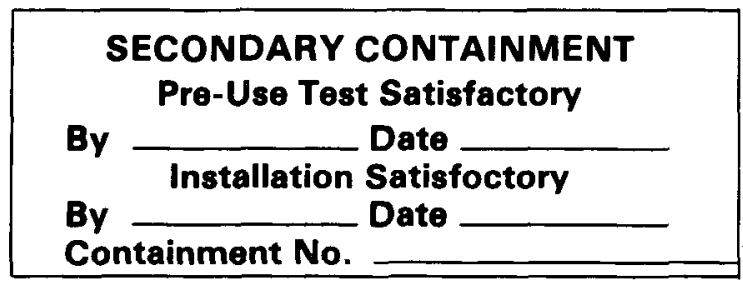

FIGURE 2-A-3

8. If the containment is rejected because of manufacturing defects, it should be sent to the Health Physics Group for evaluation. Draw another containment from stock.

B. FABRICATION OF CONTAINMENTS

1. Support the containment in a simulated working position using nylon cord and rubber band tie-offs.

2. Install new rubber containment gloves (suggested siże 10) in the glove sleeves as required by the Radiological Containment Status sheet drawing, using the following method:

a. Pull the sleeve inside out (see Figure 2-8-1). 


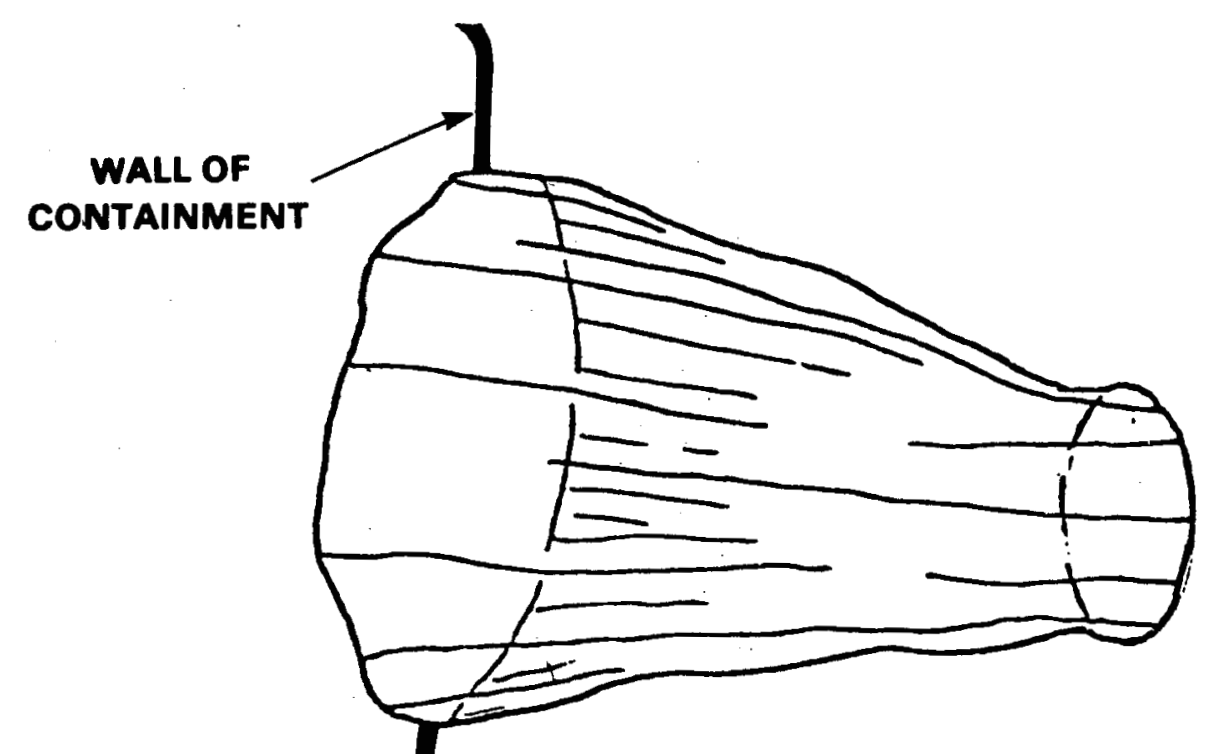

FIGURE 2-B-1

b. Insert the sleeve through the glove ring (see Figure 2-B-2).

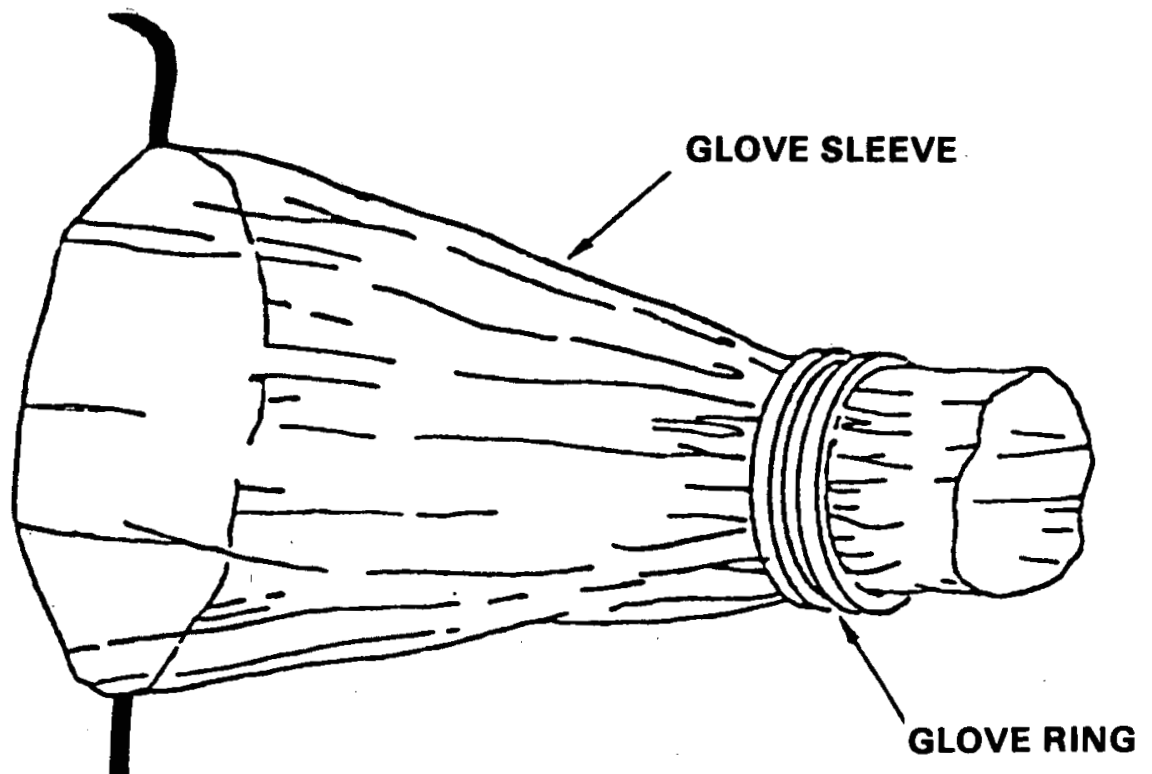

FIGURE 2-B-2

c. Fold the end of the sleeve out to cover the glove ring. Tape the sleeve to the ring (see Figure 2-B-3). 


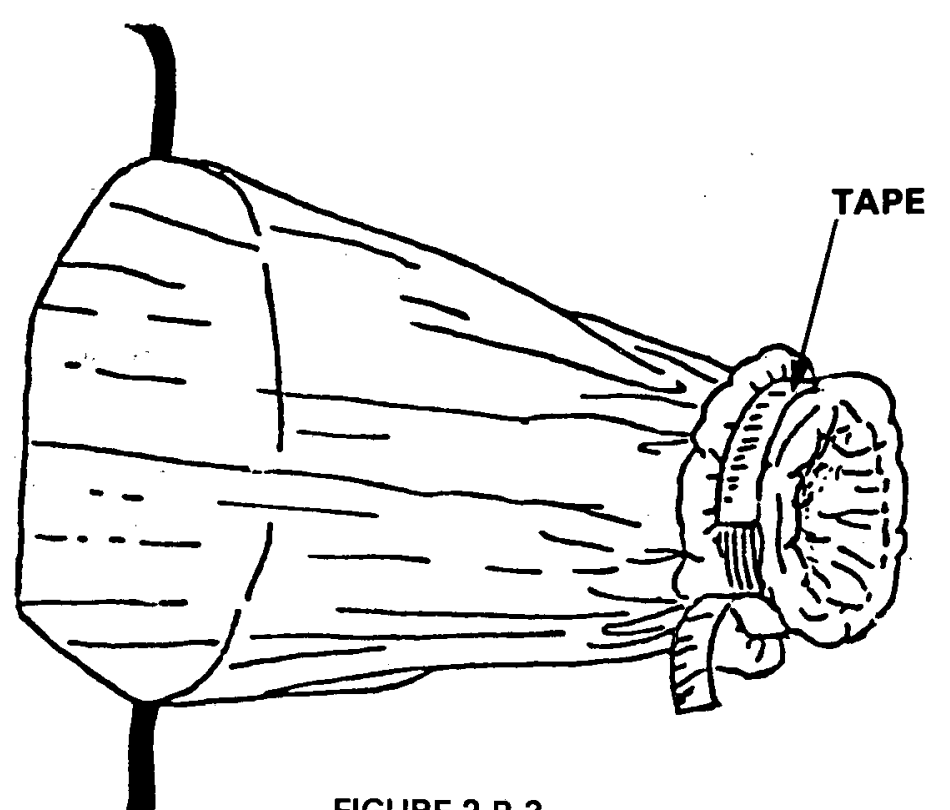

FIGURE 2-B-3

d. Insert the glove into the sleeve in the working position, fold the cuff of the glove over the sleeve and tape over the ring (see Figure 2-B-4).

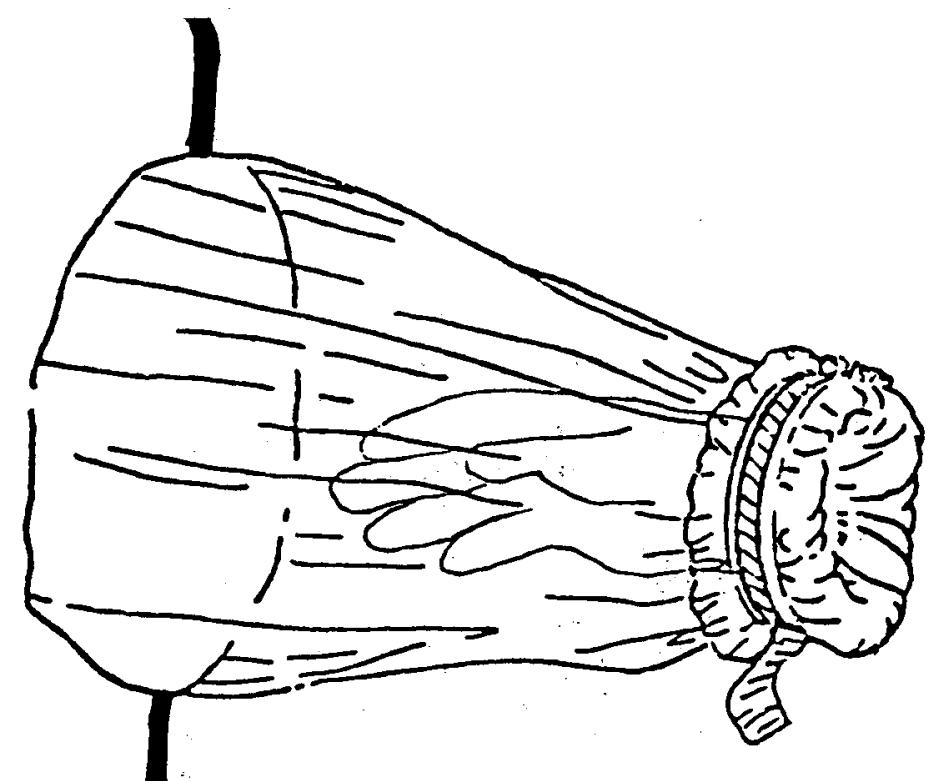

FIGURE 2-B-4

e. Apply a tab to the rubber band and place it over the glove and the sleeve, into the groove in the glove ring (see Figure 2-B-5). 


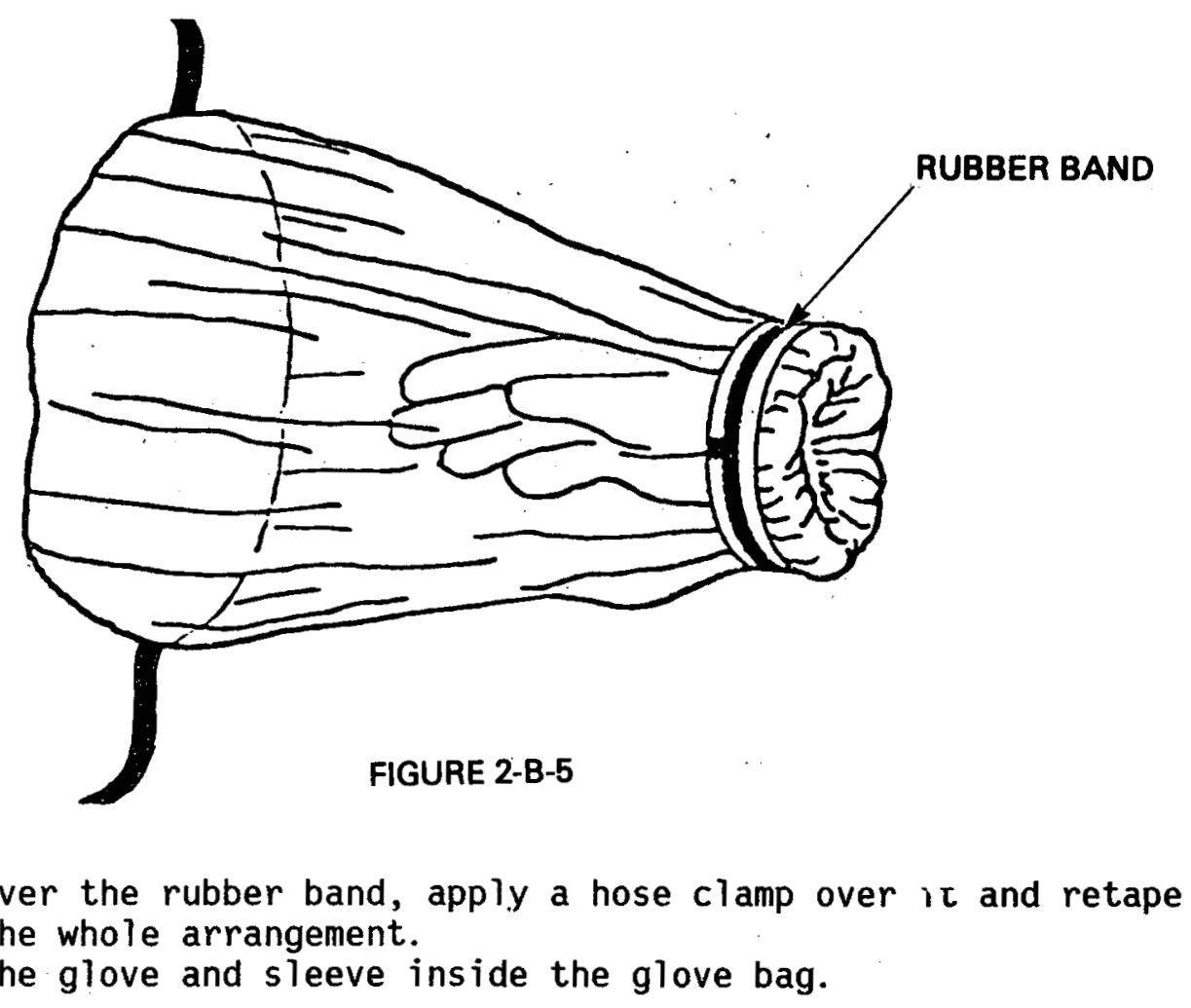

3. Install the tool transfer sleeve. Make sure that there is an eight-foot minimum length. ( 8 mil purple translucent PVC should be used.)

4. Remove any unwanted concentric sleeves or sleeve diaphragms.

5. Install a DOP tested HEPA filter (size as specified by the Radiological Containment Status Sheet) opposite the working side and at the highest practical position on the containment. Two types of filters are normally used and the ventilation technique varies a little.

\section{$40 \mathrm{cfm}$ filter}

a. Using cloth-backed tape (1.5-inch width), wrap the end of the filter that will be in the sleeve (see Figure 2-B-6).

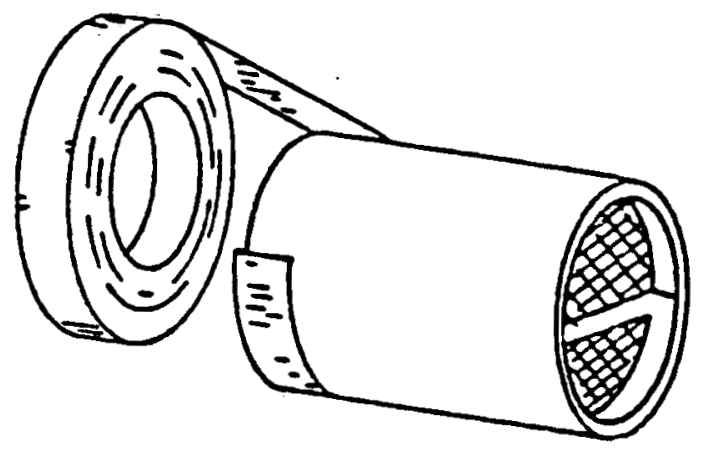

FIGURE 2-B-6 
b. Insert the filter into the sleeving. The filter should be as close to the containment as possible to prevent the sleeve from folding over and cutting off the air flow (see figure 2-B-7).

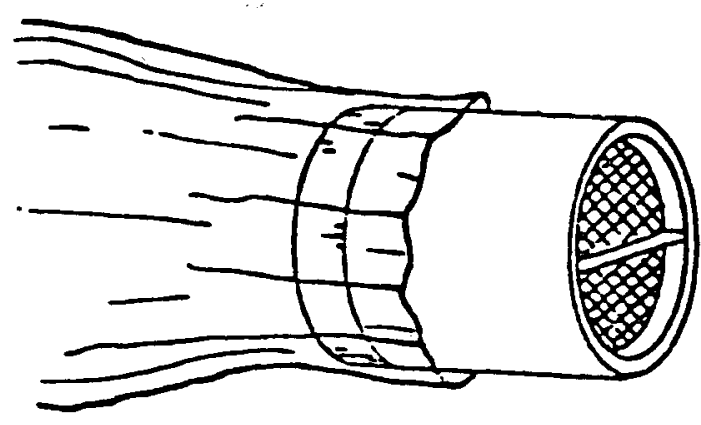

FIGURE 2-B-7

c. Pull the sleeving about two inches over the filter. Cut off any excess.

d. Tape the sleeving to the filter with cloth-backed tape (see Figure 2-B-8).

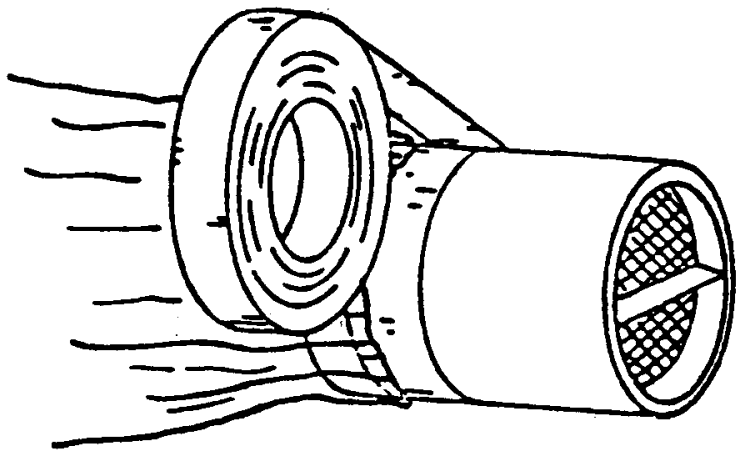

FIGURE 2-B-8

\section{2 cfm filter}

a. Assemble the following equipment:

o 1.25-inch diameter punch or equivalent,

- Protex 7500-8 cartridge filter or equivalent,

o two gaskets,

- inhalator valve, and

- filter adapter wrench. 
b. Apply a piece of cloth-backed tape over both sides of plastic where hole will be made.

c. Punch a 1.25-inch diameter hole in the containment wall through the tape where the filter will be installed.

d. Assemble the filter unit on the containment (see Figure 2-B-9).

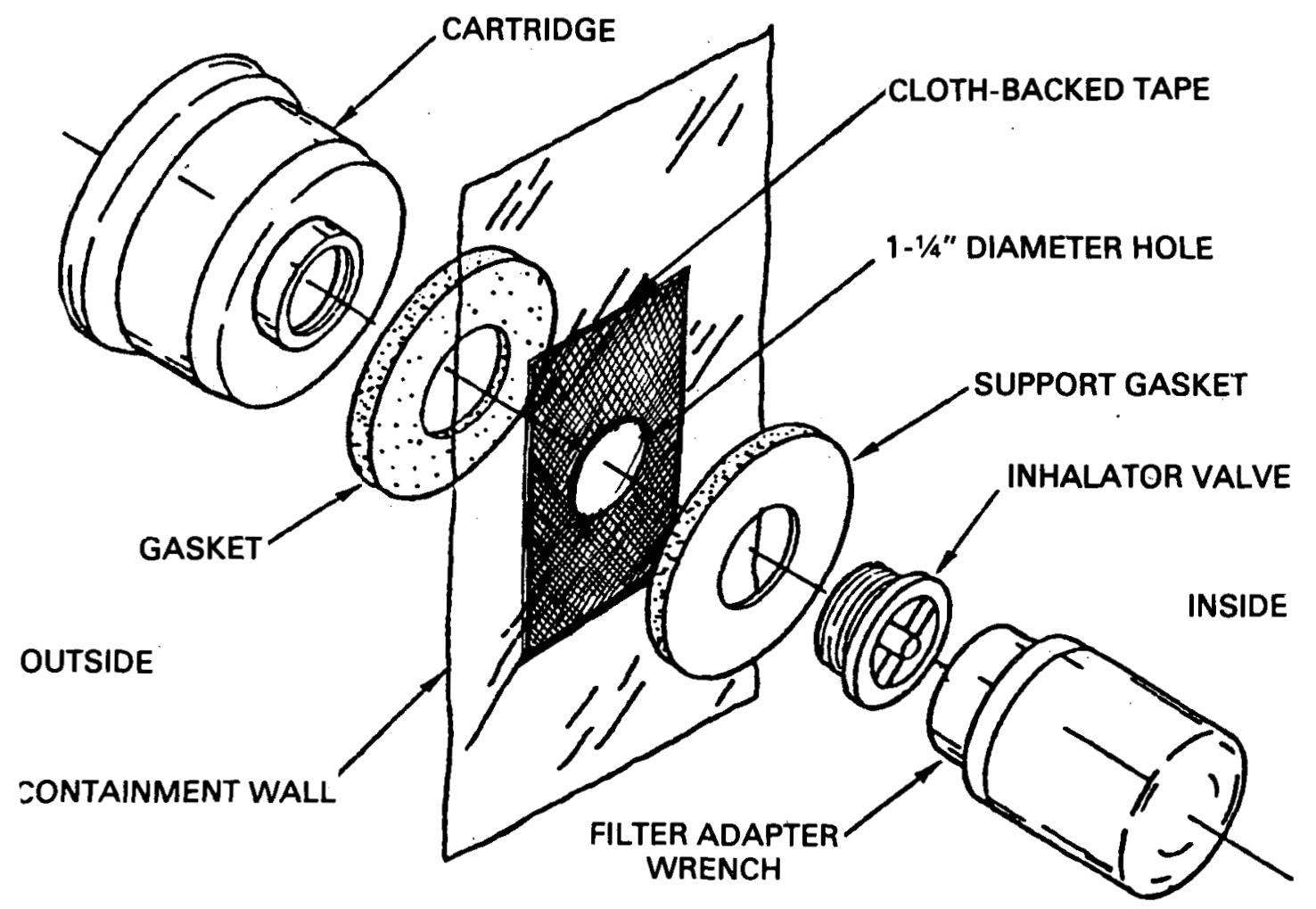

FIGURE 2-B-9

6. Package the completed containment in a clear poly bag and transport to the work site. Verify the location with the cognizant manager.

C. ON-SITE GLOVE BAG INSTALLATION

1. The containment specialist notifies the Health Physics Group of intentions to install the glove bag.

2. The Radiological Containment Log (see Figure 2-c-1) is filled out. This $\log$ should be maintained by the Health Physics Group for each facility. The Health Physics and Containment Specialists check the containment for presence of the "Pre-Use Test" sticker (see Figure 2-A-3) prior to installation and for damage when it is a secondary containment. The containment specialist provides the information for completing the Radiological Containment Log. Health Physics and Containment Specialist personnel will initial the Radiological Containment Log. 
FIGURE 2-C-1

RADIOLOGICAL CONTAINMENT LOG

\begin{tabular}{|c|c|c|c|c|c|c|c|}
\hline \multicolumn{8}{|l|}{ Area } \\
\hline \multirow{2}{*}{$\begin{array}{l}\text { Cont. } \\
\text { No. }\end{array}$} & \multirow{2}{*}{$\begin{array}{c}\begin{array}{c}\text { Primary } \\
(P) \\
\text { Secondary } \\
(S)\end{array} \\
\end{array}$} & \multirow{2}{*}{$\begin{array}{c}\text { Location } \\
\text { Tank/Room/System } \\
\text { Component } \\
\end{array}$} & \multirow{2}{*}{$\begin{array}{c}\text { Date } \\
\text { Installed }\end{array}$} & \multicolumn{2}{|c|}{ Installation Satisfactory } & \multirow{2}{*}{$\begin{array}{l}\text { Custody } \\
\text { Group }\end{array}$} & \multirow{2}{*}{$\begin{array}{c}\text { Removal } \\
\text { Date }\end{array}$} \\
\hline & & & & HP & Cont. Spec. & & \\
\hline \multicolumn{8}{|l|}{$\infty 01$} \\
\hline \multicolumn{8}{|l|}{$\infty 2$} \\
\hline \multicolumn{8}{|l|}{003} \\
\hline \multicolumn{8}{|l|}{004} \\
\hline \multicolumn{8}{|l|}{$\infty$} \\
\hline \multicolumn{8}{|l|}{$\infty 08$} \\
\hline \multicolumn{8}{|l|}{$\infty 7$} \\
\hline \multicolumn{8}{|l|}{$\infty 08$} \\
\hline \multicolumn{8}{|l|}{$\infty 09$} \\
\hline \multicolumn{8}{|l|}{010} \\
\hline \multicolumn{8}{|l|}{011} \\
\hline \multicolumn{8}{|l|}{012} \\
\hline \multicolumn{8}{|l|}{013} \\
\hline \multicolumn{8}{|l|}{014} \\
\hline \multicolumn{8}{|l|}{015} \\
\hline \multicolumn{8}{|c|}{016} \\
\hline \multicolumn{8}{|l|}{017} \\
\hline \multicolumn{8}{|l|}{018} \\
\hline \multicolumn{8}{|l|}{019} \\
\hline \multicolumn{8}{|l|}{020} \\
\hline \multicolumn{8}{|l|}{021} \\
\hline \multicolumn{8}{|l|}{022} \\
\hline 023 & & & & & & - & \\
\hline 024 & & & & & & & \\
\hline 026 & & & & & & & \\
\hline
\end{tabular}




\section{CAUTION!}

Check surrounding surfaces and ensure that sharp edges are covered with tape.

\section{CAUTION!}

In instances where the piping and/or components are thermally hot (temperatures in excess of $60^{\circ} \mathrm{C}\left(140^{\circ} \mathrm{F}\right)$ and may come in contact with the glove bag) cover the surfaces with flameguard or equivalent.

3. Cover any piping or components, which will be exposed inside the containment, with cloth-backed tape or sleeving to prevent them from being contaminated (see Figures $2-c-2,2-c-3$ ).

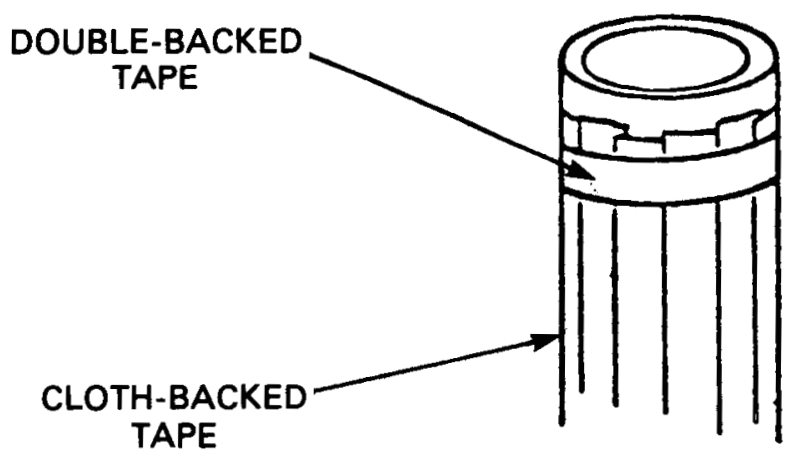

COVER COMPONENT WITH CLOTH-BACKED TAPE AND APPLY DOUBLEBACKED TAPE.

FIGURE 2-C-2

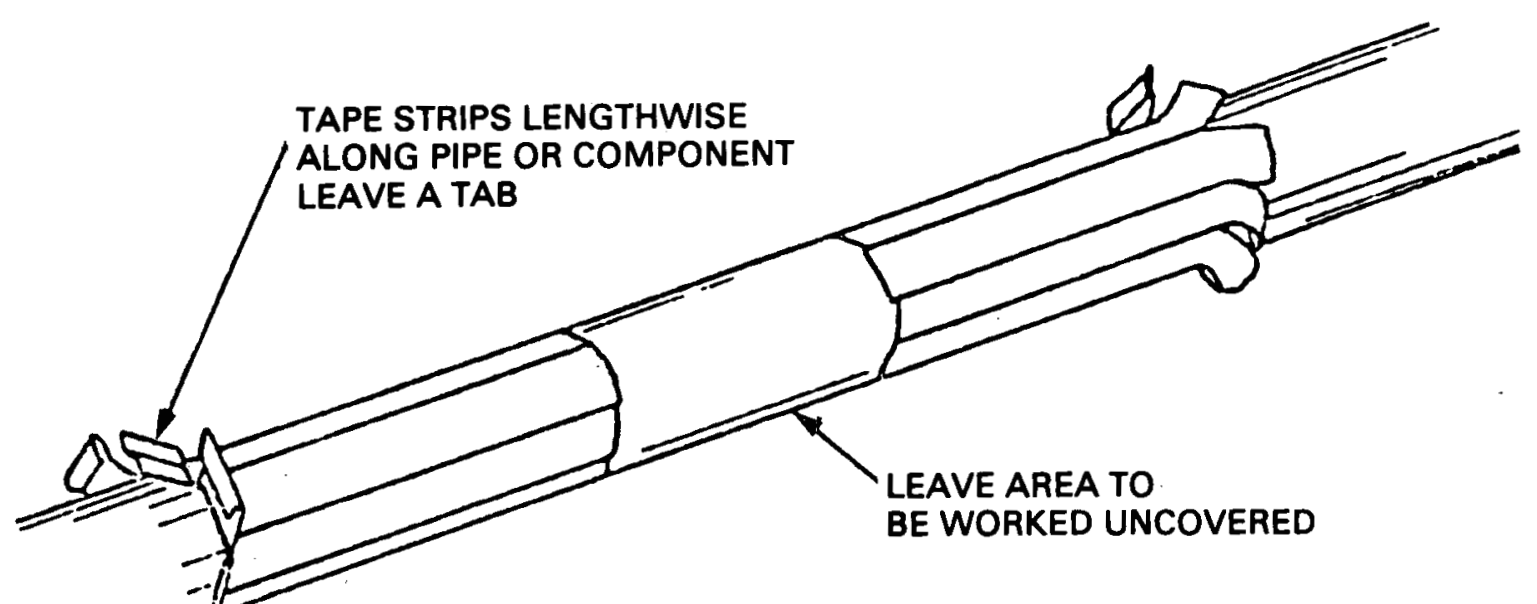

FIGURE 2-C-3 
4. Support the containment in its approximate working condition.

5. Place any equipment which is too large for the access opening inside the glove bag before sealing it in place.

6. Seal the containment in place using the closure zipper, hose clamps, double-backed tape or pressure sensitive tape as appropriate. (Seo Figures 2-C-4, 2-C-5, 2-C-6, 2-C-7, 2-C-8.)

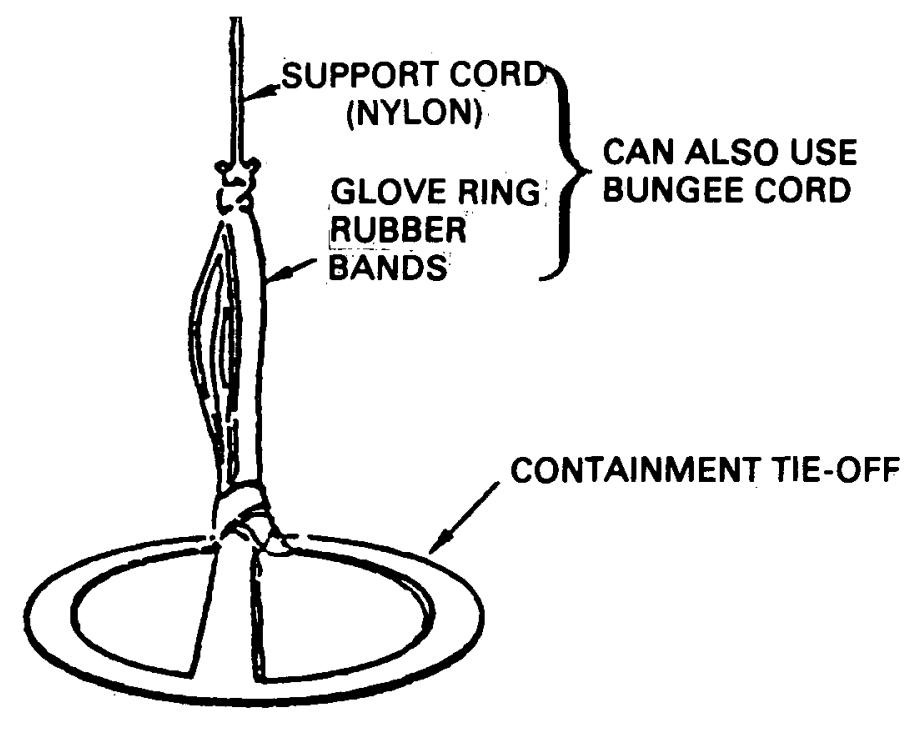

FIGURE 2-C-4

5. Inside seals should be used when liquid is expected in the containment. Outside seals are used only with Health Physics authorization.

6. If component/piping configuration requires alteration of the body of containment, alteration should'be approved by the Health Physics Group.

7. Install service leads, drain fittings and heavy equipment in the containment. Arrange to have polybottles and other equipment staged. Use those sleeves which are not required for hand access.

8. Drain valve installation, gravity feed

a. Tape an area on both sides of the bottom of the containment using cloth-backed tape, punch a 5/8th inch diameter hole with punch or sharp tool (see Figure 2-c-9). 


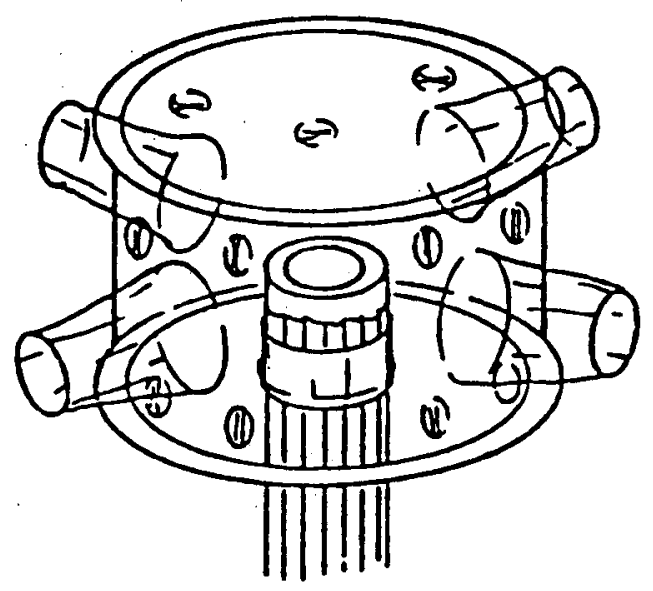

IF GLOVEBAG TO BE INSTALLED IS EQUIPPED WITH CONCENTRIC SLEEVES, REVERSE SLEEVE DESIRED AND INSTALL ON COPONENT.

FIGURE 2-C-5

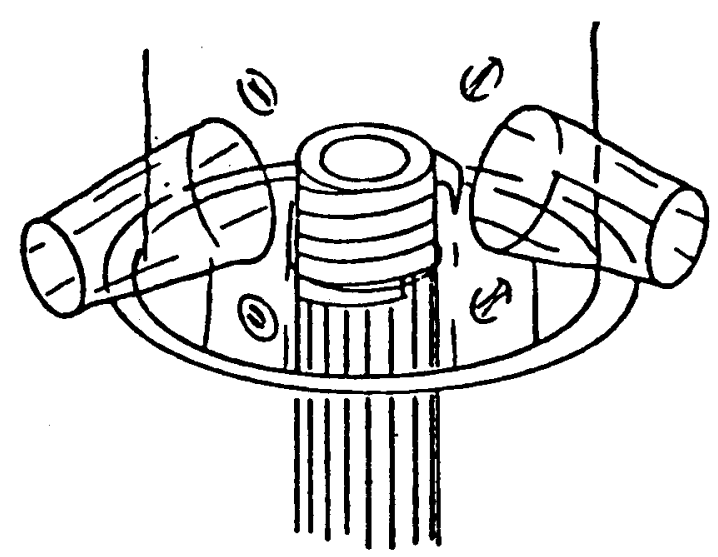

SECURE SLEEVE TO COMPONENT USING

CLOTH-BACKED TAPE, START AT BASE OF SLEEVE, OVERLAP EACH LAYER FOR SHINGLE EFFECT COVERING ENTIRE SLEEVE.

FIGURE 2-C-6 


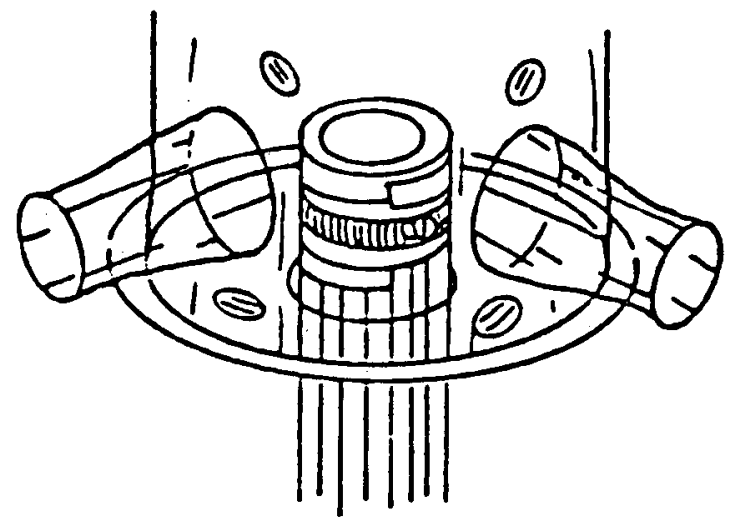

INSTALL AN ADJUSTABLE SCREW HOSE CLAMP OVER THE TAPED SLEEVE AND SECURE.

FIGURE 2-C-7

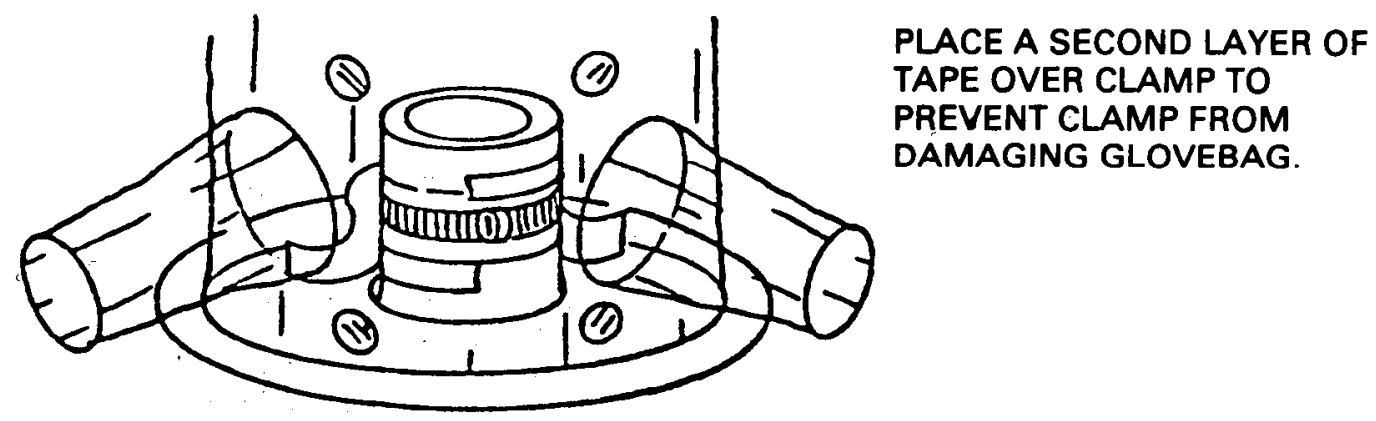

FIGURE 2-C-8

NOTE: SOME BAGS DO NOT HAVE CONCENTRIC SLEEVES. INSIDE SEALS ARE MADE AFTER CONTAINMENT IS INSTALLED ON COMPONENT BY CLOSING ZIPPERED OPENING, TURNING ENDS INWARD AND SECURING WITH TAPE AND CLAMPS. 


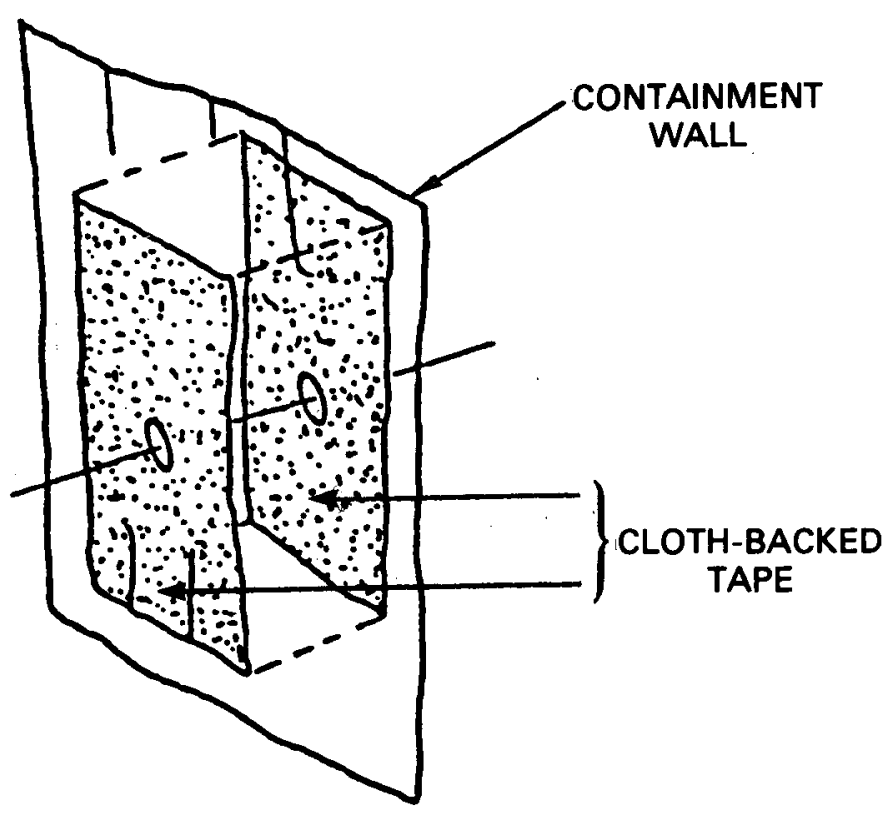

FIGURE 2-C-9

b. Install the drain using a "thru-the-bag" fitting on the bottom, at least $1 / 2$ inch away from any containment seam.

c. Assemble the stem assembly and push through wall with hexnut located outside the containment (see Figure 2-c-10).

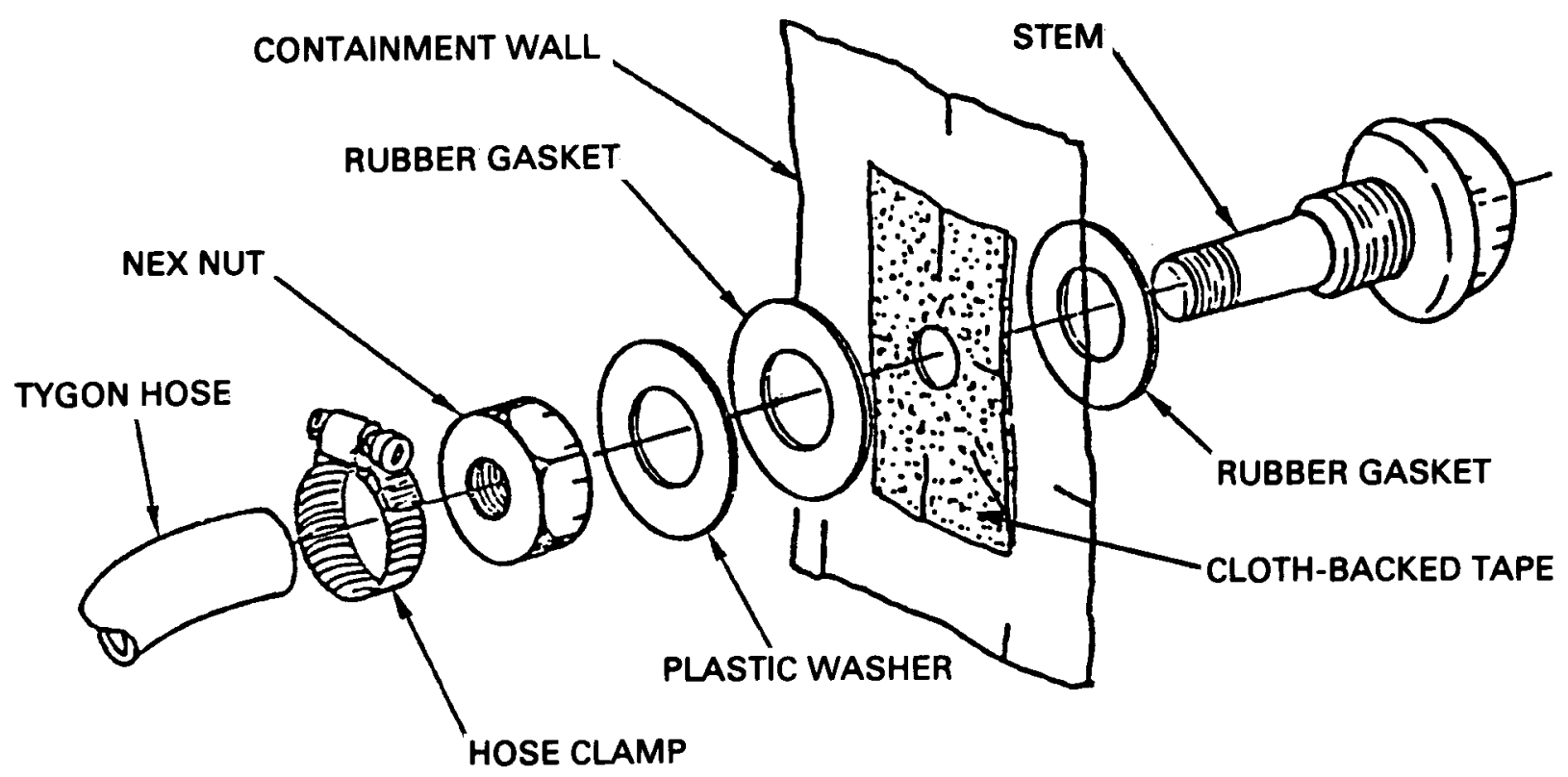

FIGURE 2-C-10 
d. Tighten the hex nut. (See Figure 2-c-11.)

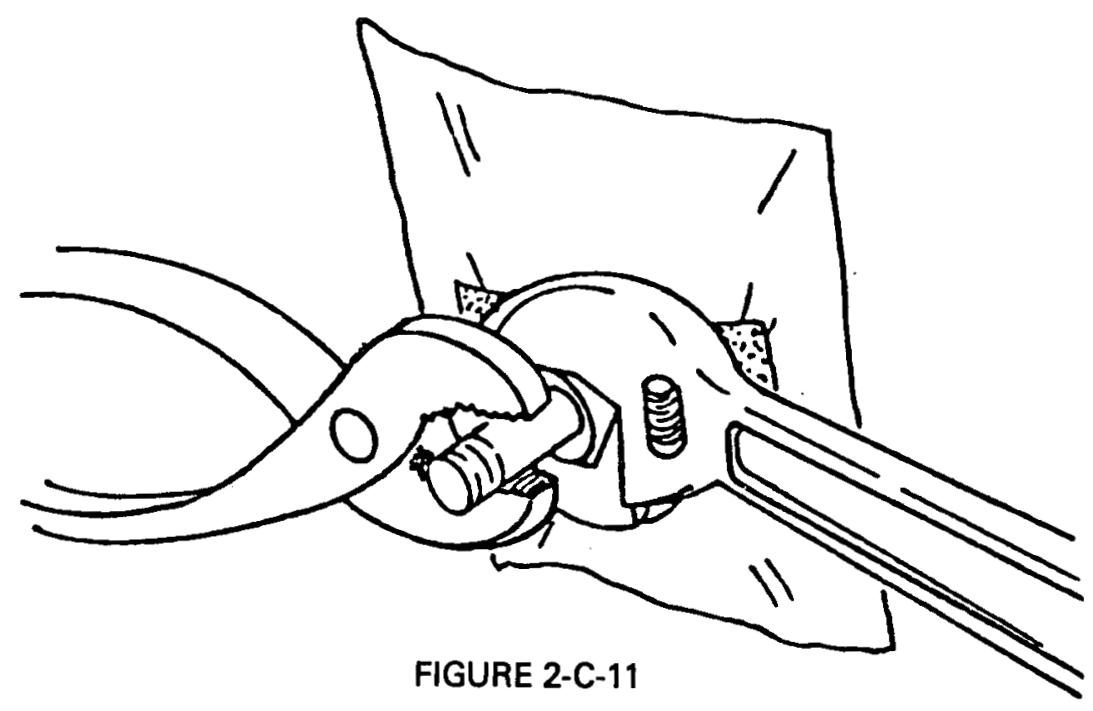

e. Tape over the hose clamp and attach a pinch clamp to the hose (see Figure 2-C-12).

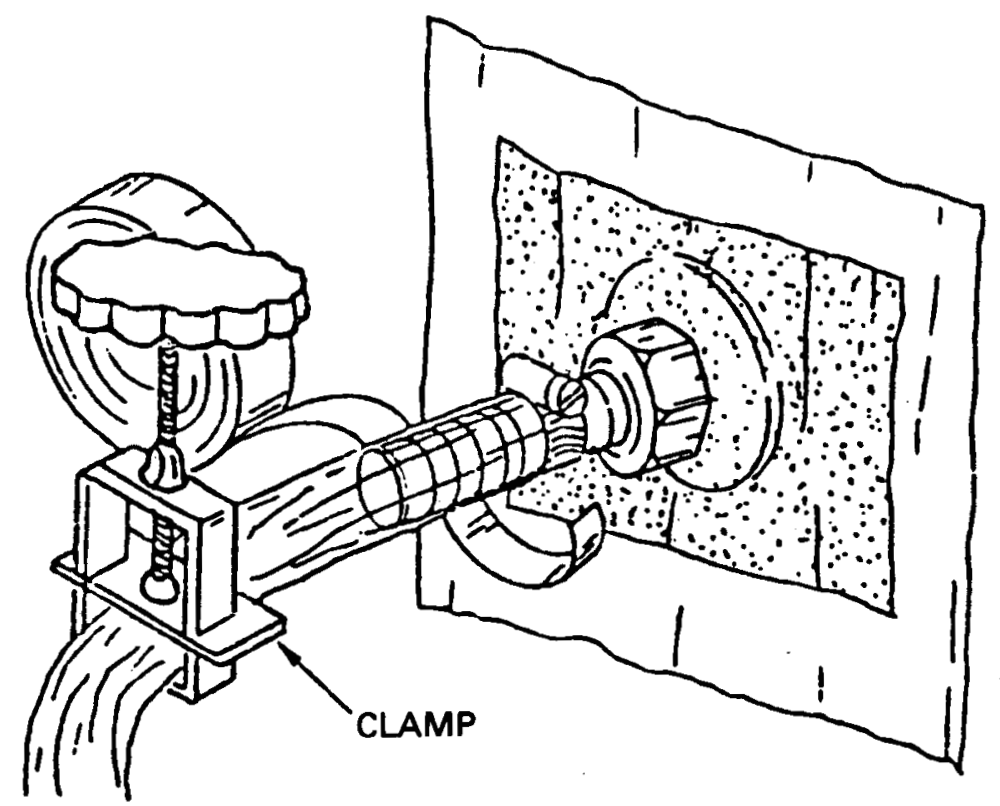

FIGURE 2-C-12

9. Drain valve installation, non-gravity feed

a. Tape an area on both sides of the bottom of the containment using cloth-backed tape. Punch a 5/8th inch diameter hole with punch or sharp tool (see Figure 2-C-13). 


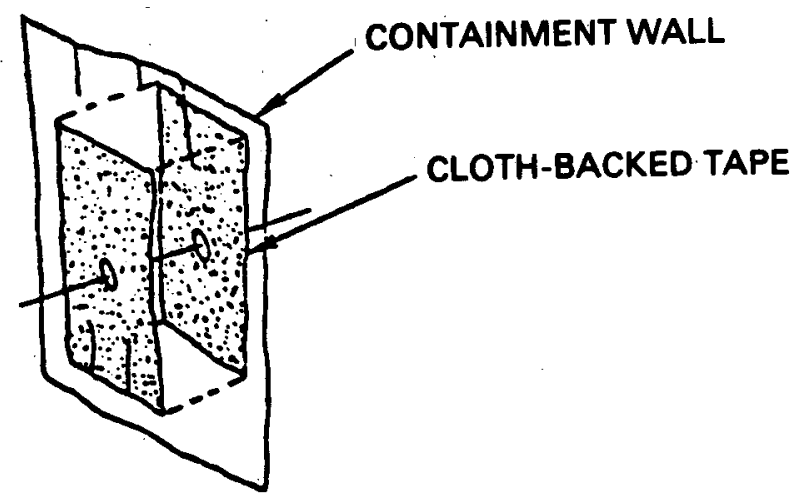

FIGURE 2-C-13

b. Install the drain using a "thru-the-bag" fitting on the bottom at least $1 / 2-$ inch away from any containment seam.

c. Fit the drain assembly to the containment (see Figure 2-c-10).

d. Attach the handpump to the drain. Pump should be in vertical position (see Figure 2-C-14).

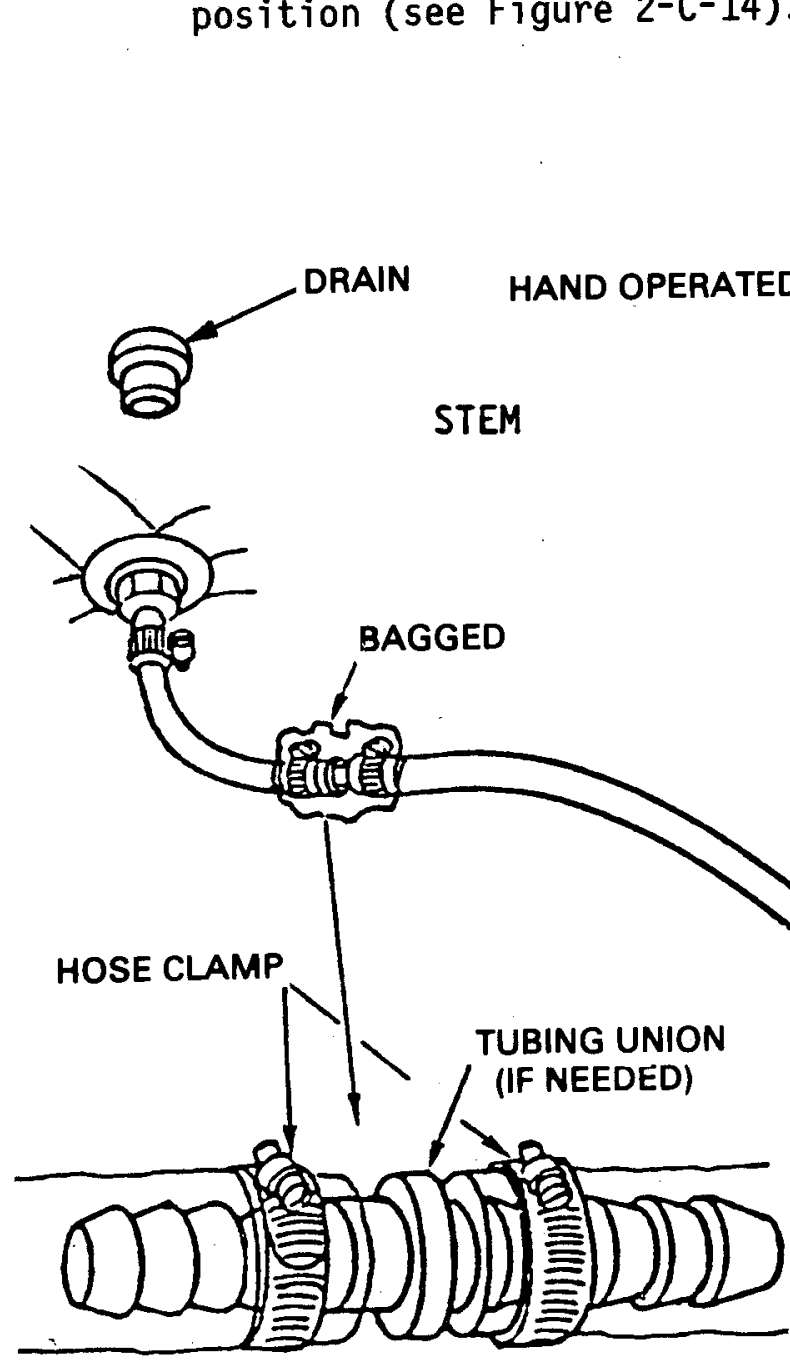

FIGURE 2-C-14 
10. Service leads, single leads

a. Short, expendable lengths of hoses and leads need not be sleeved before installing inside containment but leader hoses to air operated tools should be sleeved.

b. Hoses and leads contained within a radiologically controlled area need not be sleeved unless required by specific procedure. Temporary hoses and leads which are installed in the containment tents or glove bags should have the installed portion covered with purple poly sleeving.

c. Tape the service lead to the containment sleeve using the inside seal method (see Figure 2-C-15).

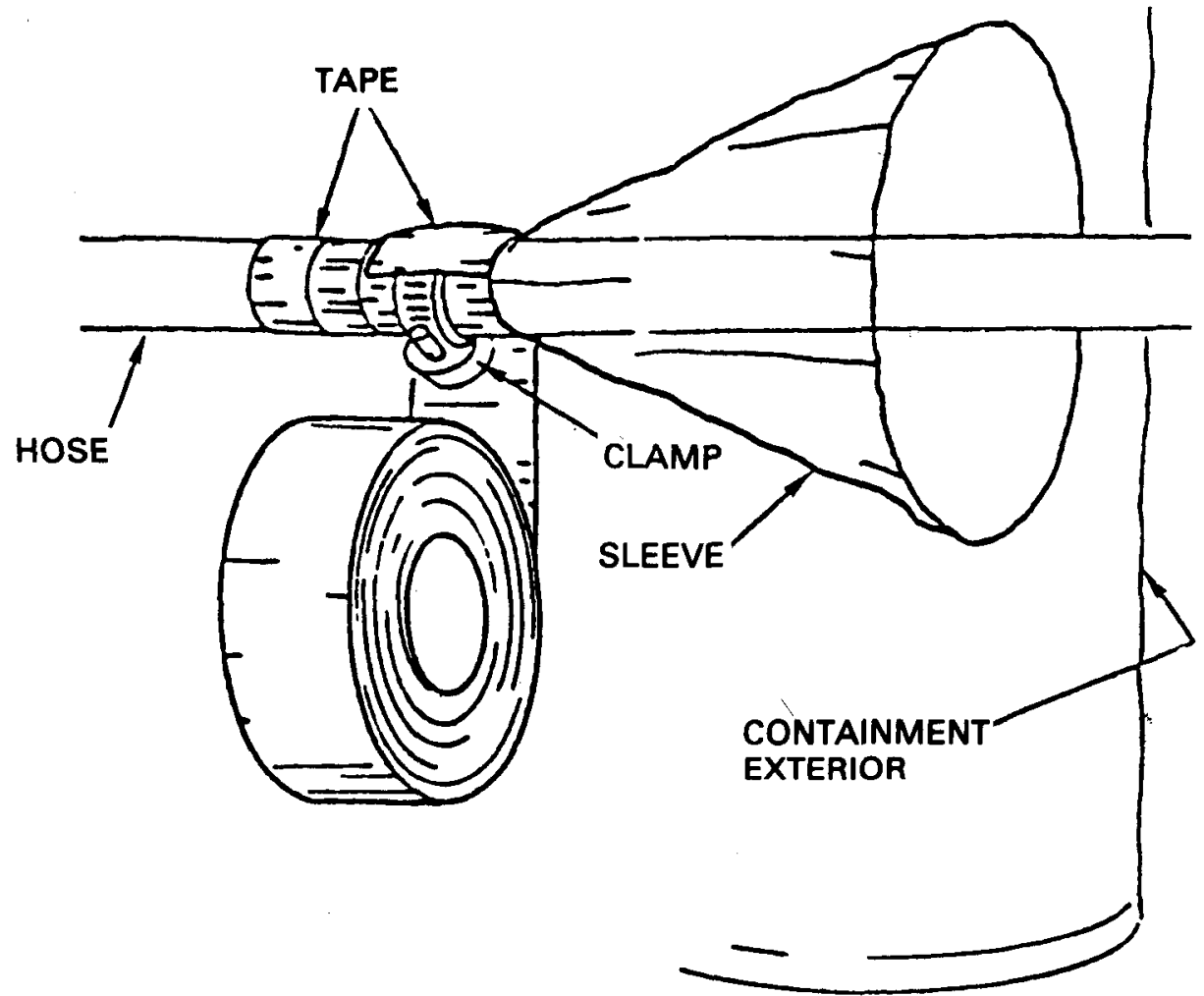

FIGURE 2-C-15

11. Service leads, multiple leads

a. Sleeve the service leads, if required. See the above section for guidelines.

b. Use one containment sleeve per service lead unless the following method is used. 
c. Install a rubber glove in the sleeve as shown in paragraph II.B.2 after the finger tips have been cut off for the required number of leads. Insert the services through the finger. Tape the fingertips and the sleeving on each lead outside the containment. Leave a tab on each piece of tape (see Figure 2-C-16).

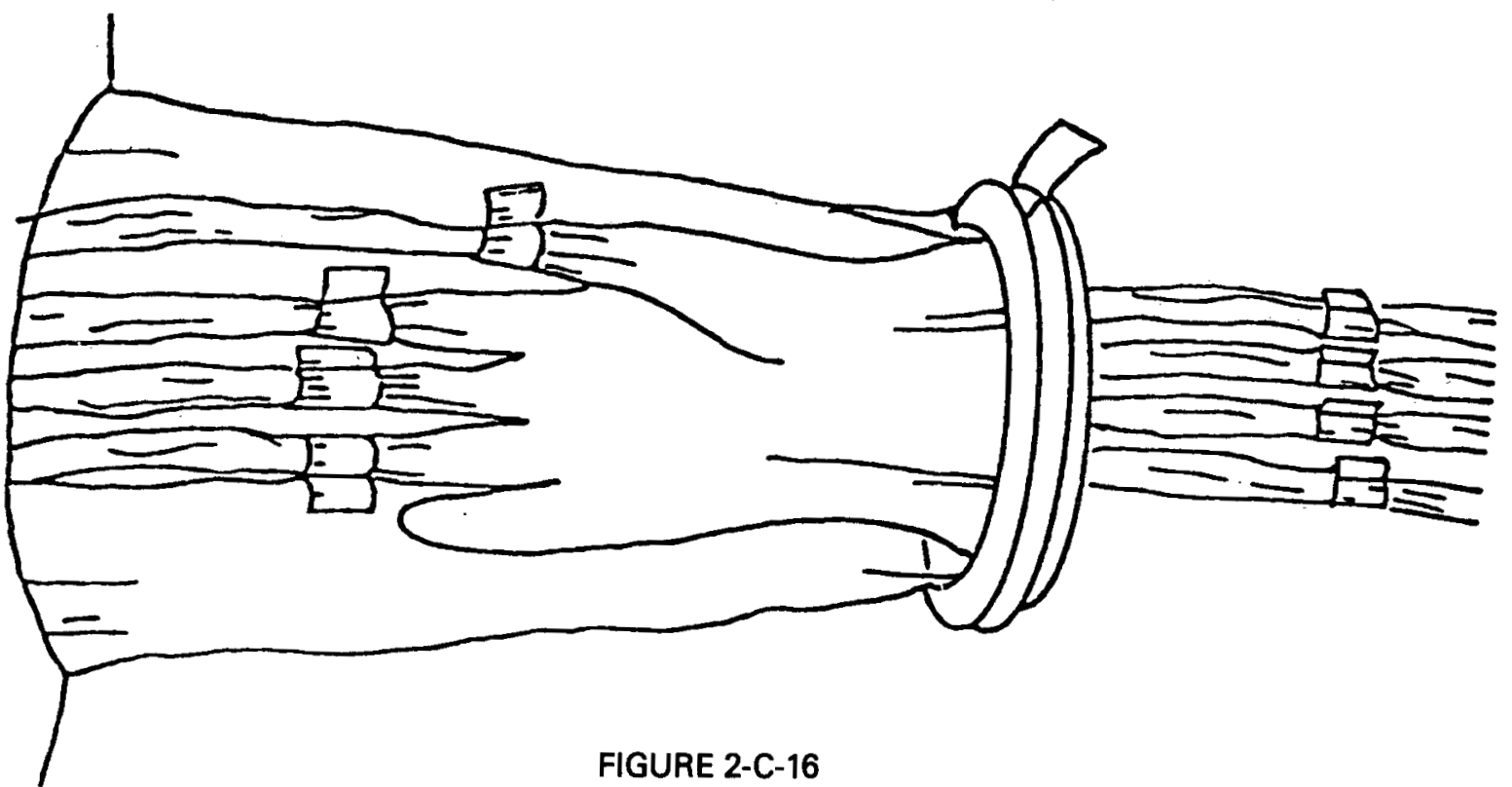

d. Support the service leads high enough so that, in case of liquid in the containment, it will not run down the sleeves.

e. Pinch together and tape the entire containment service sleeve. Tape a11 the leads outside the containment together (see Figure 2-c-17).

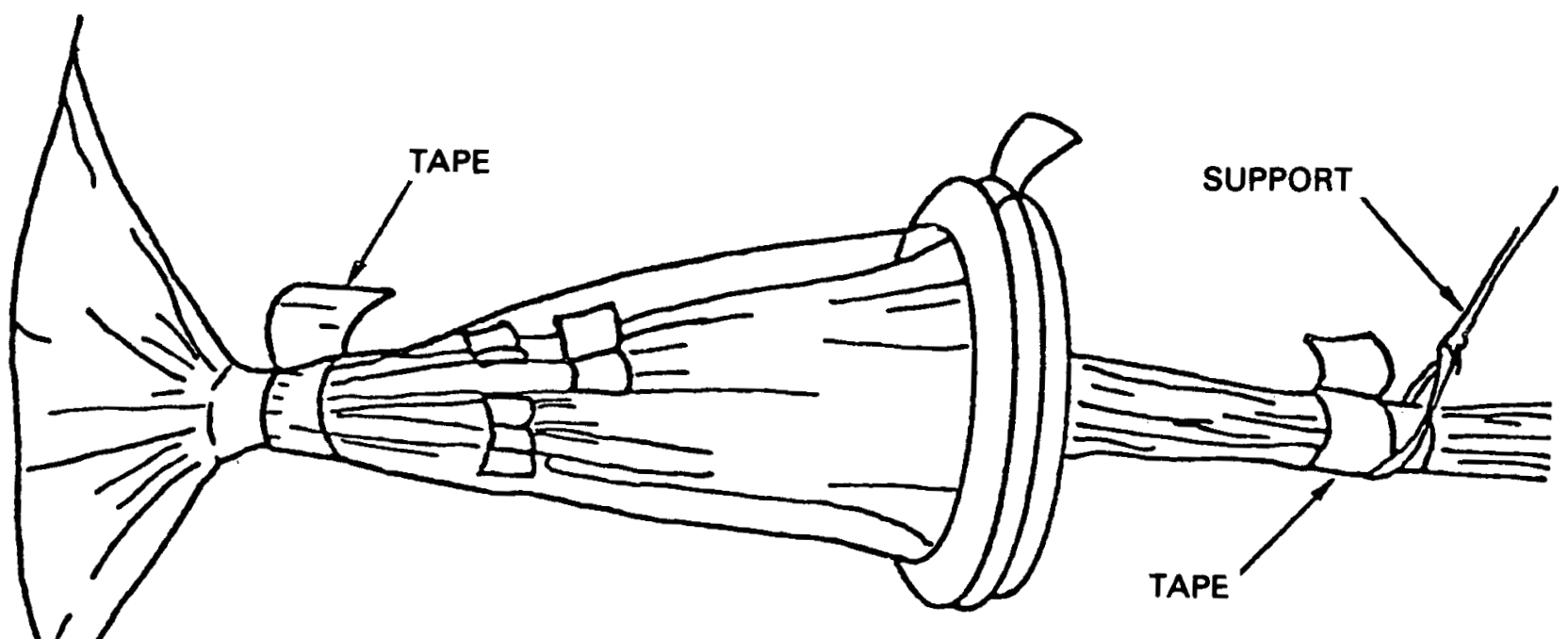

FIGURE 2-C-17 


\section{CAUTION!}

Heavy equipment and leads should

be supported in the containment

(see Figure 2-C-18).

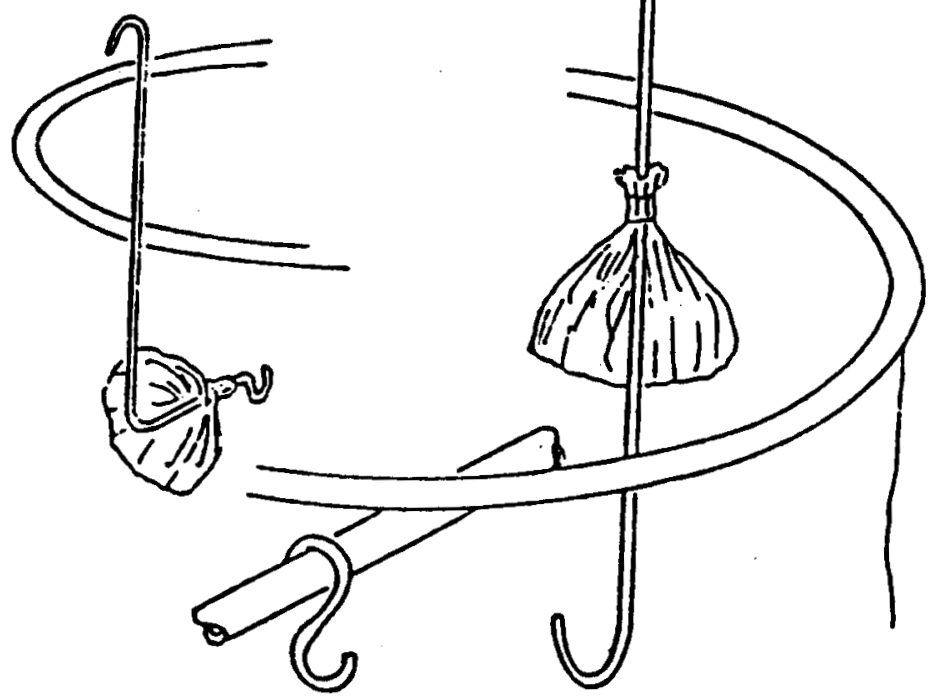

FIGURE 2-C-18

\section{CAUTION!}

Do not force zipper.

12. After closing zipper, check for leaks and possible misalignment. Tape over all zippers for extra security using 2-inch wide cloth-backed tape. Leave a tab and apply the tape so that the tab is on the opposite end from the closed zipper tab position. This is to prevent inadvertent tape opening and possible contamination.: (See Figure 2-C-19.) 


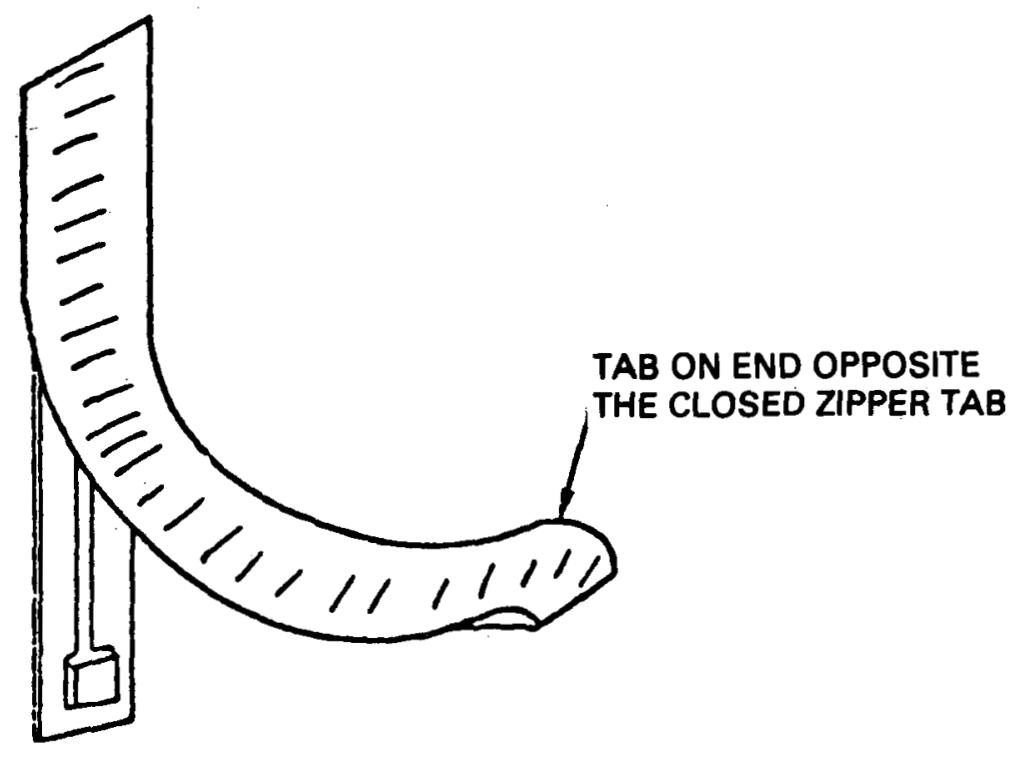

FIGURE 2-C-19

13. Place a drop cloth with absorbent material under the containment per applicable work documents (if required).

14. Install any lighting that is required on the outside of the containment. Use only fluorescent lamps because other types of lighting give off enough heat to meit the containment.

15. Make any final adjustments on the containment and request a check by using personnel.

16. If the containment is satisfactory, the using groups manager signs-off section III of the Radiological Containment Status Sheet.

17. If the containment is not satisfactory, the Containment Specialist corrects the deficiencies and requests another check by the Health Physics Personnel. If the check is satisfactory, the using group manager signs-off section III of the Radiological Containment Status Sheet.

D. INSTALLATION OF SECONDARY CONTAINMENTS

1. The Containment Specialist personnel will check the containment for any damage while ensuring that the containment has a "Pre-Use Test" sticker. If the containment is damaged (i.e., holes, rips, etc.) reject it and obtain another.

2. Notify Health Physics personnel of intentions to install a secondary containment so they can review the proposed installation. 
3. The Health Physics Group will assign a containment number, and enter all appropriate information and signature in the Radiological Containment Log.

4. Health Physics personnel will check the containment for "Pre-Use Test" sticker.

5. Install the secondary containment as per figures $2-D-1$ thru 2-D-5.

a. Install containment inside out, on low side of joint being contained. Secure several inches of press-lock zipper and apply cloth-backed tape as shown. Ensure that zipper is located at high point. If line is horizontal, use two outside seals (see Figure 2-D-1).

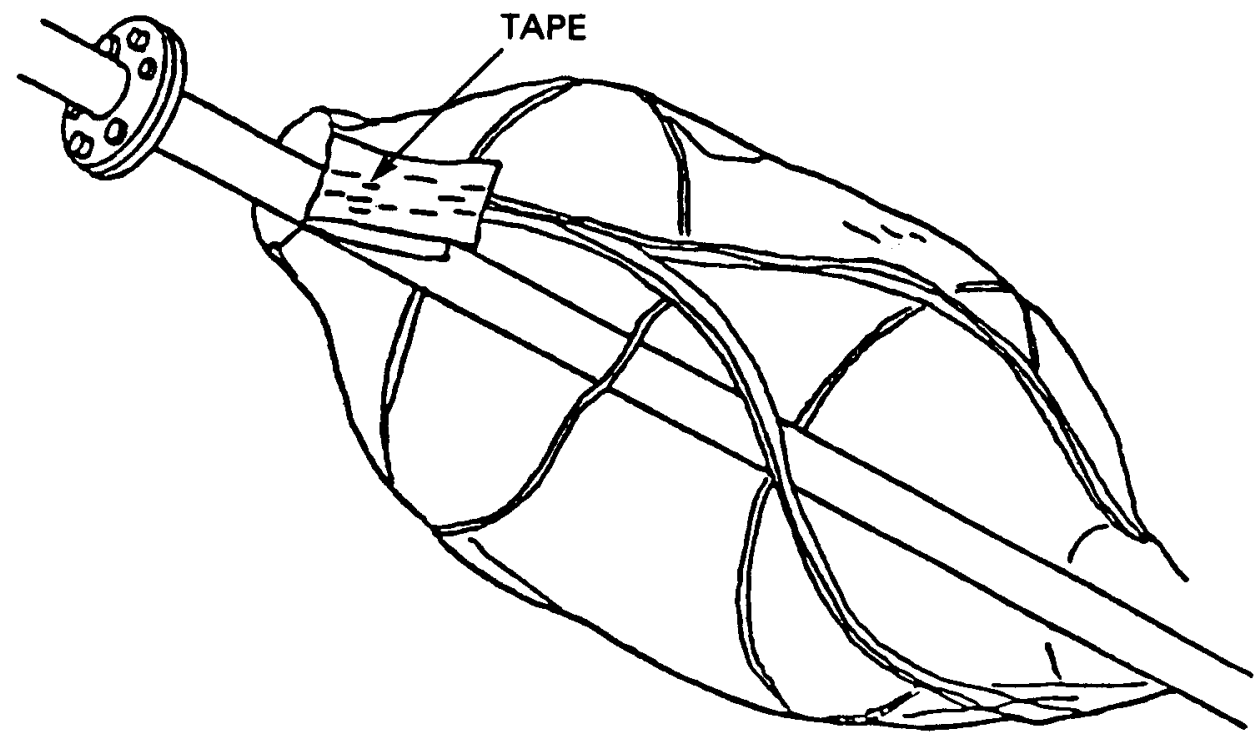

FIGURE 2-D-1 
b. Fold flaps around the pipe and tape over the seal area (see Figure 2-D-2).

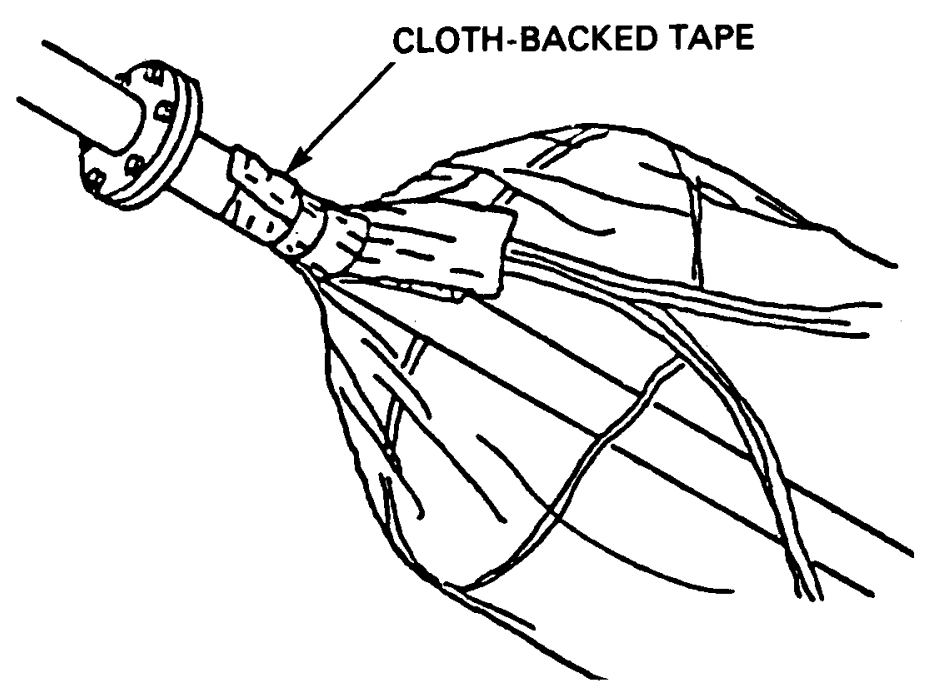

FIGURE 2-D-2

c. Install a ty-rap around the taped area and tighten. Tape over the ty-rap with a single turn of tape (see Figure 2-D-3).

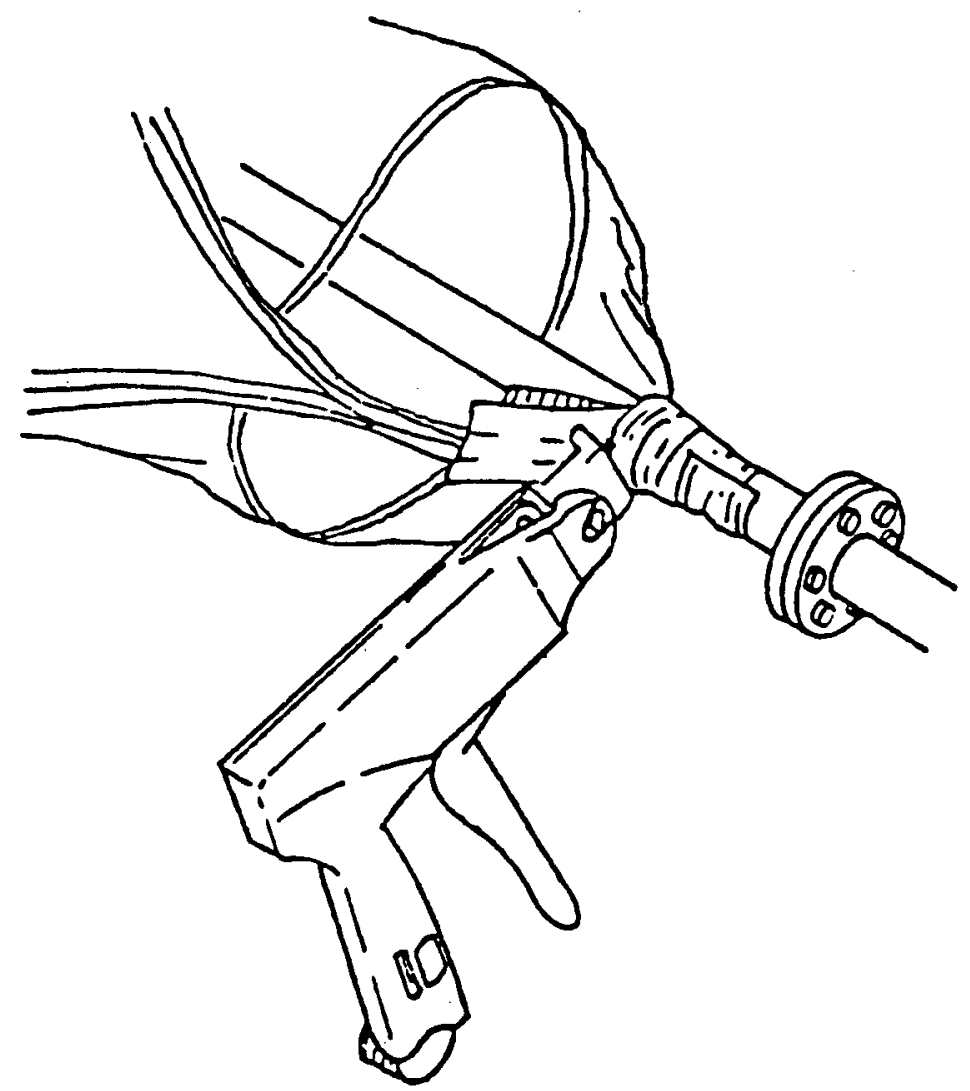

FIGURE 2-D-3 
d. Pull the sleeve or containment over the joint and place absorbent material in it (see Figure 2-D-4).

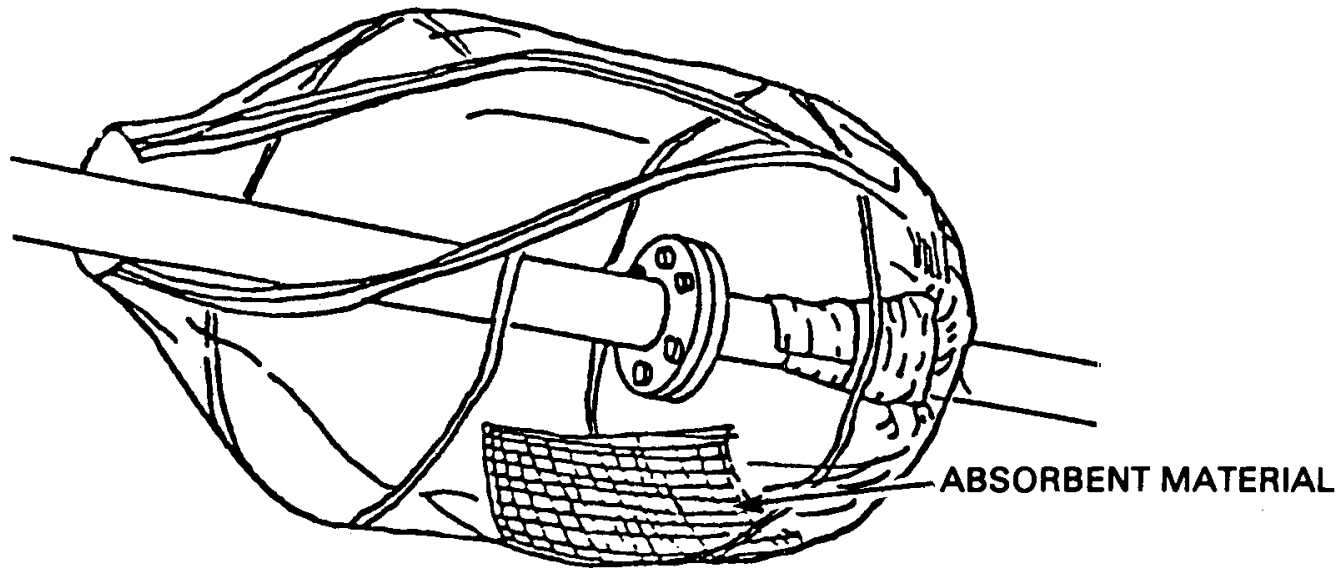

FIGURE 2-D-4

e. Close the pressure-lock zipper, tape the exterior and seal the remaining open end. Tape over the end, apply a Ty-rap and tape over it (see Figure 2-D-5).

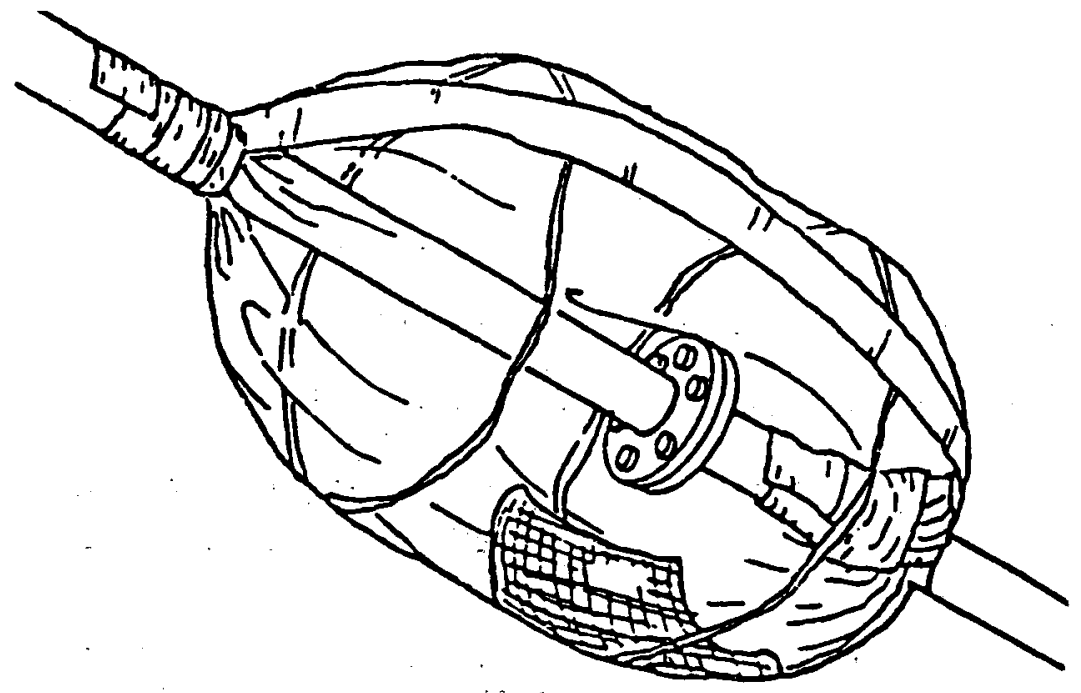

FIGURE 2-D-5

6. Health Physics personnel will inspect the installation to ensure that the containment is properly installed. 
a. If containment is unsatisfactory, notify Containment Specialist.

b. If installation is satisfactory, sign the secondary containment sticker and the radiological containment log to record acceptance.

E. INSTALLATION OF A CONTAINMENT TENT

1. Radiological Containment tents should be treated the same way as primary containments except:
a. No airtest is required,
b. Water tests will only be required if liquids are expected, and
c. No preassembly is required.

2. Notify Health Physics personnel of intentions to install a containment tent so they can review the proposed installation.

3. Health Physics personnel will assign a containment number, and enter all appropriate information in the Radiological Containment Log.

4. The Containment Specialist should install the tent using flexframe and nylon cord. Ensure each grommet is tied off securely.
a. Attach the base or rear wall opening in the same manner as a primary containment.

b. Check for physical defects during installation.

5. Section F of Chapter III, "Inspection" outlines the installation inspection criteria.

6. Temporary ventilation as defined in Chapter V, Section I should be attached through the six inch sleeve (see Figure 2-E-1).

7. Service leads should be attached through the various sized sleeves.

8. Continuous air monitoring should be required in the work area.

9. If the containment is satisfactory, the responsible manager and Health Physics sign-off section III of the Radiological Containment Status Sheet (Figure 2-A-1).

10. Health Physics personnel should post a current radiological survey of the interior of the tent and insure the proper radiological signs are displayed in the clear pockets on the outside door wall. 


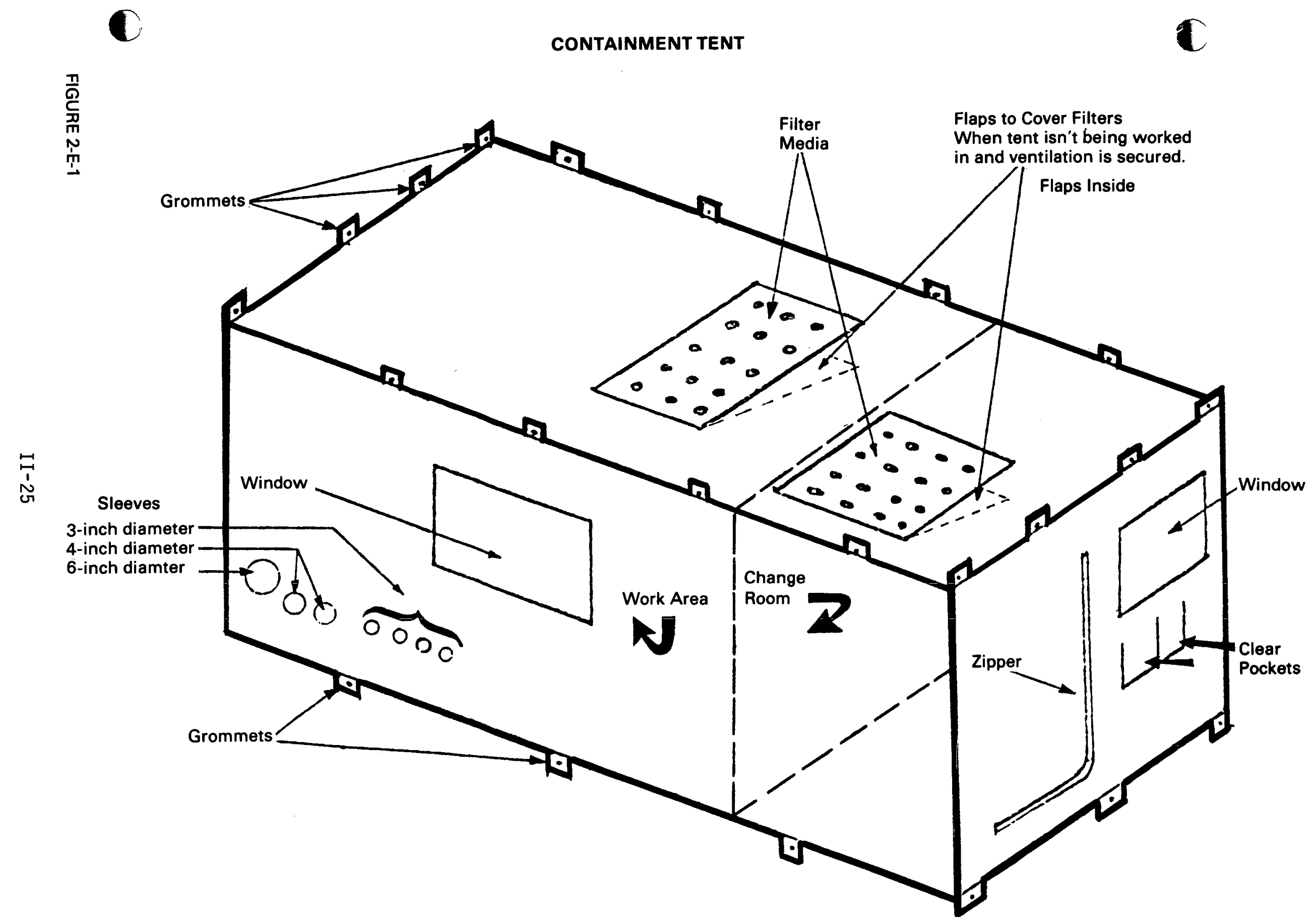




\section{INSPECTION OF CONTAINMENTS}

A. GENERAL

1. After the containment has been installed, Health Physics personnel should be notified for their concurrence.

2. A water leak test should be performed if required. This should be done in the field as a routine test after installation. All seals which would be exposed to standing liquid should be tested.

\section{Water Leak Test Procedure}

a. Introduce approximately one pint of pure water into the containment and let it settle into the component/containment seal area.

b. Manipulate the containment (tugging, flexing and pulling) to ensure that the seal does not fail.

c. Let the water stand around the seal for a minimum of three minutes and look for leakage.

d. After the test, remove all the water and dry the inside of the containment with absorbent material.

e. If the test is satisfactory, Health Physics personnel should attach the appropriate label to the containment. For a primary containment, this is the Primary Sticker (see Figure 3-A-1). Secondary containments use the Secondary Containment sticker (see Figure 3-A-2).

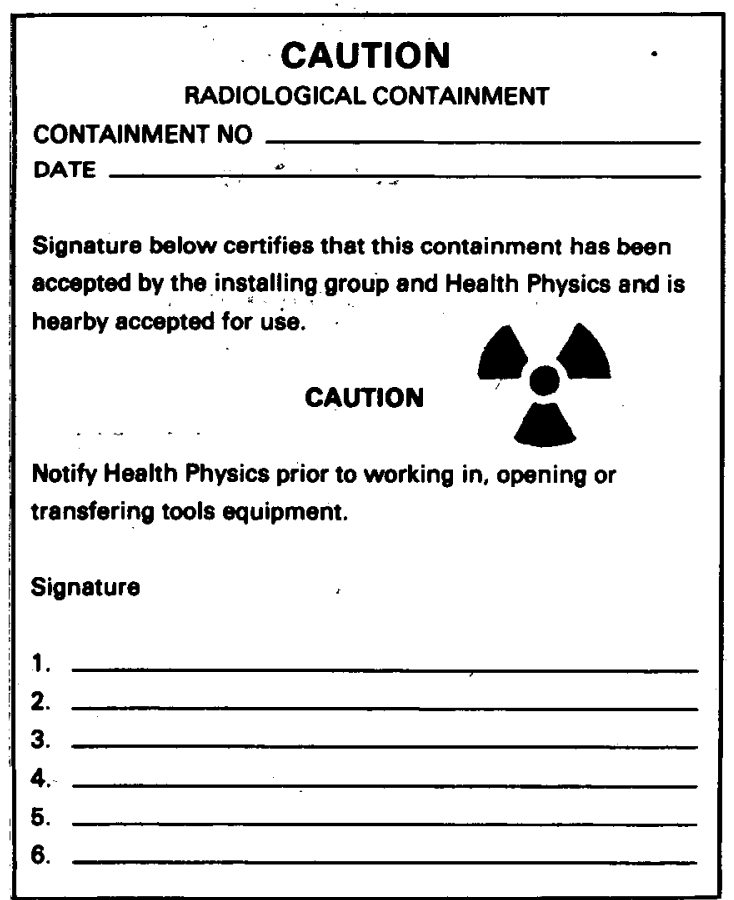

FIGURE 3-A-1 


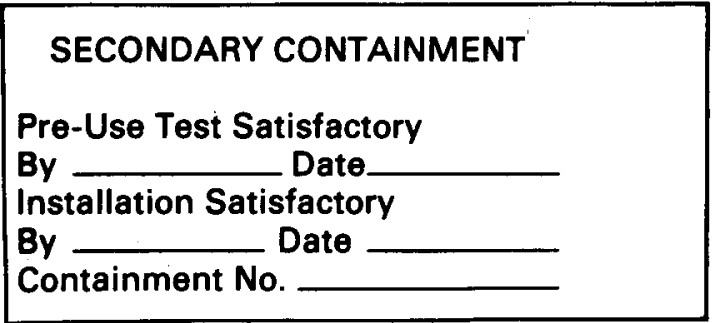

FIGURE 4-A-2

3. For primary containments, Health Physics completes section III of the Radiological Containment Status Sheet (see Figure 2-A-1). The Health Physics group should also complete the Radiological Containment Log (see Figure 2-(-1). For secondary containments, Health Physics and the Containment Specialist sign-off the Radiological Containment. Log.

4. If the water leak test is unsatisfactory, notify the Containment Specialist. In addition,

a. Primary containments which leak should be rejected, unless Health Physics Management approves it. Any containment accepted with a known leak should be noted in the Radiological Containment Log. Notify the Containment Specialist of the deficiencies and attach a "STOP" sticker to the containment (see Figure 3-A-3).

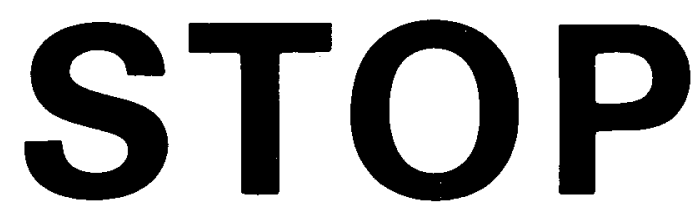

Do Not Use This

Radiological Containment

NAME

FIGURE 3-A-2

b. Any individual finding a deficiency can attach a "STOP" sticker to a containment. 
5. Retesting of primary containments may be required when:
a. The containment/component seal has to be broken to re-orient the containment,
b. Changing gloves,
c. Installation of additional equipment through glove sleeves, or
d. Containment repairs are made.

B. MODIFICATION

1. Health Physics approval is needed for any alterations that physically change the body/configuration of primary or special containments. The Health Physics manager should specify the decontamination, test and reinspection requirements.

2. Any modifications which may be required on primary containments should also be noted in section IV of the Radiological Containment Status Sheet (see Figure 2-A-1).
a. Modifications require the approval of responsible manager and Health Physics.
b. The containment should be reinspected after the modifications are made.

3. Secondary containments should be replaced, altered or modified when they no longer serve their intended purpose.

4. Secondary containments, when specified by Health Physics, can be of another color. It has to be conspicuously identified with a "Potentialiy Contaminated" warning tape in an area which remains intact during removal of the containment (see Figure 3-B-1).

\section{CAUTION POTENTIALLY CONTAMINATED CONTACT HEALTH PHYSICS PRIOR TO WORKING ON THIS SYTEM AND/OR COMPONENT.}




\section{INSPECTION FREQUENCY}

1. At the time of installation, all radiological containments should be accepted as ready for use by the Containment Specialist and Health Physics.

2. All containments in radiologically controlled areas should be inspected and surveyed dajly unless the areas are secured for 24 hours or more.

3. Primary containments should be inspected:

a. Prior to use by the using trade, and

b. By Health Physics personnel once a shift when it is in use (prior to work); otherwise it is daily.

4. Secondary containments should be inspected by Health Physics personnel daily.

5. The user is required to inspect the containment prior to each use.

D. INSPECTION CRITERIA - AFTER INSTALLATION

These criteria apply to all radiological containments except containment tents:

1. Holes, tears or other defects in the containment material;

2. Proper containment orientation, including drain lines;

3. Proper containment identification (primary or secondary, stickers present and signed-off) and posting;

4. Proper installation of gravity drain/handpump suction at the low point of the containment;

5. Drain equipment securely connected to an appropriate collection facility;

6. Properly labelled drain lines and polybottles to identify the component or system being drained;

7. Secured polybottles to prevent tipping;

8. No extraneous material (especially absorbent) in the containment to plug the drain;

9. Seals and hose clamps secured and covered with cloth-backed tape;

10. Service leads to the containment independently supported and have the right type of seal (inside or outside);

11. Containment properly secured and rubber band are used to minimize the stress; 
2. HEPA filter installed at the highest point of the containment, does not impair visibility or work performance and is properly supported;

13. Installed rubber gloves properly attached, oriented and stowed inside the containment;

14. Zippers and access openings properly taped with 2-inch wide cloth-backed tape;

15. Transfer sleeves installed in a high area of the containment and properly sealed, supported and stowed;

16. Containment protected from damage (sharp objects, hot objects);

17. Absorbent material may be present in the containment when the drain is not in use; and

18. Pinch clamps do not restrict flow in drain lines when fully opened.

E. INSPECTION CRITERIA - ROUTINE

The applicable items under the routine inspection are:

1. Check to ensure that tools and components are properily stowed or removed from the containment,

2. Check to ensure proper stickers are completed and updated,

3. Ensure that damaged containments are conspicuously identified and that the deficiency does not jeopardize radiological conditions (i.e., holes should be patched up temporarily and not just identified),

4. Check that the Radiological Containment Log (see Figure 2-C-1) is up-to-date and properly completed,

5. Minor condensation on the internal surfaces of secondary containments is not considered a deficient condition as long as the absorbent material inside is not saturated.

a. If the absorbent is saturated, the cause of the moisture should be determined and appropriate corrective action taken.

b. If no leakage is found, dry the internal surfaces of the containment and replace the absorbent material.

\section{Documentation}

1. Document routine inspections of primary containments by attaching a "Primary Containment Update" Sticker or a new "Primary Containment" Sticker as required and entering the inspection in the Log.

2. Document routine inspections of secondary containment in the Log. 
3. Make on-the-spot corrections of deficiencies noted during routine inspections, if practical.

4. Attach a "STOP" Sticker to the containment if the deficiency cannot be immediately corrected and the deficiency in no way jeopardizes safe radiological conditions in the work area.

5. Following the correction of a containment deficiency, remove the "STOP" Sticker and apply a new Containment Sticker.

F. CONTAINMENT TENT INSTALLATION INSPECTION CRITERIA

1. The Containment Specialist should check the tent for physical defects prior to installation.

2. No air or water leak test is needed unless it is specified in the applicable work document.

3. An installation inspection of containment tents is required in accordance with the following criteria (deviations from this criteria should be specified in the work document if applicable):

a. The containment tent is properly oriented and supported to hold its own weight and internal negative pressure;

b. The containment floor is properly supported and protected from tears or punches;

c. A11 seams are complete; no holes or tears are present in the fabric;

d. Service leads inside the tent are covered with sleeving, as required;

e. External lighting is enough to illuminate the tent;

f. Adequate negative ventilation within the containment;

g. Sharp objects are properly covered to prevent tears or punctures to the tent;

h. Change enclosures are provided;

i. Piping and equipment near the exit are covered;

j. Tent-to-component seal is properly made;

k. All service sleeves enter the containment through connector boards or sleeves;

1. The HEPA exhaust is installed opposite the inlet filters and the exhaust is near the floor of the containment;

m. The ventilation system capacity is adequate (negative pressure); 
n. Radiological instructions are prominently posted at the entrance/exit;

o. The work area and change area are separated by a barrier, i.e., zippered opening, wall, radiation ribbon, etc.;

p. A portable air sampler or continuous air monitor (CAM) is in close proximity (determine if the air sampler exhaust should be re-routed to the tent);

q. All velcro and/or zippered entrances are working properly.

\section{Documentation}

1. If the tent meets the criteria, put on a "Primary Containment" sticker (see Figure $3-A-1$ ) and enter the tent in the Radiological Containment Log (see Figure 2-C-1).

2. If the tent does not meet the criteria, put on a "STOP" sticker. Update the Radiological Containment Log and notify the Containment Specialist.

3. When the deficiency has been corrected, receive Health Physics concurrence to remove the "STOP" sticker, attach a "Primary Containment" sticker and update the Radiological Containment Log.

\section{G. CONTAINMENT TENT INSPECTION - ROUTINE}

A routine inspection should be performed in accordance with:

1. The applicable criteria under Containment Tent Inspection.

2. Check to ensure that tools are properly stowed or removed from the containment.

3. Check that the "Primary Containment" sticker is affixed, filled-out and up-to-date.

4. Damaged containments are conspicuously marked with a "STOP" sticker if the deficiency cannot be corrected on the spot.

5. Check for enough cleanliness to prevent a radiological problem from occurring.

6. Check that the Radiological Containment Log is updated and maintained correctly.

\section{Documentation}

1. Document routine inspection on the "Primary Containment" sticker.

2. Record any deficiencies noted. 
3. Attach a "STOP" sticker to a deficient containment tent when the deficiency cannot be corrected on the spot.

4. Following correction of the deficiency, receive Health Physics concurrence to remove the "STOP" sticker and apply a new "Primary Containment" sticker. 


\section{WORKING GUIDELINES}

A. PRIOR TO WORKING

1. Inform your manager who will in turn notify the Health Physics personnel when:

a. You are going to be working in a specific containment,

b. You will be installing or removing any item from a containment, or

c. A containment support must be moved for accessibility.

2. Coverage by Health Physics Personnel may be required at the discretion of Health Physics management or when dose rates exceed or expect to exceed $1 \mathrm{mSv} / \mathrm{hr}$ (100 mrem/hr).

3. Have all tools, equipment and protective clothing ready.

4. Ensure that the containment has the appropriate sticker (primary or secondary) (see Figure $3-A-1,3-A-2$ ) and is properly completed and updated.

\section{CAUTION!}

If the primary containment has a
STOP sticker on it, do not work
in the containment. Notify your
manager.

5. Health Physics personnel and the Containment Specialist should check the Radiological Containment Log for the status of secondary containments before working.

6. Adjust the lighting (use only fluorescent lights or flashlights). Incandescent lights may melt or soften the containment enough to cause damage.

B. DURING WORK

1. Wear surgical gloves taped to coveralls inside the rubber containment gloves. This allows the rubber gloves to slide off and on easily when working in the containment glove sleeves. Additional gloves may be required when working on sharp objects.

2. Tuck the gloves and glove sleeves inside the containment after use. Do not let them hang out of the containment.

3. Use only smooth leads in the containment because armored hose cannot provide a watertight seal.

a. Armored hose with bushings that prevent the armor from unraveling should have the sleeve-to-hose fitting made on the bushing. 
b. Other armored hose should have the armor removed at the point of contact with the containment sleeve. Cloth-backed tape is applied on this area for strength. The hose is secured to the sleeve by a hose clamp and cloth-backed tape.

c. Support the hoses so that the sleeve will be higher than the drain level.

d. Inside seals should be used unless authorization for an outside seal is made by Health Physics Management.

4. Do not burn or weld in a containment.

5. Take these minimum precautions to prevent containment punctures:

a. Cover the sharp edges of tools and equipment to prevent damage.

b. Tape over any punctures immediately and put on respirators. Remain in the area but move to low dose rate area and have someone contact Health Physics.

c. Be aware that rotating machinery will damage rubber gloves and containments.

d. Do not overload the containment. Support any heavy equipment using too thooks.

e. All non-sleeved tools should be removed from primary containments at the conclusion of each work period, if practical.

f. Mirrors placed inside a containment should be taped on the back and sides.

6. Water or other approved detergents are to be used for decontamination. Flammable liquids are not to be used because they can create an explosive hazard inside the containment.

7. Use only vacuum cleaners equipped with HEPA filters in contaminated or potentially contaminated areas.

8. Do not leave absorbent material in a containment if it has a drain.

9. Methods of insertion of items-high contamination:

a. Transfer sleeves are not normally used for tool storage but small tools can be left in there for a short time. 


\section{CAUTION!}

\section{Notify, Health Physics prior to inserting material into the con- tainment using the transfer sleeve. \\ Health Physics personnel will \\ ensure no spread of contamination \\ has occurred.}

b. Remove the tape holding the sleeve to the ring.

c. Hold the sleeving and push the tool into the sleeve and ring (see Figure 4-B-1).

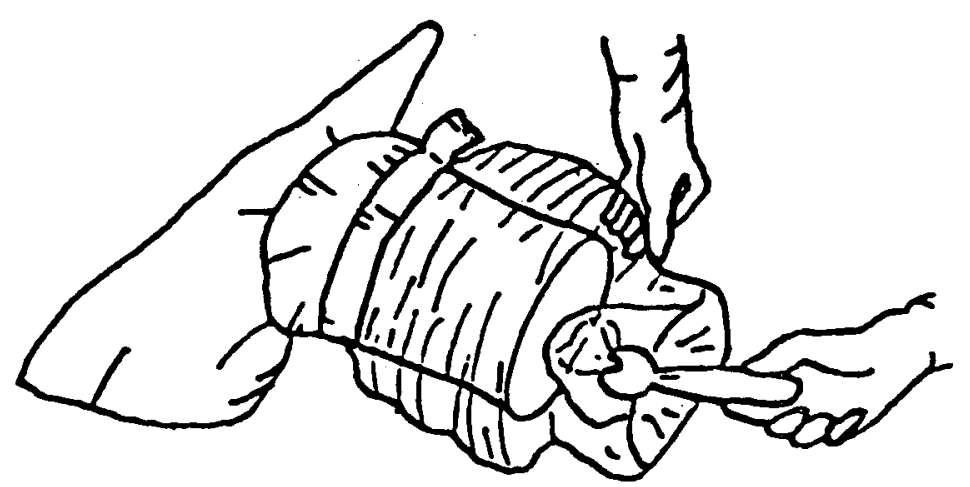

FIGURE 4-B-1

d. Gather the open end of the sleeve and tape the joint (see Figure 4-B-2).

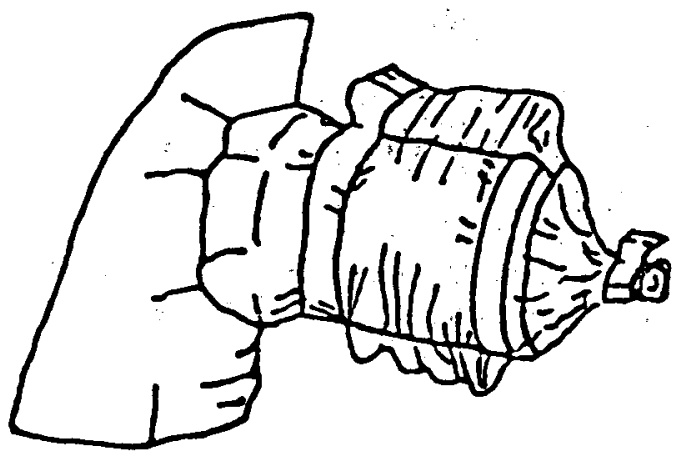

FIGURE 4-B-2 
e. Push the tool and the sleeve into the containment.

f. From inside the containment, cut an opening in the sleeving and remove the tool (see Figure 4-B-3).

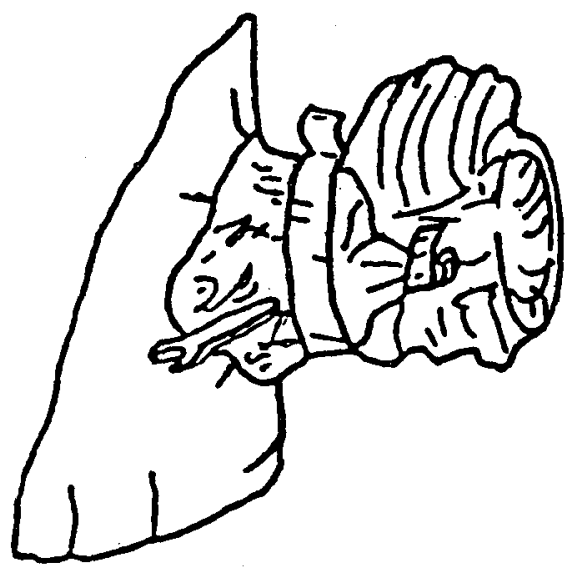

FIGURE 4-B-3

10. Methods of insertion of items directly into containment-low contamination:

a. Health Physics personnel should be present during operation.

b. Two qualified persons are required for the job.

c. A HEPA filtered vacuum cleaner is recommended when the zipper access is used instead of the transfer sleeve.

d. The first person inserts the hand into a glove sleeve and positions it adjacent to the closed access zipper.

\section{CAUTION!}

Avoid billowing actions of the containment when the access zipper

is open.

e. The second person carefully removes the tape and opens the zipper just enough to admit the tool (see Figure 4-B-4). 


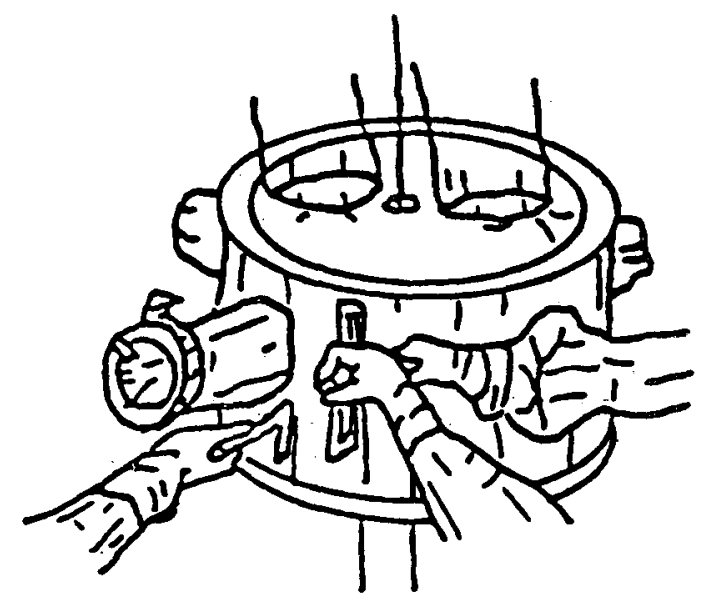

FIGURE 4-B-4

f. The second person passes the tool to the first person who then draws that arm away from the zipper to create a negative pressure in the containment.

g. The second person closes the zipper, checks it and retapes it with the closed zipper tab at the opposite end from the tape tab. Use new tape.

11. Methods of removal of items-high contamination:

a. Notify Health Physics personnel of intention to remove material from the containment.

b. Pass the tool into the transfer sleeve (see Figure 4-B-5).

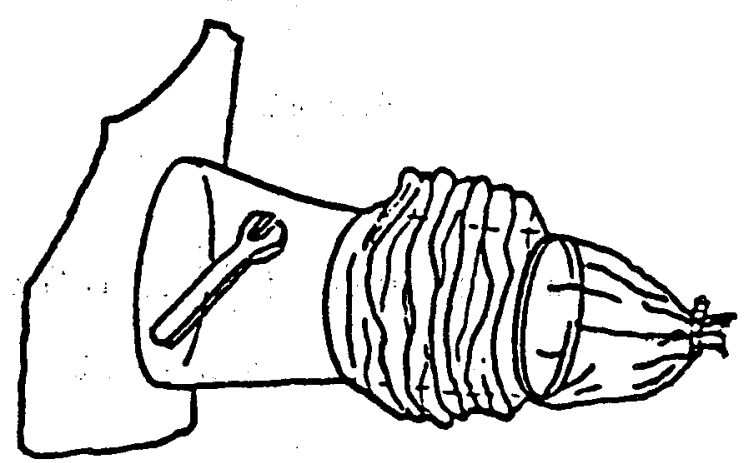

FIGURE 4-B-5 
c. Twist the sleeving tightly between the tool and ring and tape over the twisted area (see Figure 4-B-6).

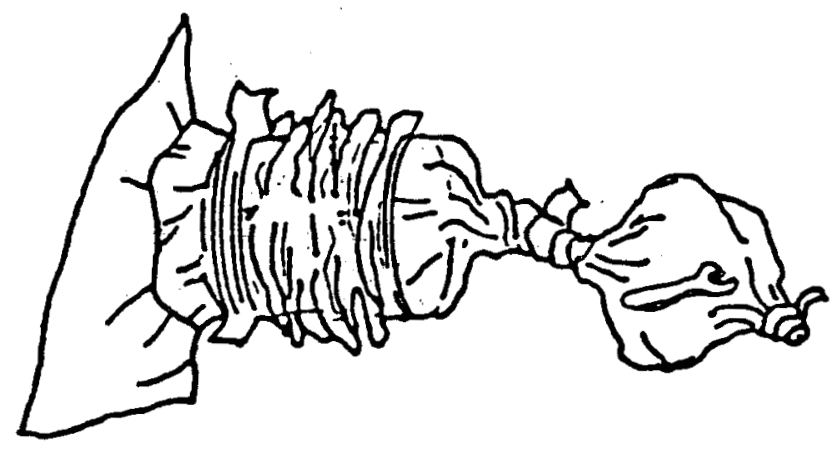

FIGURE 4-B-6

d. Cut in the center of the taped area and tape over each end of the cut to seal the edges. Slip the tool and sleeve into a poly bag (see Figure 4-B-7).

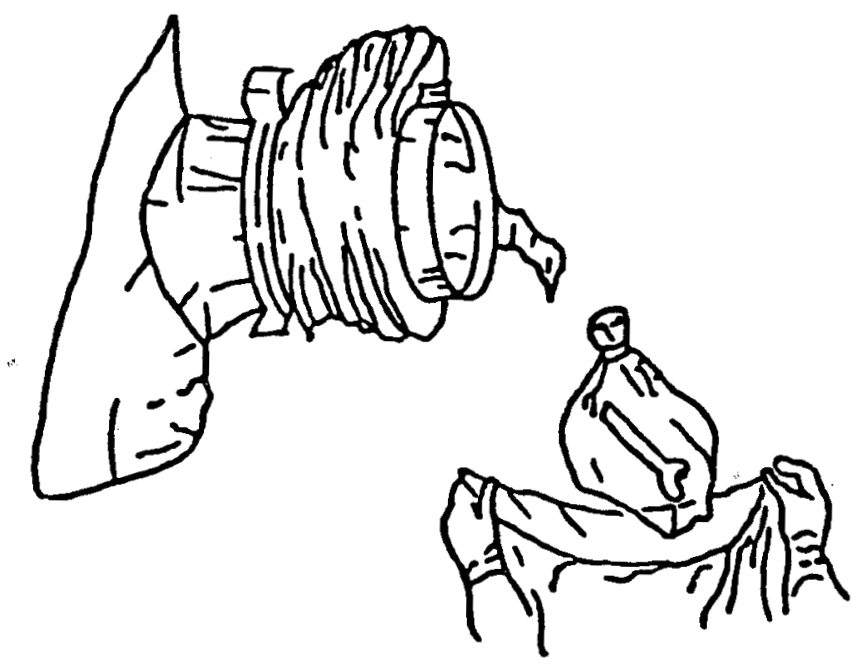

FIGURE 4-B-7

12. Methods of removal of items directly into containment-low contamination.

a. Health Physics personnel should be present during operation.

b. Two qualified persons are required.

c. The first person brings the tool over to the zipper before opening. 
d. The second person untapes the zipper and carefully opens it to the minimum required width (see Figure 4-B-8).

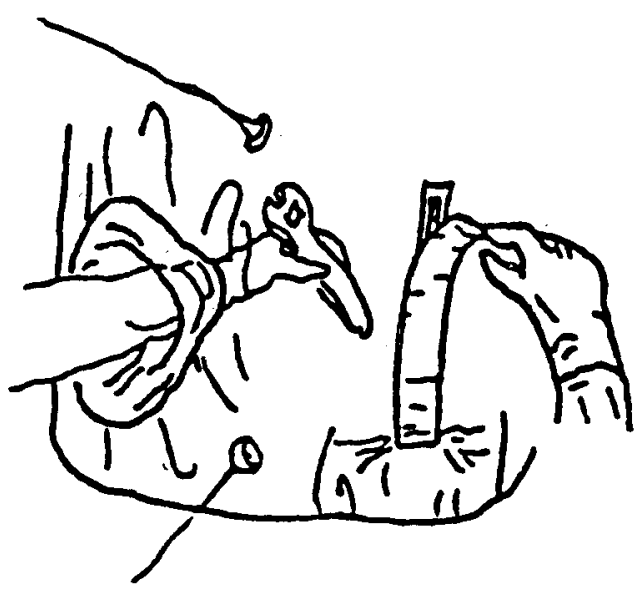

FIGURE 4-B-8

e. The second person inverts a poly bag halfway down the length and places it over the zipper opening to prevent spread of contamination. A hand is slipped through the inverted poly bag while the other holds the bag. Grasp the item with that hand (see Figure 4-B-9).

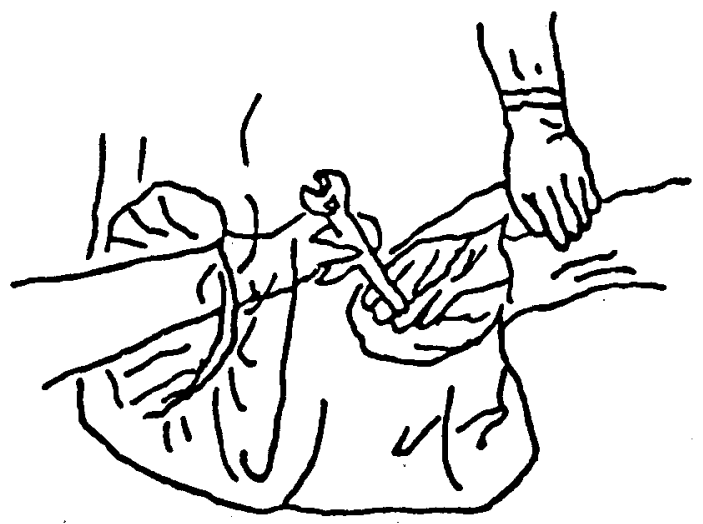

FIGURE 4-B-9

f. After the item is firmly grasped, slowly pull the bag out and down until it is right side out. At the same time the other person should pull his hand away from the zipper to equalize the pressure in the bag (see Figure 4-B-10). 


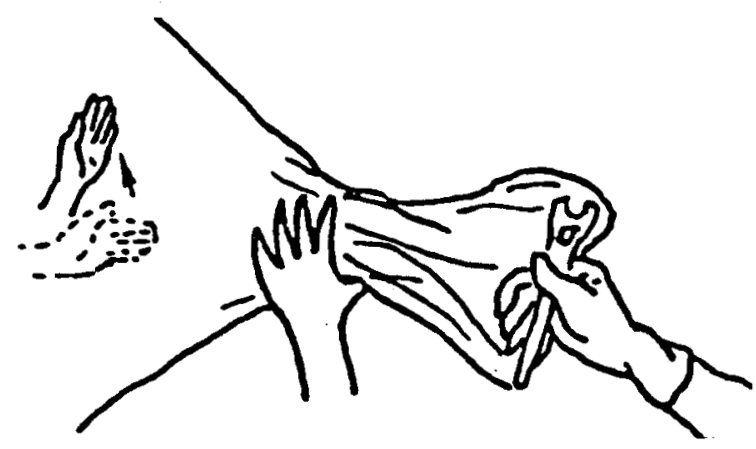

FIGURE 4-B-10

g. Seal the zipper with a new piece of cloth-backed tape. Twist the opening of the poly bag, fold it over and tape it with cloth-backed tape (see Figure 4-B-11).
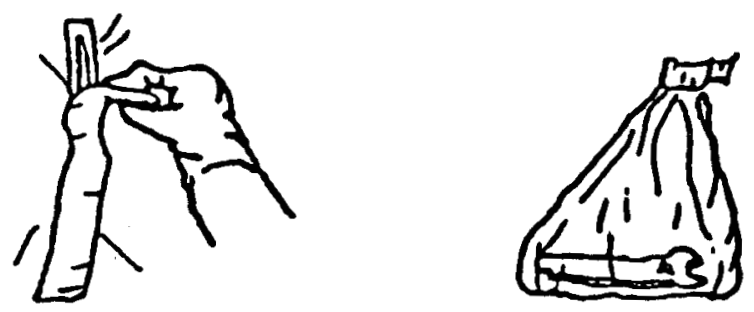

FIGURE 4-B-11

\section{GUIDELINES FOR WORKING NEAR CONTAINMENTS}

1. Take care to prevent the puncturing of the containment. In case you do puncture it,

- tape the puncture,

- stay in the area but move to low dose rate area, and

0 have someone contact the Health Physics personnel.

2. Use only flashlights or fluorescent lighting near the containments since other lighting can me1t the plastic.

3. Avoid any movements which can cause billowing of the containment. 
4. If welding, grinding, or burning in the immediate area might cause damage to the containment, contact Health Physics personnel. Cover the affected containments with fire protective blankets.

5. Do not step on or otherwise use the containments as a support.

6. Do not step on or stand on polybottles or their installations.

7. Inform responsible manager if a containment support must be moved for accessibility. Replace the support when the job is completed.

D. GUIDELINES FOR SECURING THE CONTAINMENT AFTER WORK

The containment user should ensure that the containment is not damaged during his work. Before leaving the work area, users should check the following and correct any unsatisfactory conditions:

1. Service sleeves and transfer sleeves should be supported, using suitable materials;

2. Glove sleeves should be tucked into the containment in such a way that it does not form a potential water collection point or be exposed to damage;

3. Remove heavy objects if they cannot be supported within the containment when:

o leaving the area for a significant time, or

o at the end of the normal work shift after contacting Health Physics personnel.

4. Cover any equipment with sharp edges (Cloth-backed tape may be used);

5. Secure the zipper opening with cloth-backed tape and ensure that the zipper tab and tape tab are at opposite ends;

6. Disconnect air-operated equipment at the leader connection and bag the open leader end;

7. Ensure that the catch containment is installed so that it will catch any leakage from a primary containment;

8. Ensure that the drain is at the low point of the containment if a gravity drain is installed;

9. Check that the drain hose is properly routed and supported;

10. Check that the polybottle is secured and the liquid level is not close to the full line; and

11. Make a final check of the work area and containment. Notify immediate supervisor and Health Physics personnel of any potential hazards. 


\section{OPERATING REQUIREMENTS}

A. USE OF POLYBOTTLES

\section{CAUTION!}

Polybottles shall not be used with solutions containing or systems which may contain fissile materials.

1. The need for polybottles as well as size, location and amount of liquid expected should be established in the operating documents.

2. The temperature of liquids collected in polybottles should not exceed $48^{\circ} \mathrm{C}$ $\left(120^{\circ} \mathrm{F}\right)$.

3. All polybottles used for liquid collection should be equipped with a bottle adapter and HEPA filter to provide:
a. A hose connection point,
b. Filtration of air displaced during filling, and
c. A means of directing liquid flow to prevent moisture from contacting filter media.

4. Care must be taken during all phases of installation, use and removal to prevent inadvertent spillage of liquids.

5. If required by work document, bag the mechanical joints using a secondary containment.

6. All bottles should have approximately $250 \mathrm{milligrams}$ of blue dye added prior to use as an aid for visually determining liquid level in bottle.

7. Polybottles should have a maximum fill line which represents 80 percent capacity marked on the external surface. Bottles shall not be filled above this fill line. Polybottles come in two sizes: 5-gallon and 15-gallon. Common features of both are shown in Figure 5-A-1. 


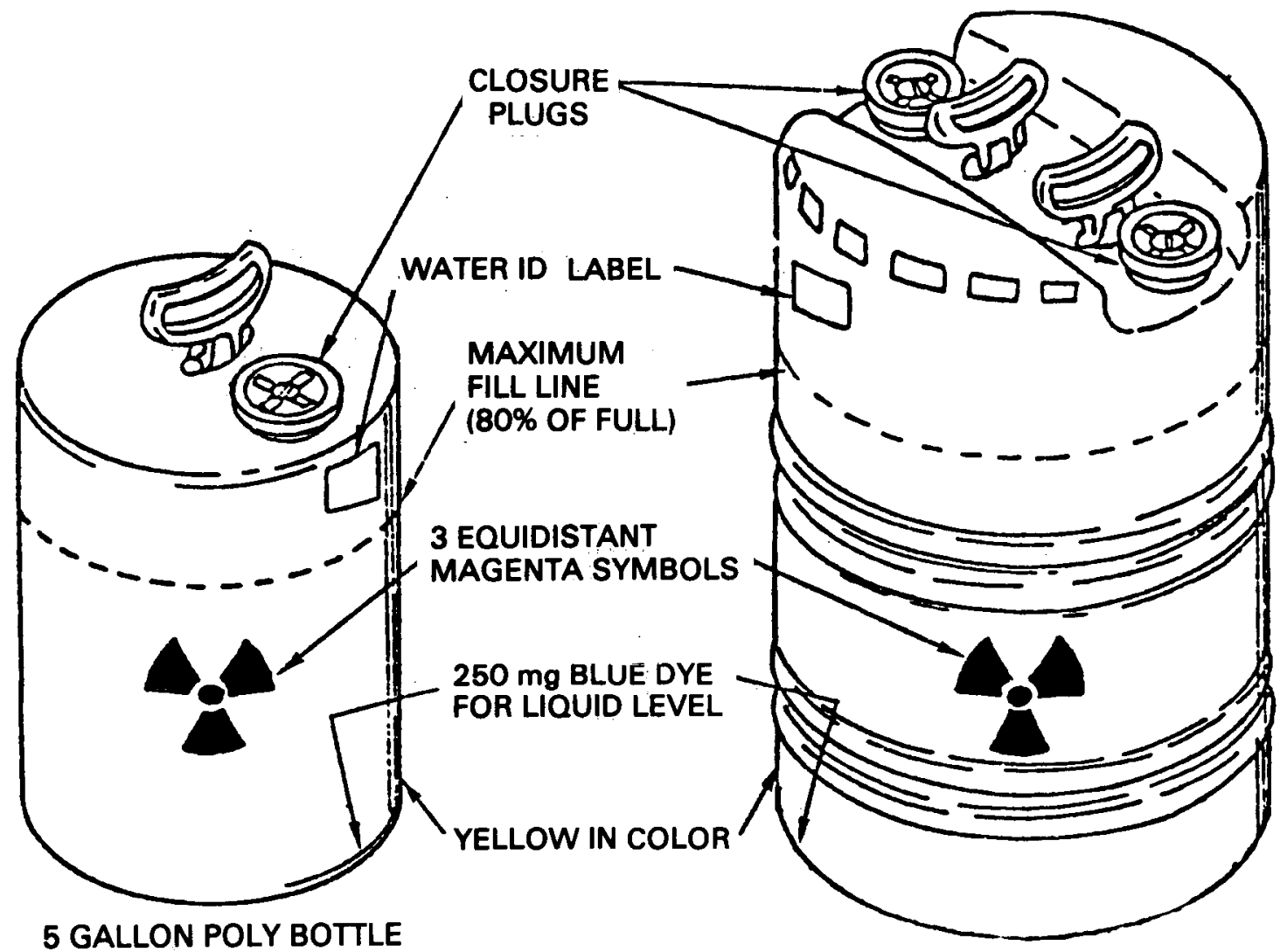

15 GALLON POLY BOTTLE

FIGURE 5-A-1

8. Useage identification.

a. After the polybottle has been installed, the Ccontainment Specialists should attach a "Source Identification" tag to the drain hose, noting the location of the drain. The label should be placed near the polybottle adapter connection (see Figure 5-A-2).

\section{SOURCE IDENTIFICATION}

\section{Connection Point}

FIGURE 5-A-2 
b. A water identification label is attached to the polybottle by the Containment Specialist before it is issued. This label identifies the location of the bottle and the source of the liquid. If there are multiple sources, all of them should be listed (see

Figure 5-A-3).

\section{WATER IDENTIFICATION}

\section{Bottle Location}

Source of Liquid

Dose Rate

FIGURE 5-A-3

c. Drain hoses from contaminated systems/sources should be identified at intervals with "CAUTION-INTERNALLY CONTAMINATED" tape (see

Figure 5-A-4).

\section{CAUTION INTERNALLY CONTAMINATION} CONTACT HEALTH PHYSICS PRIOR TO OPENING THIS SYSTEM AND/OR COMPONENTS

FIGURE 5-A-4

d. Drain hoses from potentially contaminated systems/sources should be identified at intervals with "CAUTION-POTENTIALLY CONTAMINATED" tape (see Figure 3-B-1).

9. Installation precautions.

a. Drain lines should be arranged and supported so that there are no low points where liquid could collect. Some standing liquid is expected when hand or power operated pumps are used.

b. Liquid may remain in the lines connected to system drains after draining or venting. Where possible, they should be arranged to allow gravity drain after the system drain is secured.

c. Do not install any damaged HEPA bottle filters. 
10. Installation procedure.

a. For new polybottles, remove the closure plug and cut out the diaphragm. Avoid damaging the threads. Remove the shipping plug from the closure plug. Bag it securely and tape it to the top of the polybottle (see Figure 5-A-5).

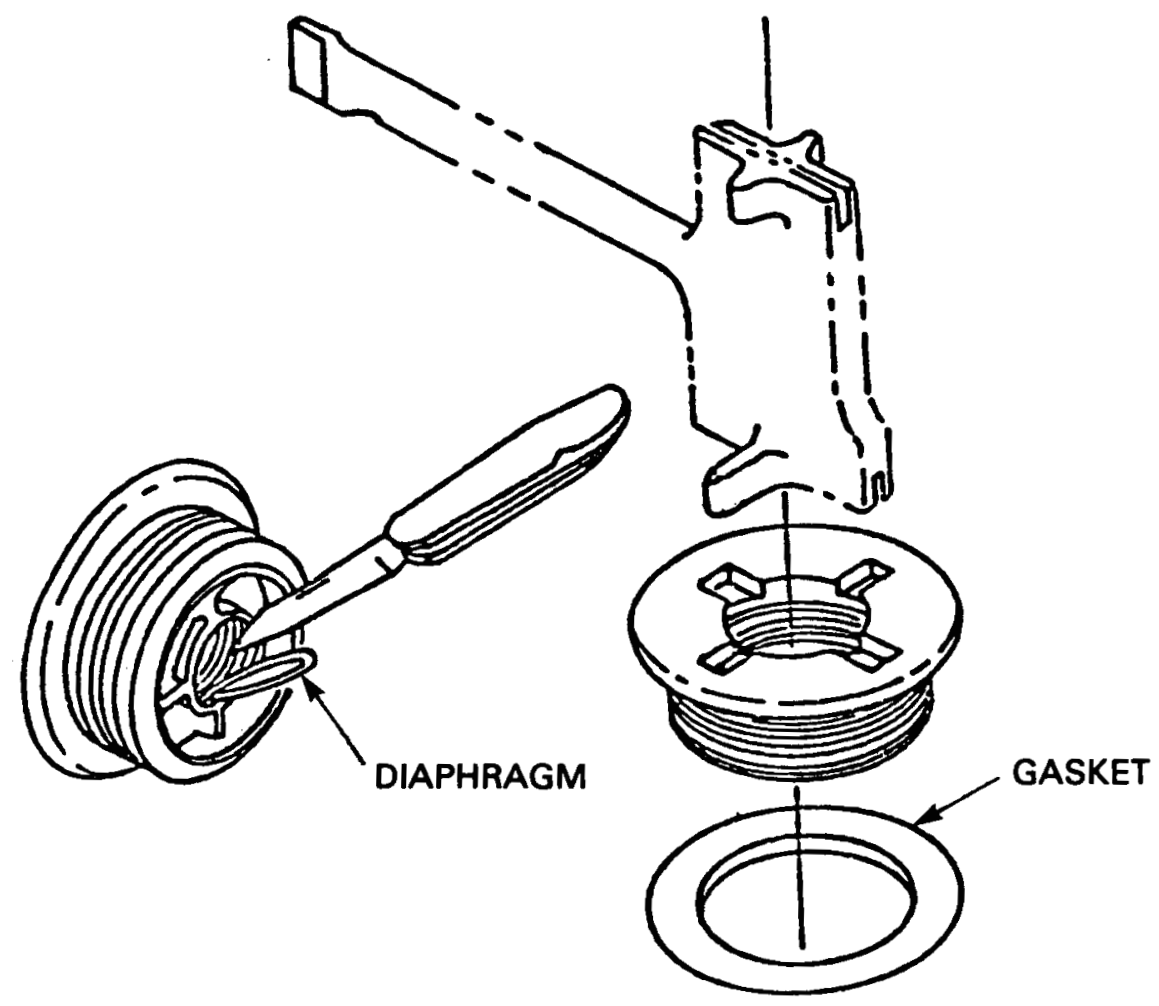

FIGURE 5-A-5

b. Re-install the gasket and closure plug. Tighten snugly with a plug wrench.

c. For all polybottles, install the bottle adapter.

\section{CAUTION!}

Make sure that the filter connector faces inward to protect the filter

from damage. Hand tighten only. DO

NOT OVERTIGHTEN. (See Figure 5-A-6.) 


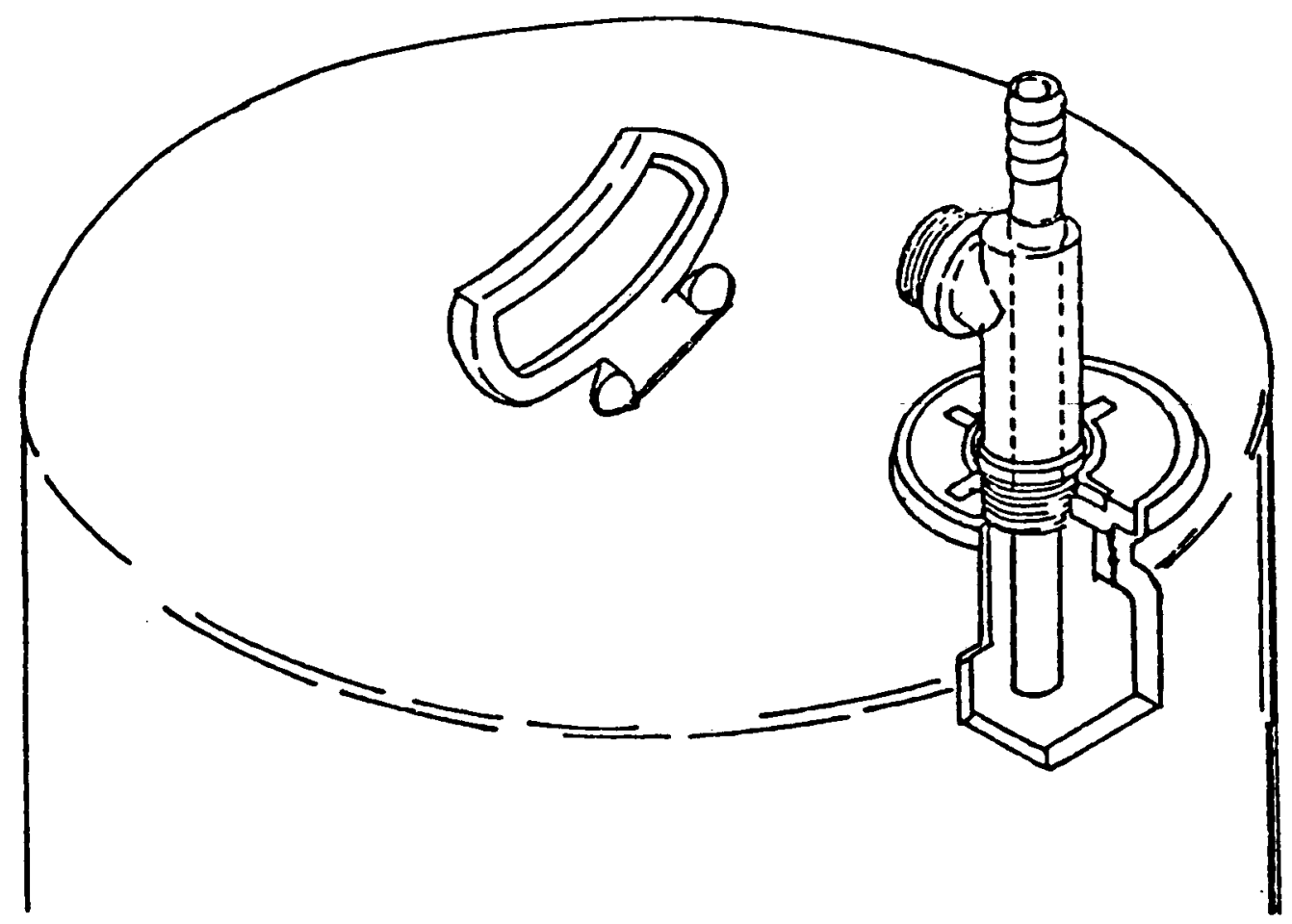

FIGURE 5-A-6

d. Remove the protective cover from the filter threads. Check the filter to ensure that the rubber gasket is in place. Ensure filter connector threads face inward to preclude filter from protruding past edge of bottle. Install the filter by hand tightening only. Remove the cover from the face of the filter housing (see Figure 5-A-7).

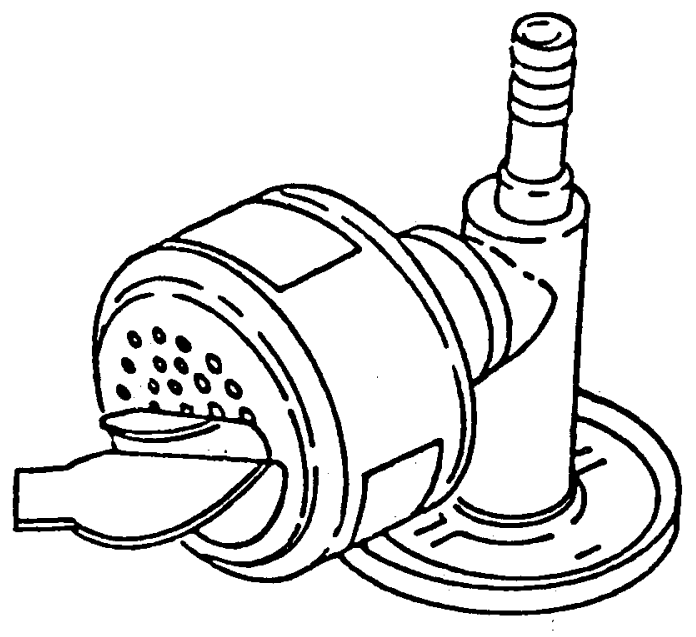

FIGURE 5-A-7

e. Secure the polybottles in place to prevent tipping or overturning. Rigid structures such as hangers, stanchions or system piping of one 
inch diameter or greater shall be used. Locate the bottle in a low traffic area if possible (see Figure 5-A-8).
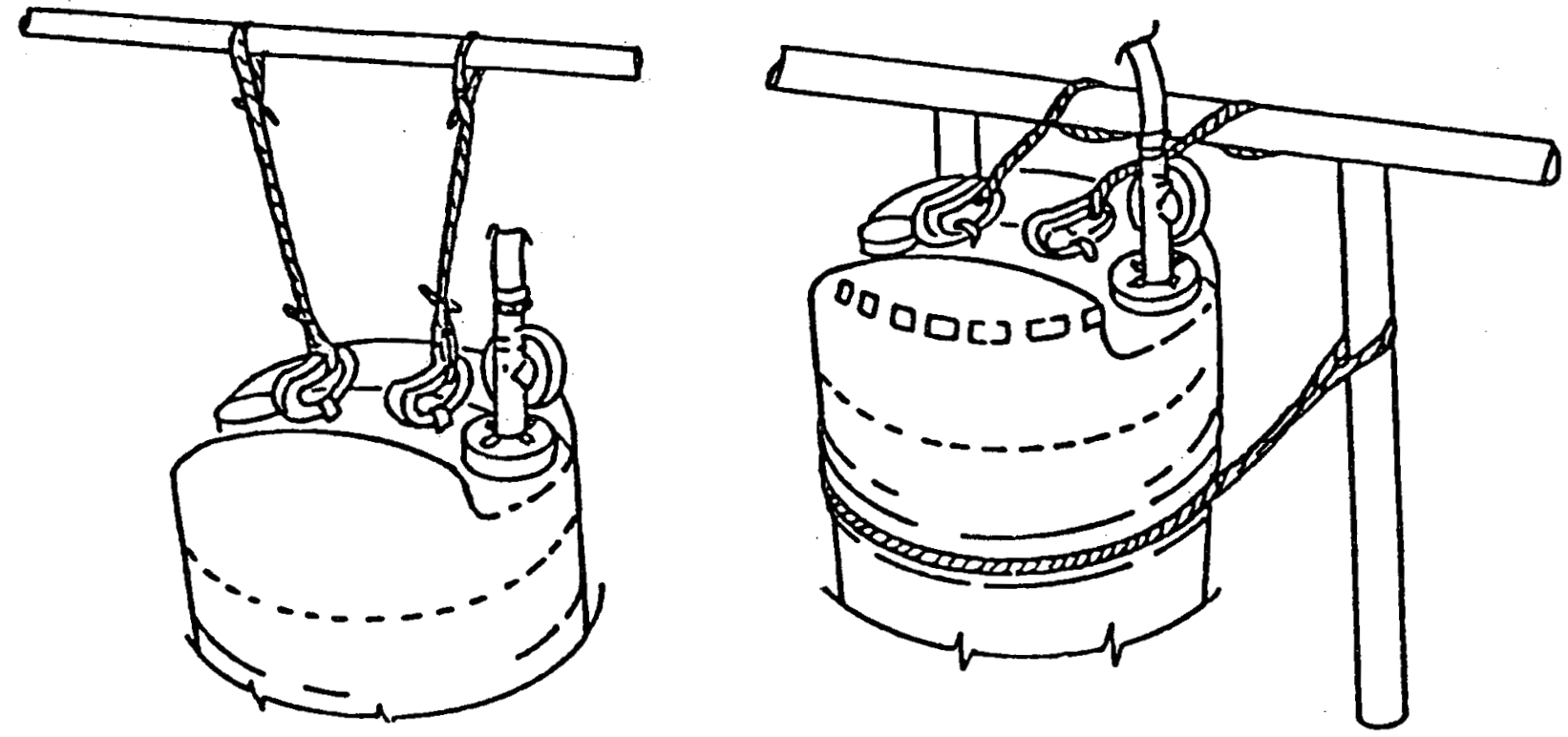

FIGURE 5-A-8

f. Install the drain hose (usually tygon) onto the barbed fitting on the top of the bottle adapter. Install a hose clamp, tighten and then wrap one layer of cloth-backed tape over it. Install a pinch clamp upstream of the bottle as a flow regulator (see Figure 5-A-9).

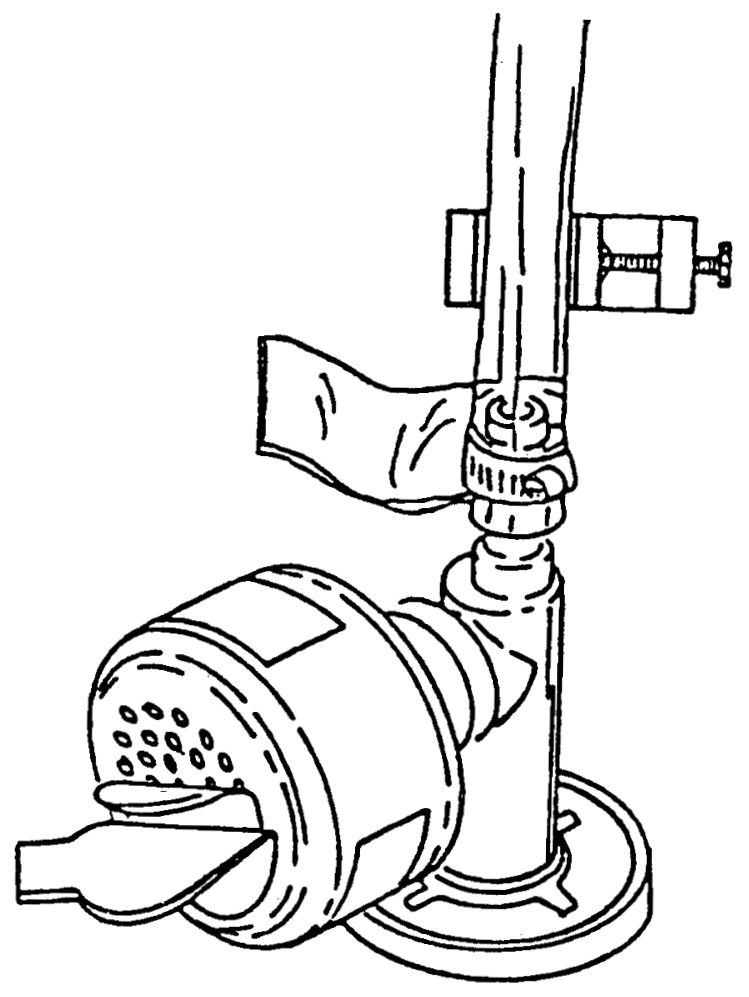

FIGURE 5-A-9 
g. Hook up the other end of the drain hose to the designated drain or to the pump, if required in the applicable work document (see Figure $5-A-10)$.

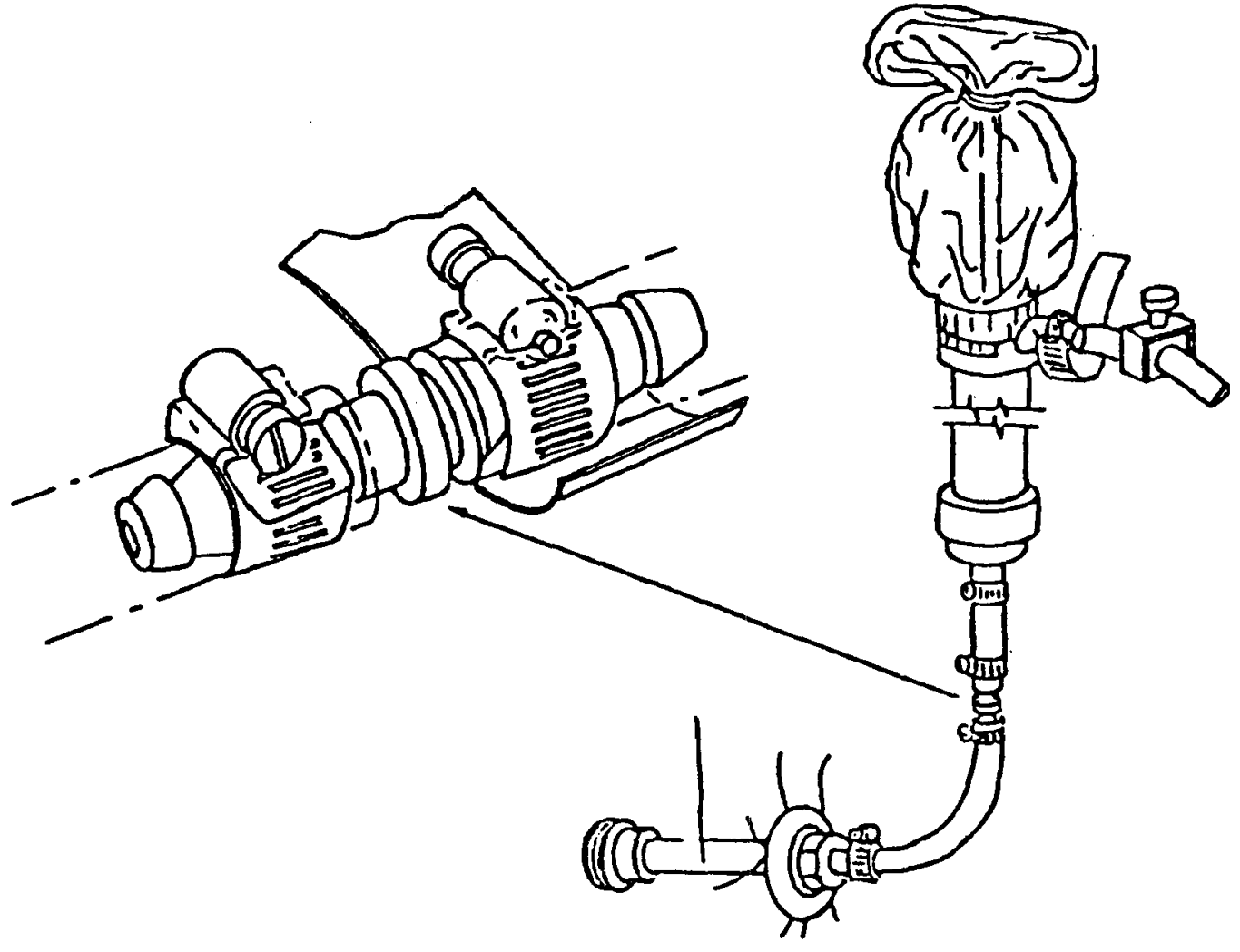

FIGURE 5-A-10

11. Use of polybottles.

a. Do not fill the polybottle past the marked fill line. Personnel engaged in draining operations are responsible for ensuring the polybottles are not overfilled. Notify Health Physics personnel of polybottles requiring replacement.

b. Using personnel should notify cognizant manager for repair or removal of polybotties.

c. Polybottles in use should not be stacked. This applies to installed bottles and those awaiting transportation and filled with liquid.

d. Empty bottles awaiting transportation need not be secured. Bottles with liquid should be secured, located in low traffic areas and placed in a spill pan or catch containment.

e. Do not step or stand on polybottles. 
B. REMOVAL OF POLYBOTTLES

1. Precautions.

a. Health Physics personnel are required to be notified prior to removal.

b. When it becomes necessary to tip the polybottle in order to remove it from interferences, the bottle should be plugged prior to tipping and then prepared for shipment.

c. When an overfilled bottle has to be removed, the remover should ensure that Health Physics personnel are aware of the over-full condition. Health Physics personnel should advise the transportation personnel of any special handling requirements.

2. Procedure for Containment Specialist personnel responsible for removal.

a. Ensure that the drain hose is completely drained. Gently tap the hose to promote drainage on gravity flow systems. After all the liquid has drained from the line, secure the hose with the pinch clamp.

b. Remove the tape covering the hose clamp. Then loosen and remove the hose clamp (see Figure 5-B-1).

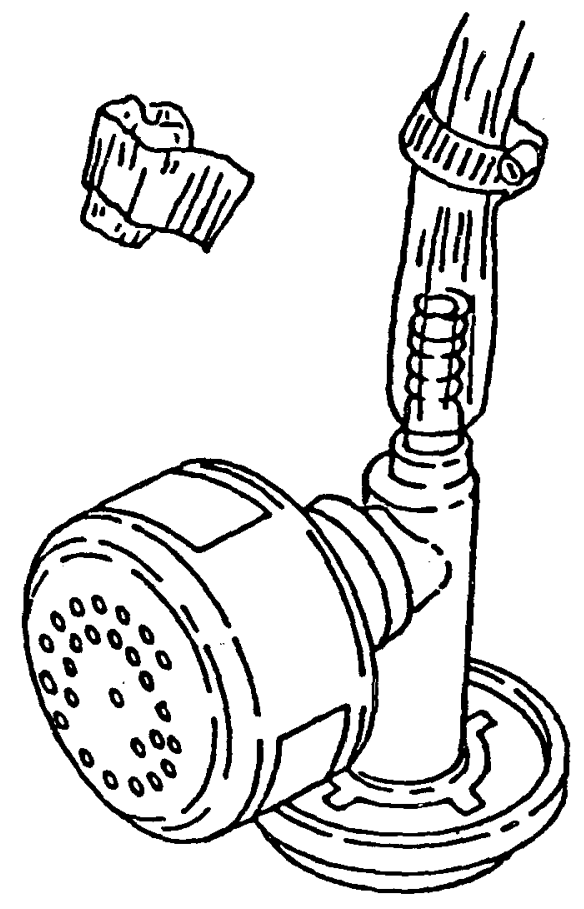

FIGURE 5-B-1 
d. Wrap a piece of absorbent around the bottle adapter, just below the barbed fitting. Gently remove the hose with an up and twisting motion, keeping the absorbent around and under the hose end as it becomes free (see Figure 5-B-2).

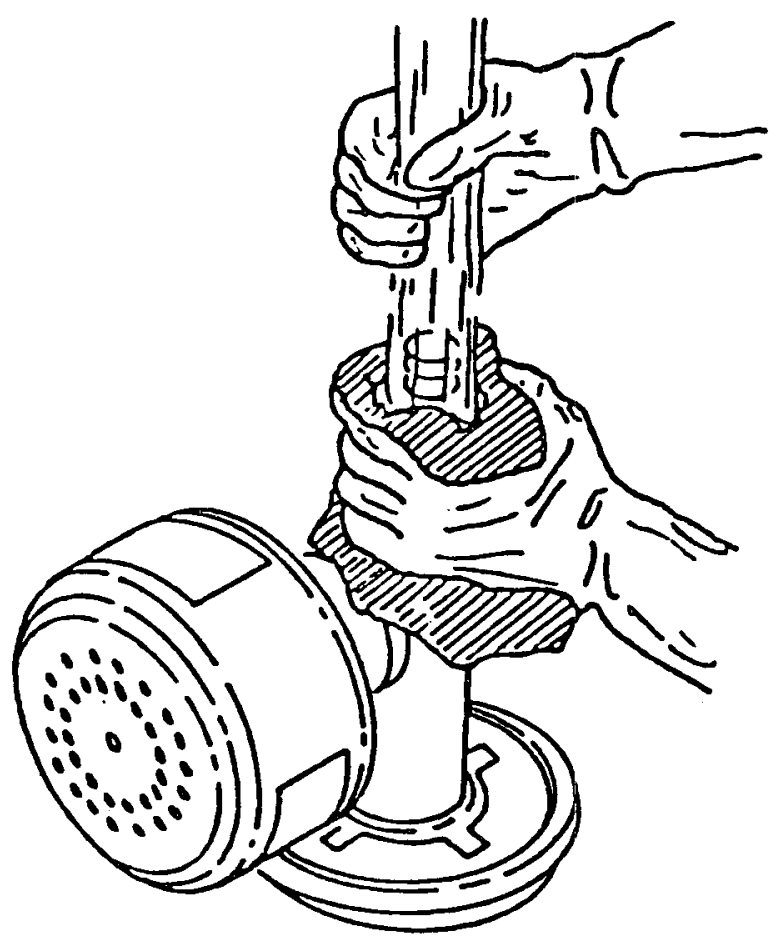

FIGURE 5-B-2

e. After the hose is free, place it and the absorbent into a poly bag and tape it securely. (See Figure 5-B-3.)

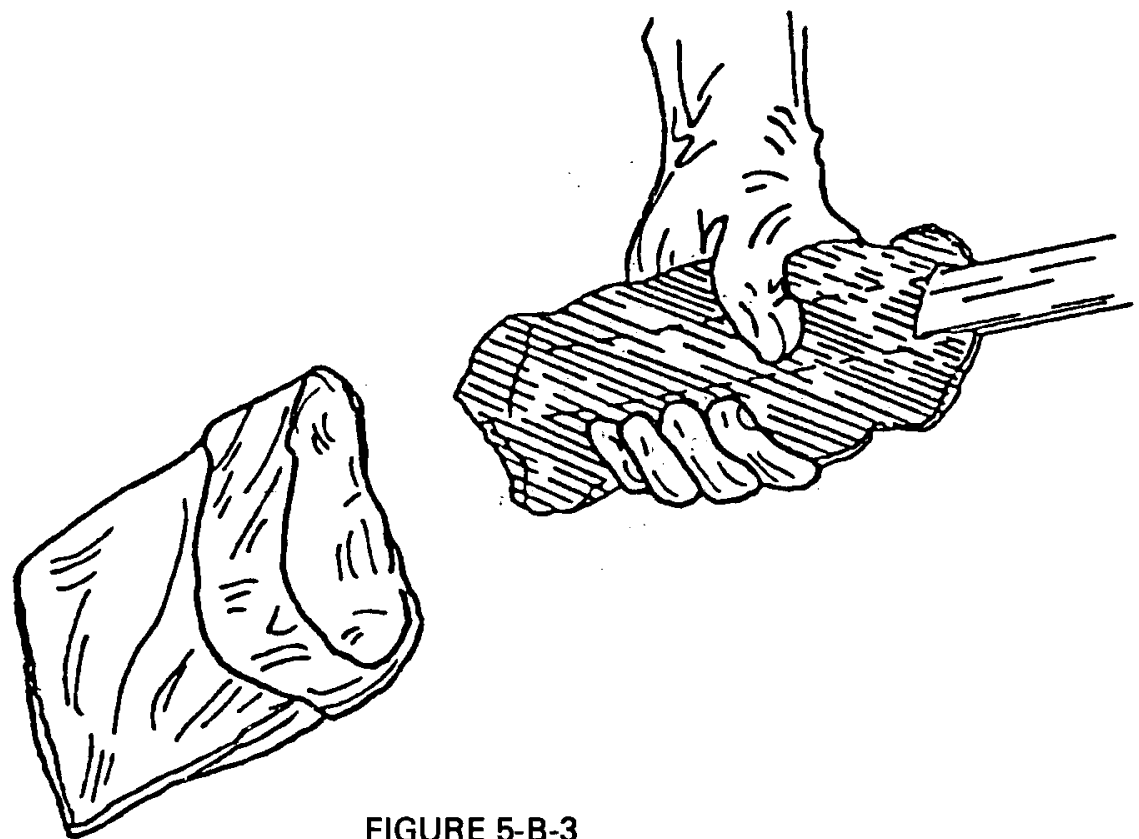

FIGURE 5-B-3 
f. Tape over the end of the barbed fitting on the bottle adapter (see Figure 5-B-4).

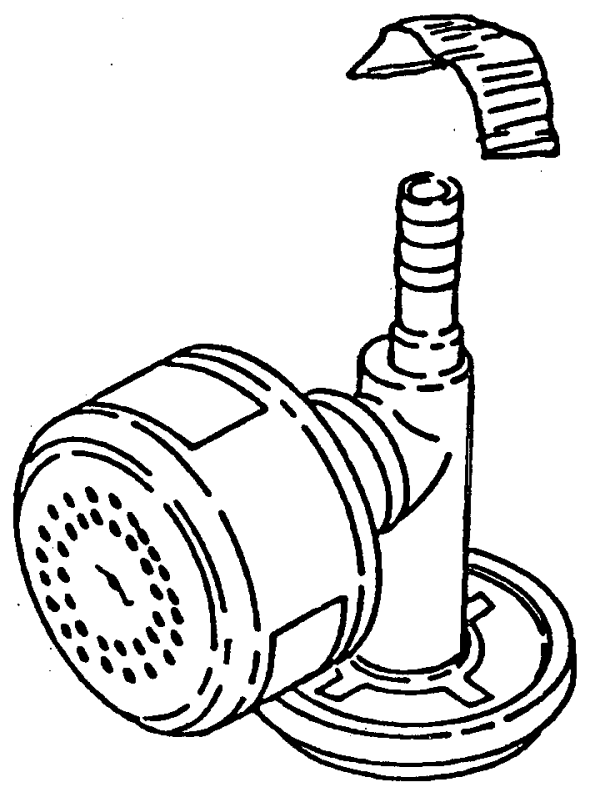

FIGURE 5-B-4

g. Wrap another piece of absorbent around the base of the adapter. Gently unscrew the adapter so that the closure plug does not become loose. Keep the absorbent around and under the end of the adapter as it becomes free (see Figure 5-B-5).

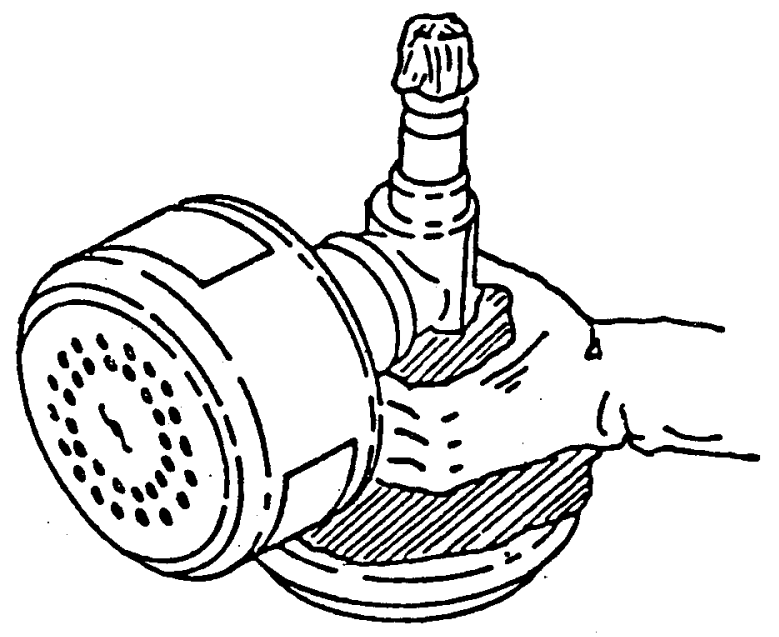

FIGURE 5-B-5 
h. After the bottle adapter is free, place it in an appropriate size and inverted poly bag. Tape it securely (see Figure 5-B-6).

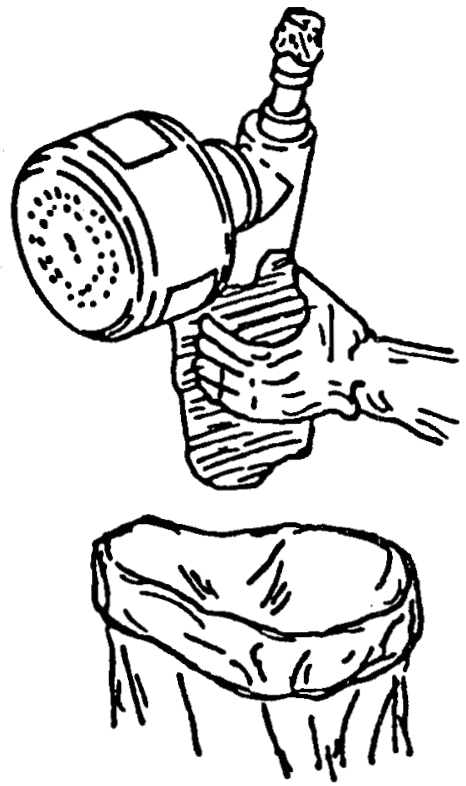

FIGURE 5-B-6

i. Remove the shipping plug from the polybag. Re-install it in the closure plug. Use the plug wrench but do not overtighten. The plug should be snug (see Figure 5-B-7).
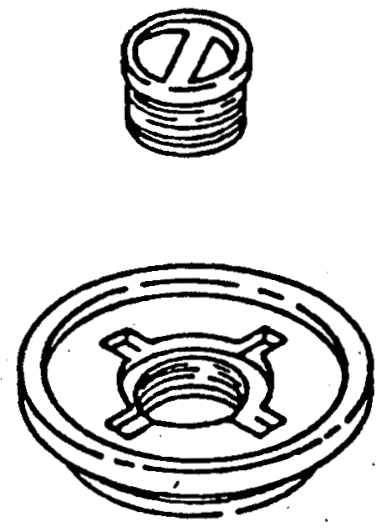

FIGURE 5-B-7

j. Install and tape absorbent around the closure plug (see Figure 5-B-8). 


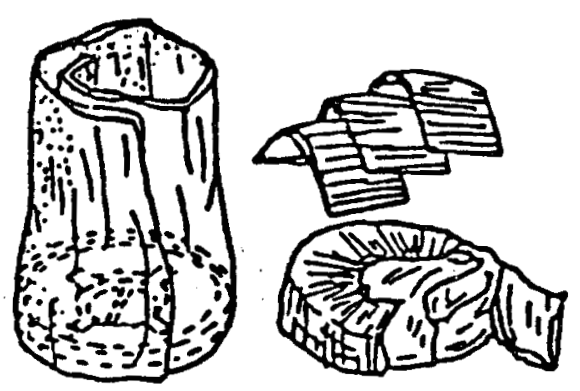

FIGURE 5-B-8

3. Polybottles should be shipped using techniques that avoid tipping.

a. Do not attempt to hand carry full polybottles.

b. Use a rigging bag to transport polybottles. These are reinforced plastic and nylon webbing bags which are sewn together to carry the polybottles. (See Figure 5-B-9.)

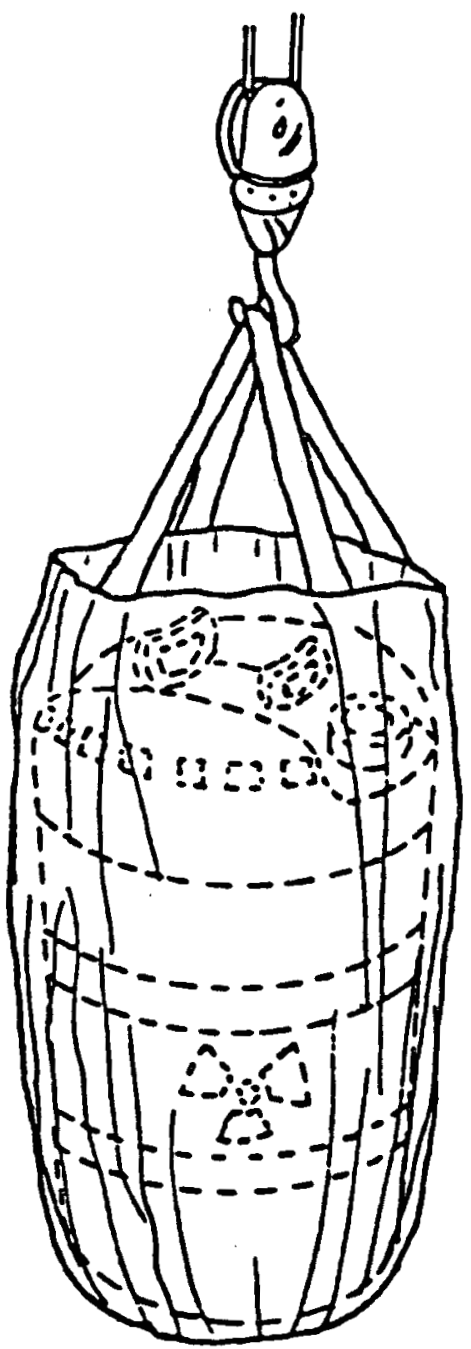

FIGURE 5-B-9 


\section{USE OF HIGH EFFICIENCY FILTERED VACUUM CLEANERS}

1. Requirements.

a. Health Physics personnel should be present whenever pre-specified dose rates are expected to be exceeded.

b. Vacuum cleaners used in radiologically controlled areas should be identified by "INTERNALLY CONTAMINATED" tape on the suction hose and body of the unit.

c. Seal wires on clamps securing the motor housing and filter to the container should be intact. Do not operate the vacuum cleaner if they are damaged. Report the damage to responsible manager and obtain a contamination survey.

d. A DOP test sticker should be applied on the filter housing by qualified vent and balance personnel. DOP testing is required at least every 12 months and the sticker should be current (see Figure 5-(-1).

HEPA FILTER SERVICE RECORD

\begin{tabular}{|l|l|l|l|l|l|l|l|l|}
\hline System Identity & & & & & & & & \\
\hline DOP Pretest & & & & & & & & \\
\hline Date Installed & & & & & & & & \\
\hline $\begin{array}{l}\text { DOP Test \% } \\
\text { Efficiency }\end{array}$ & & & & & & & & \\
\hline Flow CFM & & & & & & & & \\
\hline Filter D/P & & & & & & & & \\
\hline Date Testod & & & & & & & & \\
\hline
\end{tabular}

FIGURE 5-C-1

e. Electric vacuums should have no more than 25 feet of $1.5^{\prime \prime}$ I.D. flexible vacuum hose.

f. Vacuum cleaners may be used for liquid pickup provided there is a special polybottle arrangement and radiological engineering personnel concur. Liquid pickup using 15-gallon polybottles should be with 
electric vacuum cleaners. The vacuum inlet line on the polybottle should be above the full line (see Figure 5-c-2).

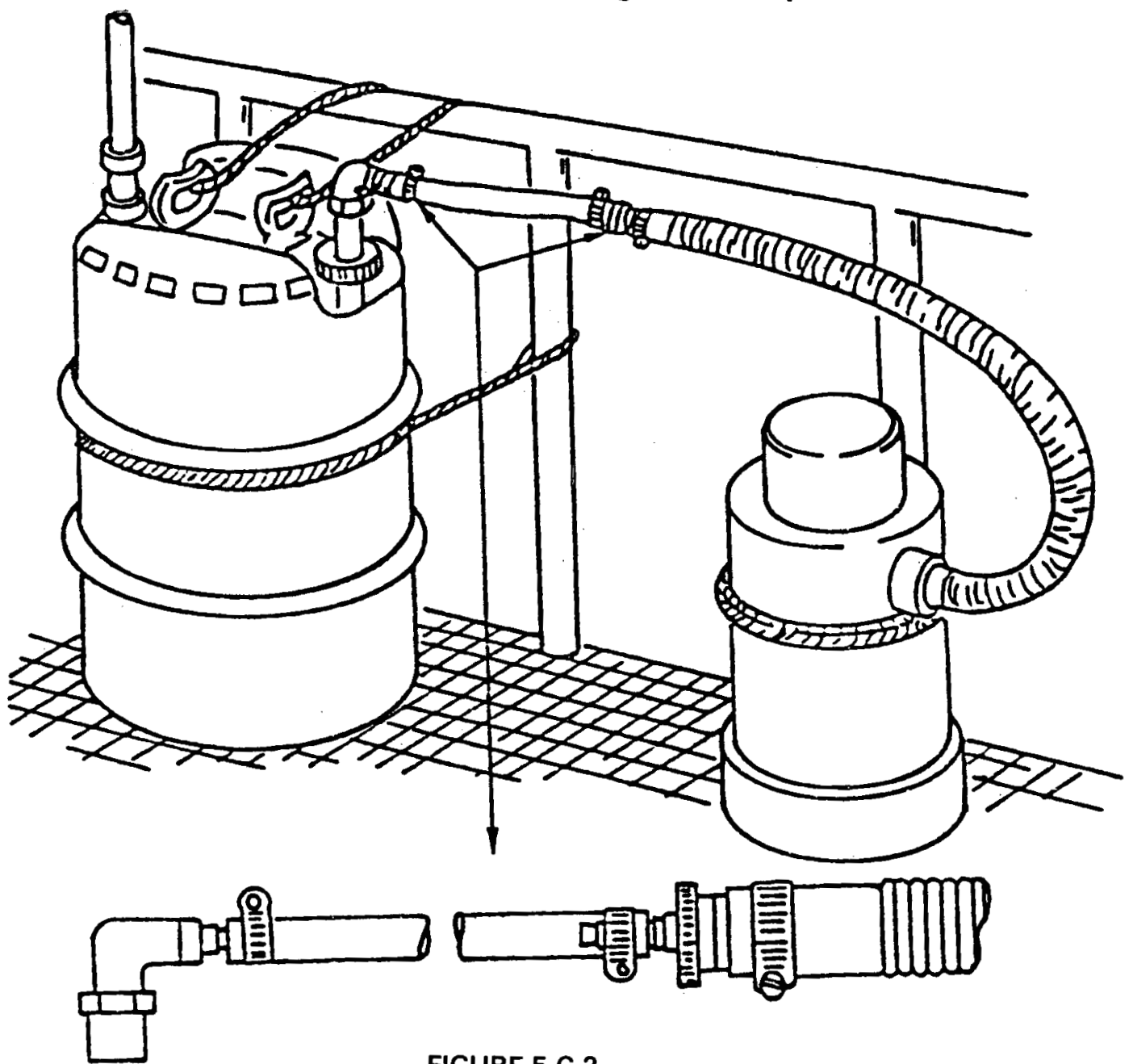

FIGURE 5-C-2

g. All hose connections should be clamped.

h. Vacuum hose ends should be sleeved and taped when not in use. The sleeving material should be $8 \mathrm{mil}$ purple transparent PVC. The hose should be neatly coiled and stowed near the cleaner after each use. Those permanently installed in containments are exempt from this requi rement.

i. Vacuum cleaners should be secured to prevent accidental tipping of the unit. Do not secure it to electrical cables or delicate equipment which could be damaged.

$j$. When a vacuum hose is required for use within a containment, a $1.5^{\prime \prime} \times$ 0.75 " reducer should be used. When removing the containment, dispose of the 0.75" I.D. hose along with the containment. Bag the end of the hoses. 
k. Accessories are available to clean accessible, large surface areas. Other types of accessories may be used at the discretion of the responsible trade. Hose lengths for reduced diameter hoses should be as short as practical (see Figure $5-C-3$ ).
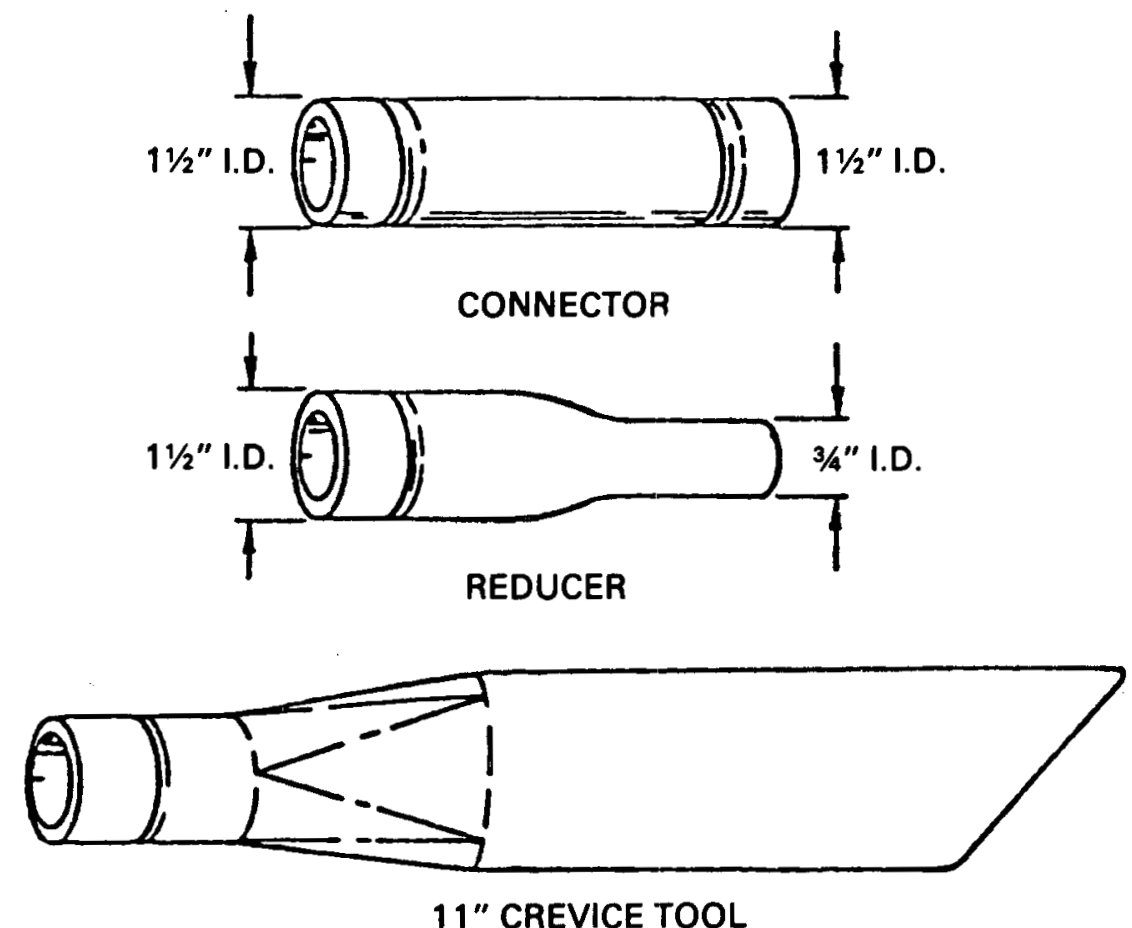

19" CREVICE TOOL

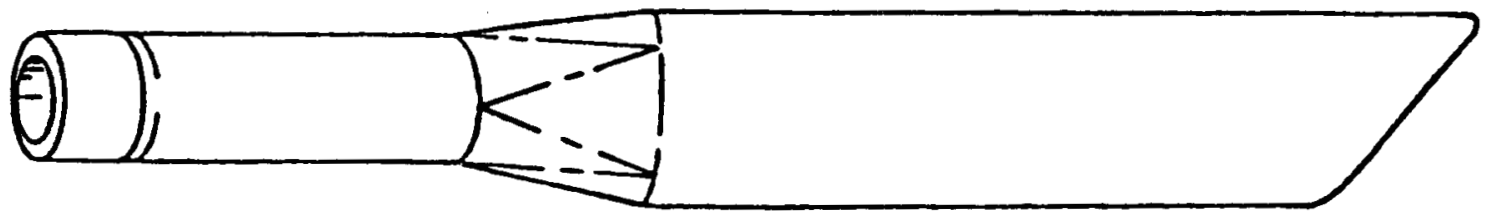

FIGURE 5-C-3

2. Disconnecting vacuum hoses and fittings.

a. Check with responsible manager to determine which method should be used. These methods are based on the results of radiation surveys, contamination levels and estimates of hazard by Health Physics personne].

b. Method A.

- Measured or expected hose/fitting contamination level less than or equal to $16.8 \mathrm{Bg}\left(1 \times 10^{3} \mathrm{dpm}\right)$ alpha or beta-gamma. 
- Wear cloth and rubber gloves. Health Physics personnel may require additional protective clothing for this operation.

- Arrange a drop cloth or inverted polybag under the fitting. Turn on the vacuum cleaner.

- Disconnect or cut the hose fittings. Ensure that any tools that are used remain on the drop cloth or polybag. Place the fittings in a polybag.

- Secure the vacuum cleaner and seal the disconnected ends. Have Health Physics personnel survey the hose ends, tools and waste polybag.

c. Method B.

- Measured or expected hose/fitting contamination level greater than $16.8 \mathrm{Bg}\left(1 \times 10^{3} \mathrm{dpm}\right)$ alpha or beta-gamma but $<100 \mu \mathrm{Sv} / \mathrm{hr}$ $(<10 \mathrm{mRem} / \mathrm{hr})$.

- Wear cloth and rubber gloves. Health Physics personnel may require additional protective clothing for this operation.

- Remove any hose clamps which hold the hose connections (see Figure 5-(-4).

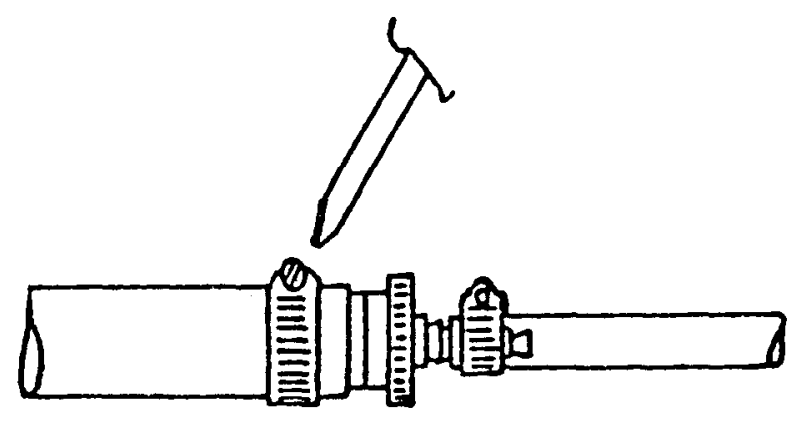

FIGURE 5-C-4

- Sleeve or bag the hoses and/or fittings to be disconnected but leave enough slack to permit the separation of components. Tape the ends of the sleeve or bag with cloth-backed tape.

- Turn on the vacuum cleaner and carefuliy disconnect the hoses and fittings. Leave the vacuum on as long as practical after disconnecting the fittings.

- Make an umbilical cut in the slack, tape the ends and rebag it as necessary. Turn off the vacuum after the ends are taped to prevent vacuum motor burnout (see Figure 5-C-5). 

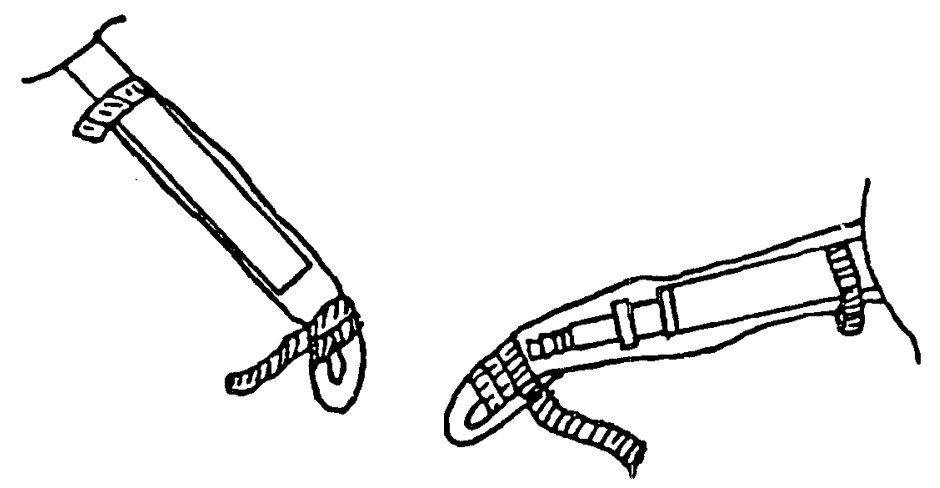

FIGURE 5-C-5

d. Method $C$.

- Hose/fitting contamination/radiation levels greater than $100 \mu \mathrm{Sv} / \mathrm{hr}(10 \mathrm{mR} / \mathrm{hr})$.

- Install a primary containment over the area to be worked on. Have enough slack in the containment sleeves used for sleeving the hoses to make an umbilical cut.

- Have Health Physics personnel inspect and certify the containment. Ensure that the required sign-offs are made.

o Wear protective clothing as directed by Health Physics personnel.

- Turn on the vacuum cleaner, disconnect and bag the hoses or fittings within the containment.

- Bag the ends of the disconnected hoses and turn off the vacuum cleaner.

- Decontaminate the hose surfaces and containment interior, as required. Remove the bagged components or use the containment sleeves for an umbilical cut.

\section{GRINDING WELDS INSIDE A CONTAINMENT}

\section{Precautions}

a. Health Physics personnel should be present.

b. The piping to be cut should be isolated, flushed, and drained as much as possible. 
c. Have all required equipment such as polybottles, pipe plugs, grinders and HEPA-equipped vacuum cleaners staged in the work area.

d. Have the pipe adequately supported.

2. Procedure

a. Install the containment in accordance with Section II, "Installation of Containments." Typical examples are in Figures 5-D-1 and 5-D-2.

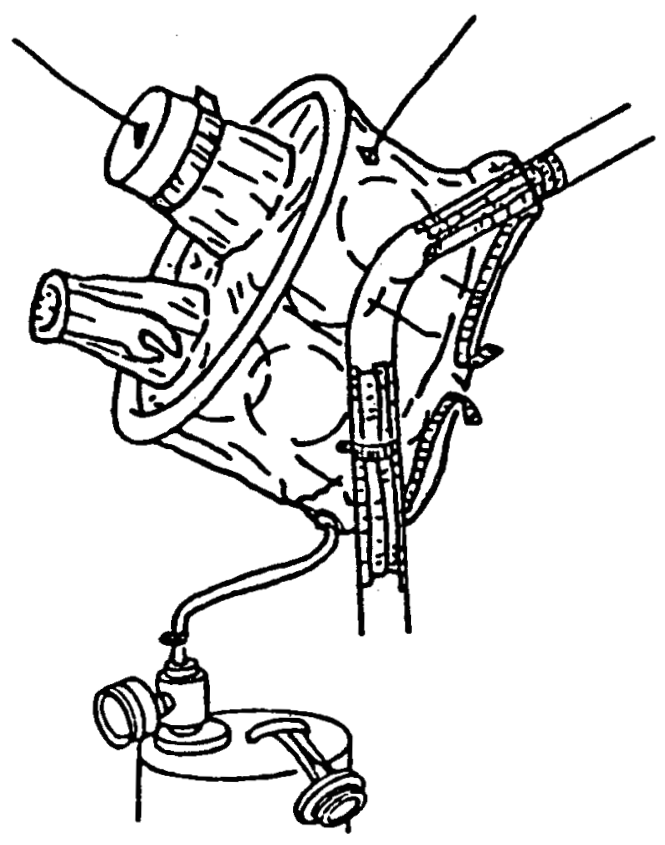

FIGURE 5-D-1 


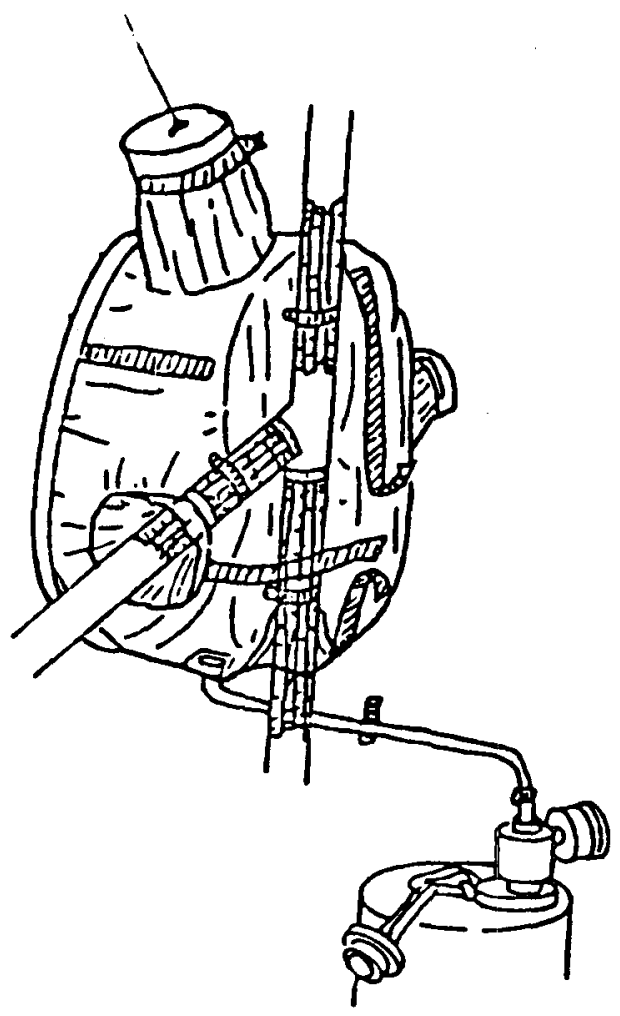

FIGURE 5-D-2

b. Install Lucite shields, as needed, inside the containment to minimize scratching or tearing of the containment when grinding.

c. Place drop cloth with absorbent under the containment.

d. Place all necessary tools and equipment in the containment and support them as needed to avoid strain on the containment seams.

e. Install and bag, as required, the service leads. Have Health Physics personnel inspect and certify the containment before any work is started.

\section{CAUTION!}

Operation of vacuum cleaner while grinding may collapse the glove bag, with the possible danger of cutting the bag with the grinding wheel.

i. Vacuum or wipe down the containment after grinding is complete. 
j. Break the pipe with a pipe parting tool, mallet, strap, wrench or wooden $2^{\prime \prime} \times 4^{\prime \prime}$.

k. Drain any leakage as soon as possible.

1. Install the pipe plugs if required.

E. CUTTING PIPES INSIDE A CONTAINMENT

1. Precautions

a. Health Physics personnel should be present at critical points during the operation.

b. Ensure that the piping is still adequately supported before breaking it.

c. Flush and drain the line, if possible, prior to breaking.

d. Have the necessary materials in the containment to remove any liquids.

2. Procedure-primary method

a. Attach the pipe parting tool such that the cutting wheel is located in the pre-ground groove on the pipe (see Figure 5-E-1) and cut the pipe.

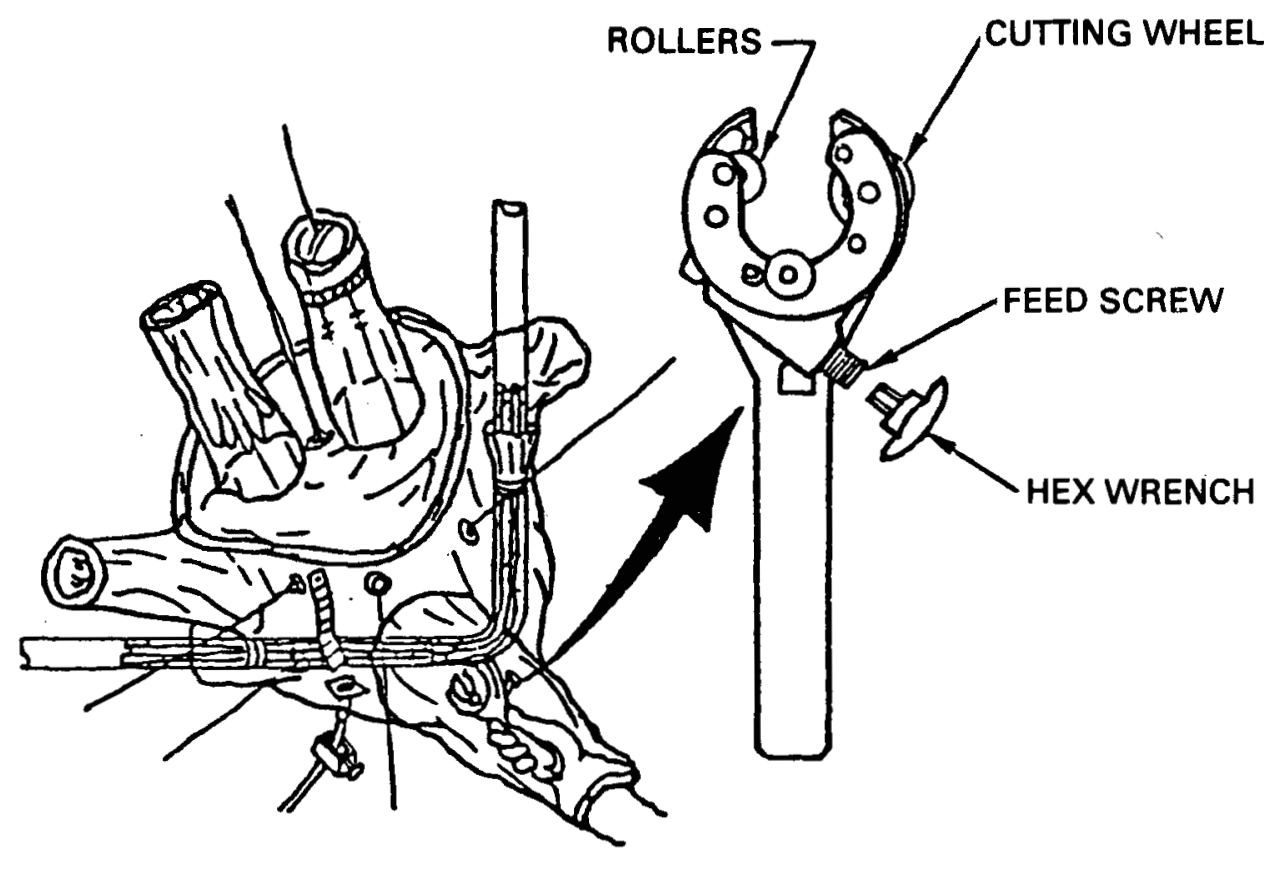

FIGURE 5-E-1 
3. Procedure-alternate method

a. This method is used only if a pipe parting tool cannot be used.

b. After grinding has been completed, use a $2 \times 4$ and mallet (see

Figure 5-E-2). Block of wood is wrapped in reinforced plastic and installed in an unused access sleeve and secured with tape.

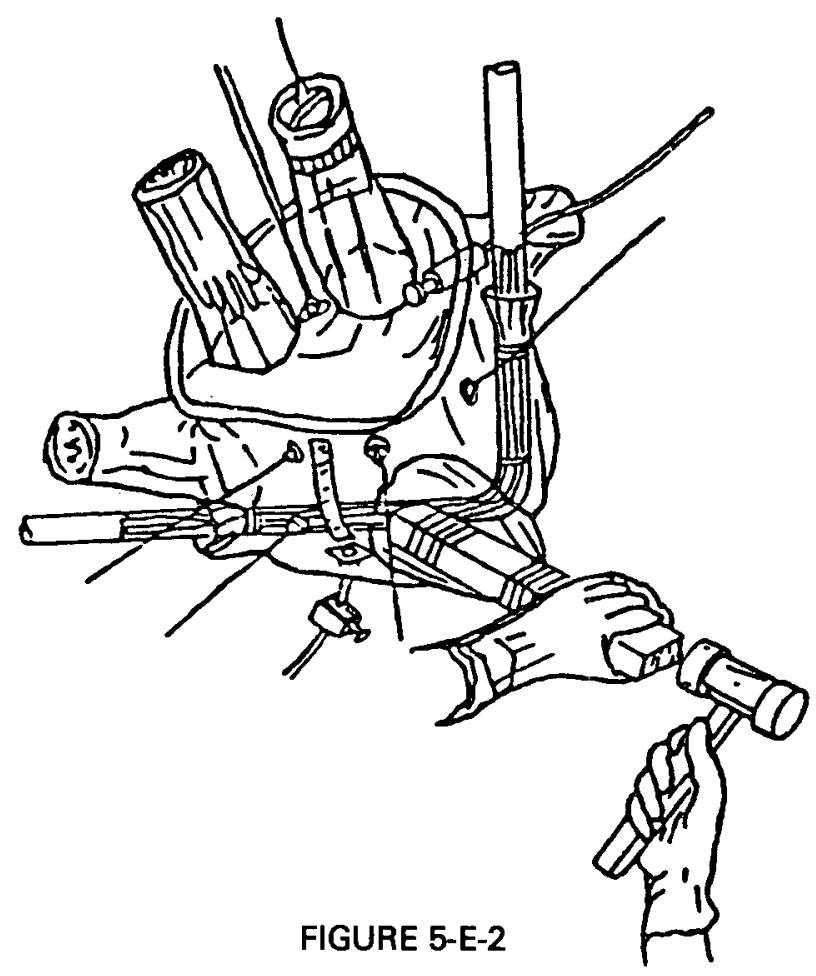

c. Or use a chipping gun. Sleeve only the chipper with the containment sleeve (see Figure 5-E-3).

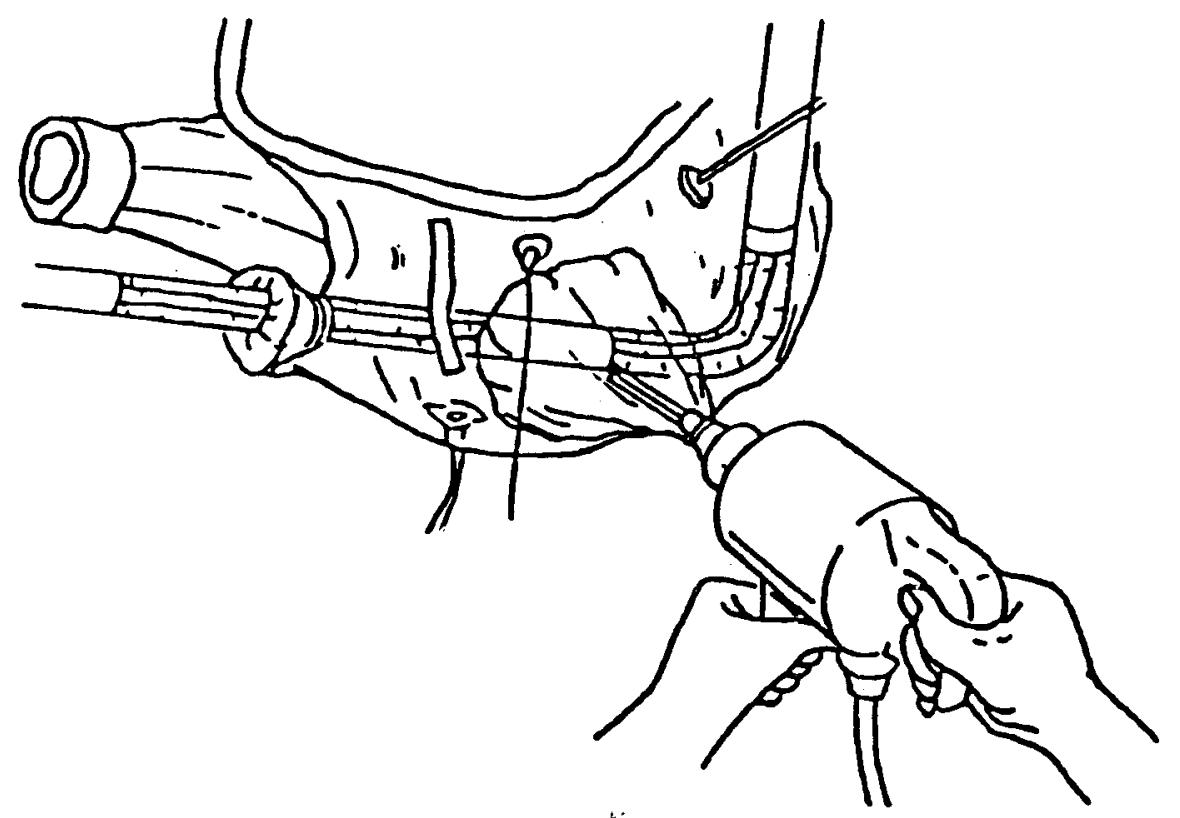

FIGURE 5-E-3 


\section{F. FITUP AND WELDING OF PIPES}

1. Precautions

a. Health Physics monitoring should be provided.

b. Potentially contaminated systems should be considered contaminated unless released from radiological controls by Health Physics personnel.

c. Welders should wear approved respiratory protection during weld repair of root passes and tack and root passes on contaminated piping, whether the pipes can be externally decontaminated or not. If the external surfaces cannot be decontaminated to less than release limits, work gloves or canvas gloves should be worn. Full protective clothing would be required at the option of the Health Physics supervisor. Full protective clothing should be required for externally contaminated weld surfaces. Protective clothing requirements may be eliminated for subsequent passes if Health Physics personnel determine that the welding surfaces and surrounding areas are free of contamination.

\section{CAUTION!}

Do not weld in a glove bag.

d. If a mishap occurs during any pass which could release contamination, stop work immediately and notify Health Physics personnel who will advise responsible manager. Proceed under instruction from the Health Physics personnel and responsible manager.

e. Install a drop cloth (with absorbent) and/or fire resistant drop cloth under the work area.

f. Complete, as far as possible, weld prepping of the component prior to fitup.

g. Place a HEPA-equipped ventilation exhaust line above and within 6-12 inches of the work. Ensure that the line will direct any fumes away from the welder.

h. Assure containments are sufficiently far away from joints to be welded to avoid damage from heat or splatter. Containments which are close should be protected from damage.

i. During the period between removal of the glovebag and completion of the root pass, precautions should be taken to contain any water which could drop from unsealed pipe joints. The acceptable practice for containing this minor leakage is an absorbent drop cloth installed under the joint. If the glovebag is removed to permit fit-up over a drop cloth, the joint will be sealed after fit-up with a suitable type mechanical joint containment (e.g., PVC bag with absorbent material in it taped/sealed to cover the joint). (Inflation test is 
not required.) Containment will be removed just prior to beginning tack or root welding, after ventilation has been established at the joint vicinity. It is mandatory to minimize the time span between containment removal and start of welding.

2. Purging

a. Ensure that the purge path is unobstructed and can handle the intended flow.

b. Provide HEPA filtration at the purge outlet.

3. Fitup within a primary containment

a. Install a drop cloth with absorbent under the work area. Clean the containment of any gross dirt, contamination and unnecessary equipment.

b. Pull the pipe plug from the end in the containment and remove it. Drain any liquids and clean, if necessary (see Figure 5-F-1).

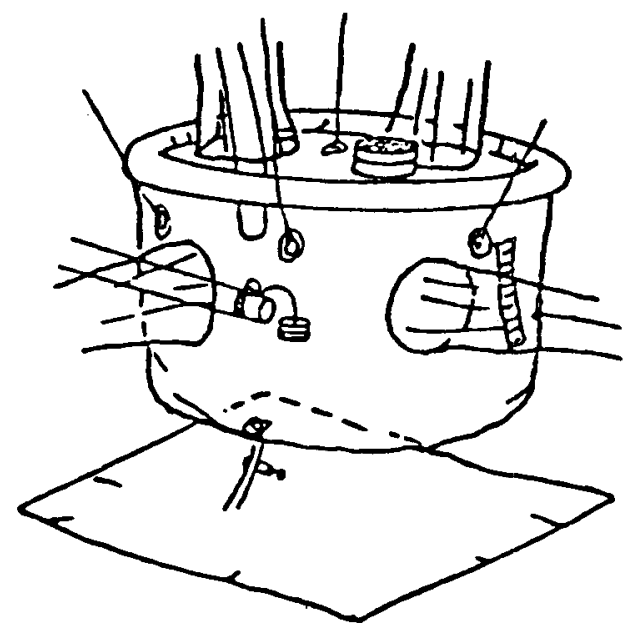

FIGURE 5-F-1

c. Bring the sleeved pipe into position outside the glovebag, carefully untape the end and fit the insert ring to it. If smearable contamination is expected in the pipe is greater than the release limits, this part has to be done inside the containment.

d. Introduce the sleeved pipe into the containment via a containment sleeve (see Figure 5-F-2). 


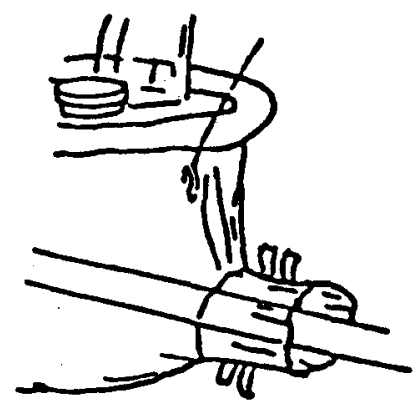

FIGURE 5-F-2

e. If any weld prep is required, it should be done by hand or similar manual means. Use of air-operated tools at this time require either:

- existing containment contamination levels be less than release limits, or

o a new containment if limits are exceeded.

f. Remove the containment, polysleeving, tape and absorbent drop cloth just before tack or root passes and after ventilation is established. Use the drop cloth to wrap the containment. Remove any water at the end.

g. Precautions should be taken to contain any leakage during the period between the removal of the containment and completion of the root pass. A drop cloth with absorbent under the joint will fulfill this need.

h. Proceed to step 5, welding.

4. Fitup outside a primary containment

a. Remove the pipe plugs and check for liquids before attempting to remove the containment. Remove the liquid, determine and correct the cause. Decon the plugs and one inch of the pipe internals to the lowest practical level (less than reasonable limits desired).

b. Re-install the internal plugs. Decon the exterior pipe surfaces, as required. Bag the pipe ends.

c. Remove the containment. Install a new drop cloth, if required, under the pipe ends to catch leakage.

d. Install a HEPA filter ventilation suction near the area. 
e. Health Physics personnel should determine the protective equipment and respiratory protection requirements. Hand protection is required as a minimum.

f. Carefully remove the PVC bag from the pipe ends.

g. Remove the pipe plugs, install the insert ring (if required) and fitup the ends. Use a hanger clamp to hold the fitup, if possible.

h. If welding is not being done immediately, install a suitable secondary containment (e.g., PVC bag with absorbent taped/sealed to cover the joint). If purging is required, also install a suitable HEPA in the containment.

i. Proceed to step 5, welding.

5. Welding of pipe

a. Replace the drop cloth with a fire-protective cloth. Protect adjacent equipment and containments as necessary. If covers are required for adjacent containments, tape "INTERNALLY CONTAMINATED" tape to the outside of the cover.

b. Have Health Physics personnel survey the weld area to assure that it is still less than established levels. Decontaminate to less than release limits or as low as practical.

c. Install a trunk type exhaust and proceed with welding. Welder should wear respiratory protection and exhaust shall be directed away from him (see Figure 5-F-3).

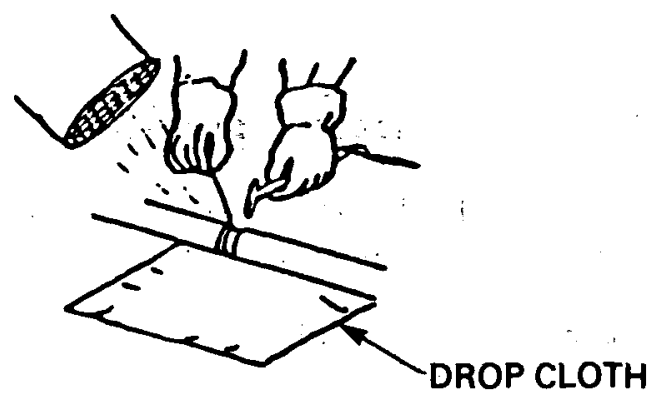

FIGURE 5-F-3

d. Health Physics personnel should take a portable air sample when welding starts and at subsequent intervals as specified by Health Physics Management. The use of personal air samplers should be considered. 
e. After completion of the root pass, Health Physics personnel should perform a swipe survey of the weld area and determine the radiological requirements for subsequent work.

f. Finish the weld, clean it, have the Health Physics personnel survey the weld area before weld inspection or testing.

G. USE OF LUCITE SHIELDS

1. This is optional when grinding or other operations which could damage the inner containments walls.

2. Do not install the shield over access openings, sleeves or drains.

3. Cut a section of $0.03^{\prime \prime}$ Lucite to the desired size and round off the edges to prevent cutting the containment walls.

4. Hold the Lucite in position and tape it on the inside of the containment in such a way that it will stay in position if the containment is flexed.

5. The shield may remain in place or be removed at the option of the user, with Health Physics personnel concurrence.

H. USE OF DROP CLOTHS

1. The drop cloth minimizes the effects of an accidental spill and reduce the possibility of release of contamination during cleanup.

2. Use drop cloths only where required so as to minimize clutter. Drop cloths are not required under secondary containments or beneath containments expected to be dry.

3. Drop cloths should be installed:

- Under untested mechanical joints during hydrostatic testing of potentially contaminated systems,

- When contaminated liquids can be expected from equipment being disconnected from contaminated systems, or

o Under primary containments where there is a potential for a spill.

4. When drop cloths are observed to be wet, notify Health Physics personnel and replace the drop cloth.

5. The drop cloth does not need to be changed if there are tears or dirt on the absorbent.

6. Tears, other than those made to secure the drop cloth, in the reinforced plastic should be repaired or the drop cloth should be replaced. 


\section{TEMPORARY VENTILATION}

1. Precautions

a. Health Physics personnel should be present when pre-specified limits may be exceeded at the work area.

b. The ducting length between the ventilation area, filter boxes and blowers should be kept as short as possible to minimize the flow loss and the amount of material subject to contamination.

c. Mount the blowers properly to prevent unnecessary vibration when running. Support the flexible ducting with $1 / 8$ th-inch diameter nylon line, as required, to prevent damage by personnel and/or equipment.

d. When airborne levels are expected to be greater than the MPC, sleeve the flexible ducting up stream of the filters with purple PVC. Ensure that there is enough slack so that the ends can be covered later.

e. All blowers used for radiologically controlled areas should have the blower capacity marked conspicuously on the blower casing in letters at least $3 / 8$ th-inch high.

f. Y-fittings are not to be installed between the containment and the filter boxes.

g. Flexible metal ducting is to be used; optional spiratube TD-S flexible duct may be installed downstream of the filter.

h. All portable ventilation systems should be inspected for proper radiological controls. When air from a radiologically controlled area is exhausted via HEPA filters directly to the environment, ventilation exhaust monitoring (VEM) is required. The VEM should be connected to the ventilation so that it will automatically start and monitor the air when the system is started. A VEM is not required when exhausting to a ventilated and monitored area. When a VEM is required, the inspection should be documented and approved prior to flow balancing (see Figure 5-I-1). Health Physics personnel should be notified when started or shut-down.

i. Alterations to an approved ventilation system may be made after the system has been tagged out of service in accordance with a lock-and-tag system. Reinspection of the altered system should be performed by Radiological Engineering personnel and documented (see Figure 5-I-1). Damper adjustments are not considered alterations.

j. Installation and removal of contaminated components should be done with health physics coverage.

k. Always have filters in line between the containment and the blowers. 
To:

DATE:

FROM:

SUBJECT: Authorization to Discharge Monitored Air to the Environment from Radiologicaliy Controlled Ara Through Temporary Portable Ventilation Systems

FACILITY OR AREA:

REASON FOR INSTALLATION:

DISCHARGE FROM: T0:

INSPECTION:

1. System Installation (Use Reverse Side of this Form or Sketch)

2. VEM Installation

3. Flammable Atmosphere Requirements (When Applicable)

4. Marking

5. Miscellaneous.

ACCEPTED

NOT ACCEPTED

cc:

Applicable Health Physics Manager Manager, Environmental, Monitoring Manager, Radiological Engineering Radiological Engineering Files

FIGURE 5-I-1 
2. Installation

a. Perform the following:

- Determine the containment volume to be ventilated and the air flow required.

- Obtain the necessary equipment and ensure that the filters have been currently DOP tested to have dp gauges.

- Obtain the flexible ducting and hose clamps. For tight clamping, slit the ends of the ducting lengthwise: 2 slits, $1^{11}-1.5^{\prime \prime}$ long and equally spaced. Overlap the split ends as necessary. Tape the joint and attach the hose clamp (see Figure 5-I-2).
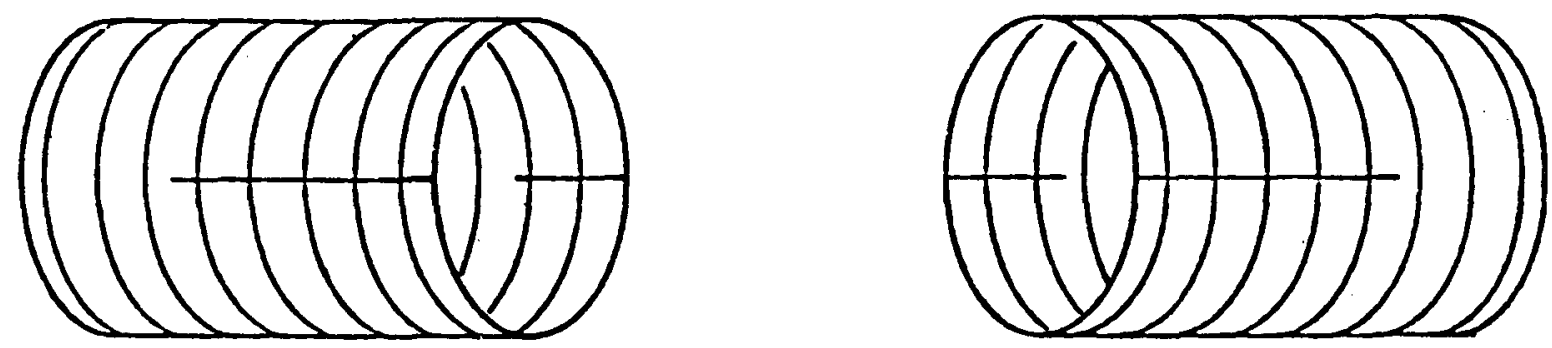

FIGURE 5-1-2

- Install the temporary portable ventilation.

o Tape the ducting with "POTENTIALLY CONTAMINATED" tape.

b. Health Physics personnel should:

- Furnish the ventilation exhaust monitor (VEM) when required.

- Establish radiological controls, as required, to install/remove contaminated ventilation components.

- Inspect all filter systems for proper radiological controls prior to flow balancing.

- Record dp gauge readings in the $\log$ when the system is operating.

c. Radiological Engineering should inspect the systems containing a VEM and complete the Authorization to Discharge form prior to allowing discharges to the environment (see Figure 5-I-1). 
d. Ventilation balance personnel should measure the volume flow, as necessary, using appropriate instruments. Measurements are made at the containment exhaust ducts and adjustments made with the damper. The initial damper settings depend upon how many filters are used.

3. Removal of ventilation

a. Notify Health Physics personnel and request the radiological requirements.

b. Disconnect the components and decon as necessary.

4. Guidelines for Acceptance of Temporary Ventilation System

a. System Instaliation

- System installation arrangement correct in accordance with local procedures.

- Dp gage installed.

o. Blower motor and VEM power supply are interlocked.

- Emergency shut-off switch installed.

b. VEM Location

- VEM sampling point in a straight smooth run of ducting at least 5 duct diameters in length, if possible.

- VEM sampling point located so that all air discharged from radiologically controlled areas is monitored.

- All air sampled is HEPA filtered.

- VEM filter holder located as close as practical to duct.

- VEM unit located in the lowest radiation area practical.

c. Marking

o Downstream of filter seal and on VEM - "Monitored System" tape.

o Upstream of filter seal - "Potential" tape.

- Upstream of filter - purple - PVC sleeving (when greater than MPC expected).

- DOP sticker (seal) properly affixed. 
J. DECONTAMINATION DURING WORK

1. After work is completed in a containment or component, it becomes the responsibility of group having custody of the containment to effectively clean the work area.

\section{Precautions}

a. Have all equipment and materials required before starting decontamination.

b. Use only approved cleaning solutions and mark the container used to carry the liquid (water or detergents which are not flammable).

3. Procedure-staging the materials

a. Where a component is to be decontaminated inside a glove bag, the minimum protective clothing should be cotton and double rubber gloves.

b. Estimate the amount of wiping material required. Tear or cut the material into convenient sizes - about $3 \mathrm{~cm} \times 3 \mathrm{~cm}\left(8^{\prime \prime} \times 8^{\prime \prime}\right)$. Ensure that the material has no lint, ragged edges or strings.

c. Place the wiping material in a clear polybag for transport to the work area. Identify the cleaning fluid by marking the container.

d. Add enough cleaning solution to the polybag to wet the rags but not make them soggy. Shake the bag so that all the rags will be wetted. Tape the bag opening shut (see Figure 5-J-1).

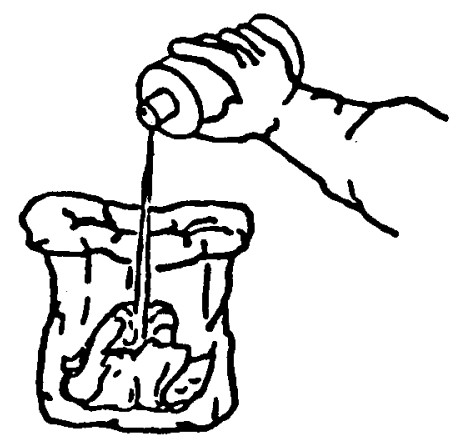

FIGURE 5-J-1

4. Procedure-decontamination

Note: Notify Health Physics personnel prior to beginning any decontamination operations. 
a. Depending upon the contamination levels inside the containment, insert the rags along with another polybag, using either the access zipper or transfer sieeve.

b. Untape the polybag. Wring out each rag inside the bag before removal.

\section{CAUTION!}

Do not use a scrubbing action!

c. Begin decontaminating from less contaminated areas to higher contaminated areas.

d. When decontaminating vertical components, wipe from the top to the bottom. Do not let the cleaning solution run down the component.

f. Move the rag in one direction only (see Figure 5-J-2).

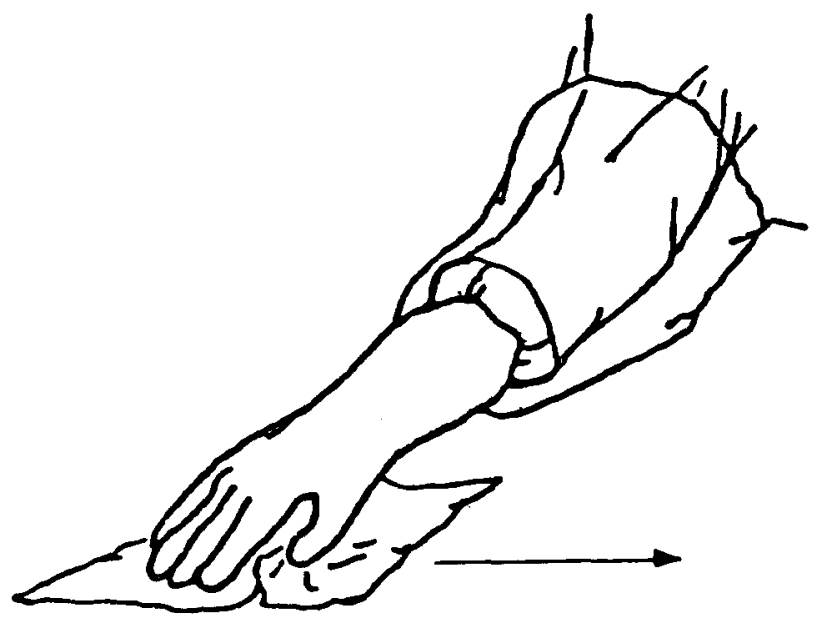

FIGURE 5-J-2

g. Work from the edge of the contaminated area toward the center.

h. If the rag is large enough so that it keeps the glove from being further contaminated, fold it over. Use a clean side to wipe again (see Figure 5-J-3).

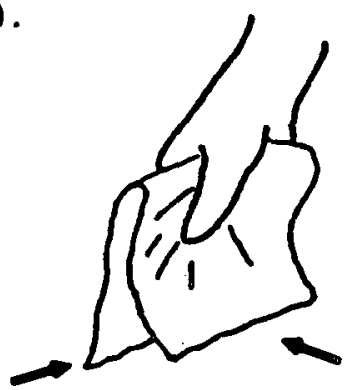

FIGURE 5-J-3 


\section{EMERGENCY PROCEDURES}

A. SPILL PROCEDURE

1. In all emergency situations,

- Remain calm.

- Immediately evaluate the situation and determine the action to follow.

2. In the event of a radioactive spill, initiate the following procedure:

- Stop the work if possible;

- Warn other personnel in the area, call Health Physics personnel;

- Isolate the spill area, stop thru traffic; and

- Minimize your exposure, move to the edge of the area and wait for Health Physics assistance.

3. Emergency liquid disposal from a glove bag

a. This procedure is used only:

o If the glove bag is in danger of bursting from flooding, or

- Normal draining time is inadequate (see Figure 6-A-1).

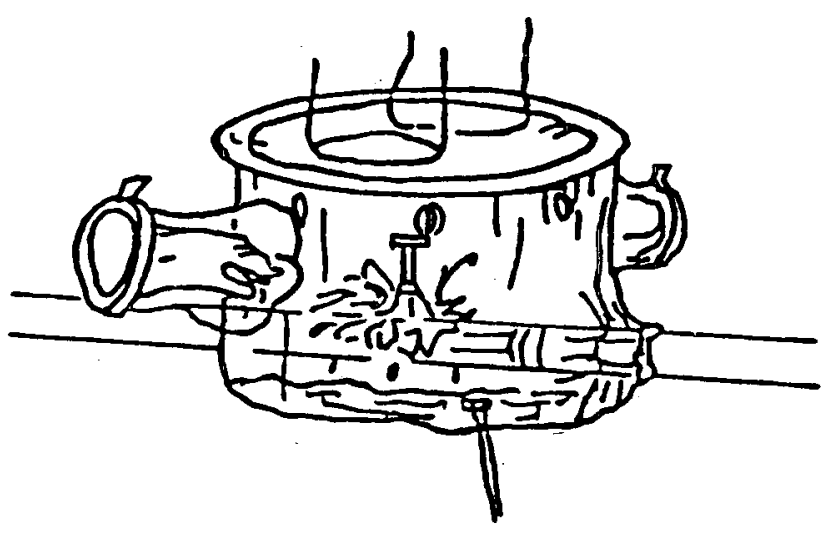

FIGURE 6-A-1

b. Twist a sleeve on the low side of the containment and quickly remove the tape and/or rubber band, glove ring, etc. from the sleeve (see Figure $6-A-2)$. 


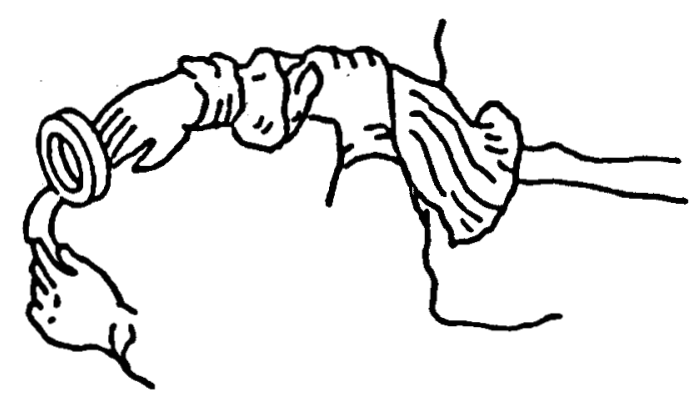

FIGURE 6-A-2

c. Hold an open and partically inverted $8 \mathrm{mil}$ PVC bag or any available container under the sleeve and let the liquid run into it (see Figure $6-A-3)$.

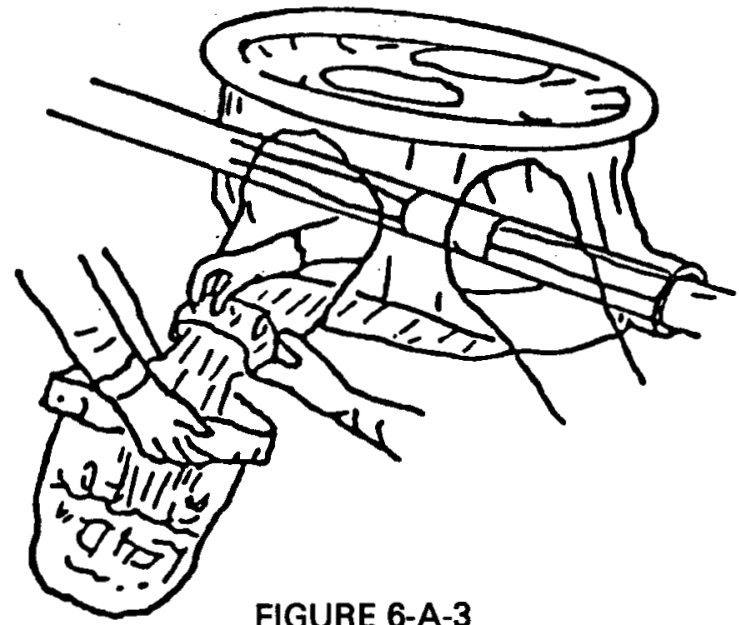

d. If the above steps are not adequate to contain the amount of liquid entering the glove bag or suitable containers are not available, direct the flow into a localized area.

e. If these steps are not sufficient for personal safety, leave the immediate area but remain in the vicinity and contact Health Physics personnel and your supervisor.

B. DAMAGED GLOVE REMOVAL AND REPLACEMENT

1. Two men may be required.

2. Quickly turn the damaged area down, to prevent any liquids from entering the tear (see Figure 6-B-1). 


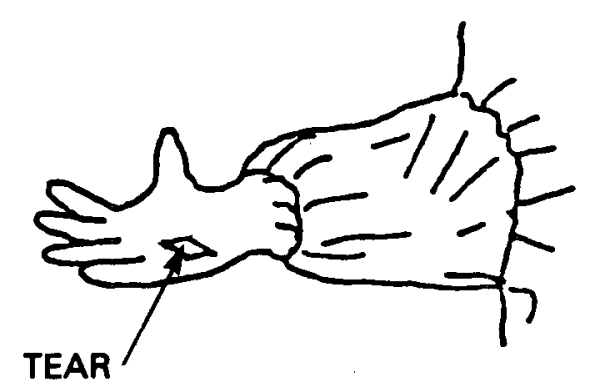

FIGURE 6-B-1

3. Pull the damaged hand upward and out until just the containment glove is in the sleeve and isolate the area to prevent the spread of contamination (see Figure 6-B-2).

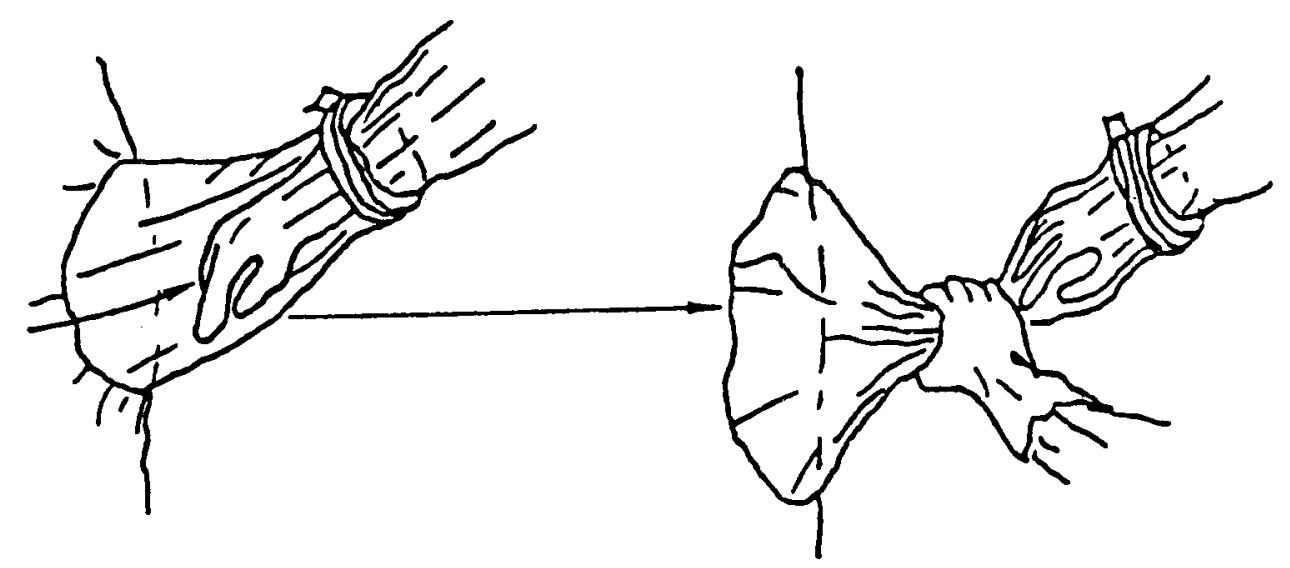

FIGURE 6-B-2

4. Tape the sleeve together. If radiation levels are critical, cut the sleeve at the tape, put the damaged glove hand in a bag and go to the step-off area (see Figure 6-B-3). 


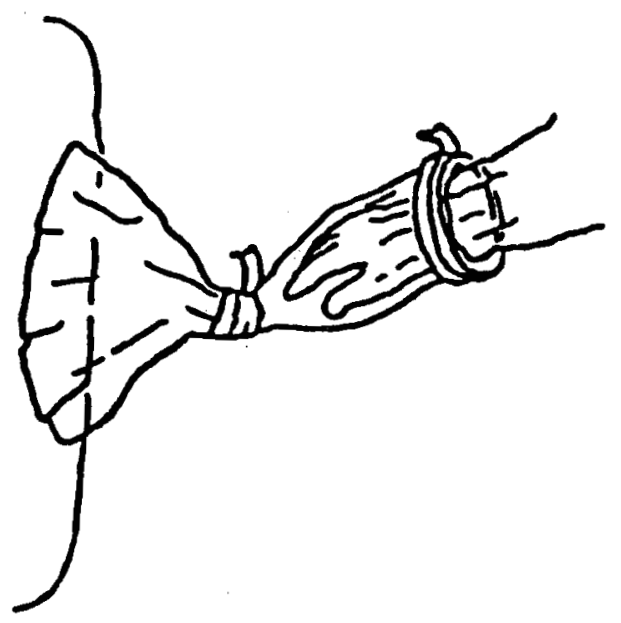

FIGURE 6-B-3

5. If exit is not required quickly, remove the rubber ring from the sleeve/glove ring (see Figure 6-B-4).

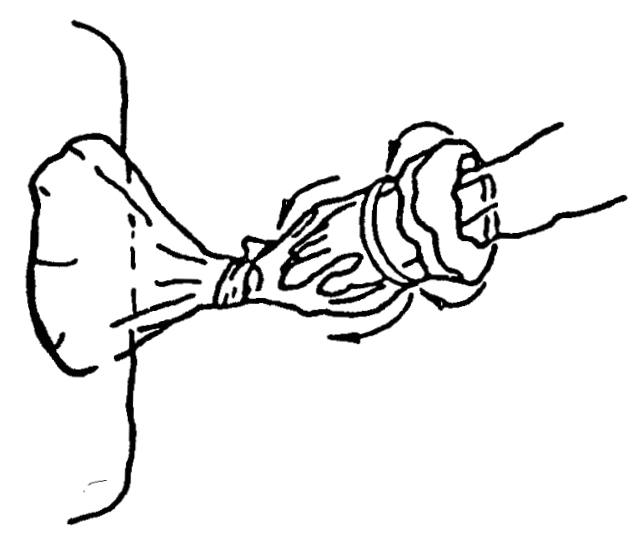

FIGURE 6-B-4

6. The first person partically inverts a polybag, holds it under the sleeve and hand. Withdraw the hand and let the sleeve fall into the bag (see Figure 6-B-5). 


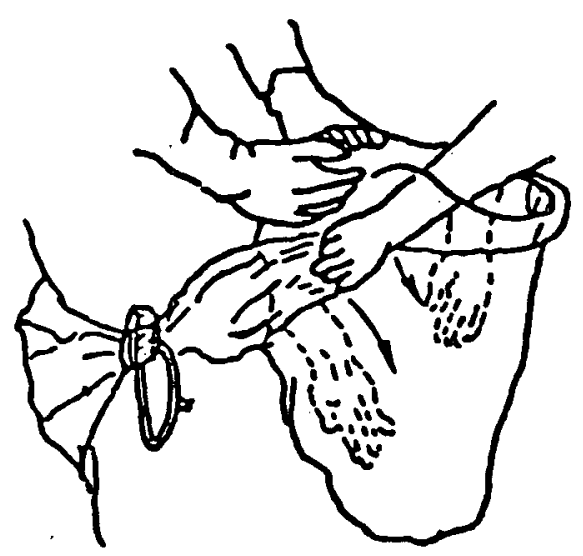

FIGURE 6-B-5

7. Slip the hand into another polybag or clean rubber glove and have it checked by Health Physics personnel (see Figure 6-B-6).

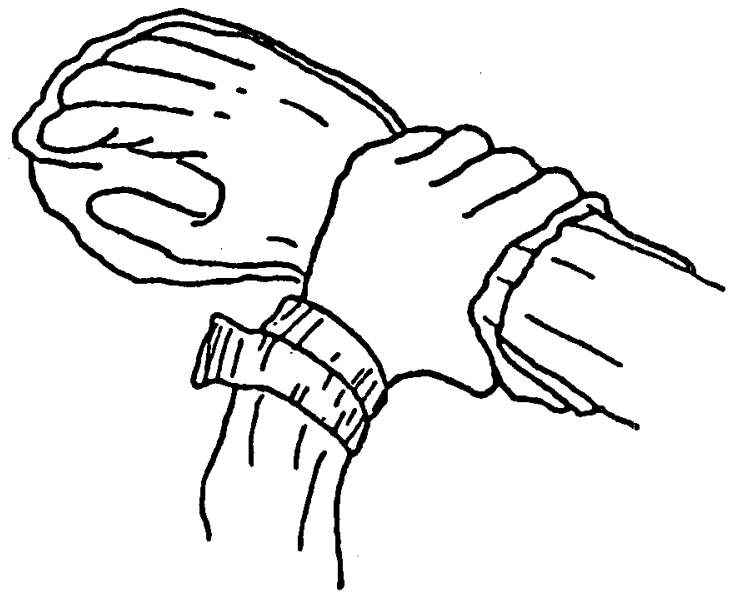

FIGURE 6-B-6

8. Remove the damaged glove from the sleeve with the polybag used to contain the sleeve. Let the glove slip into the bag. The second person keeps the sleeve up high and the end covered (see Figure 6-B-7). 


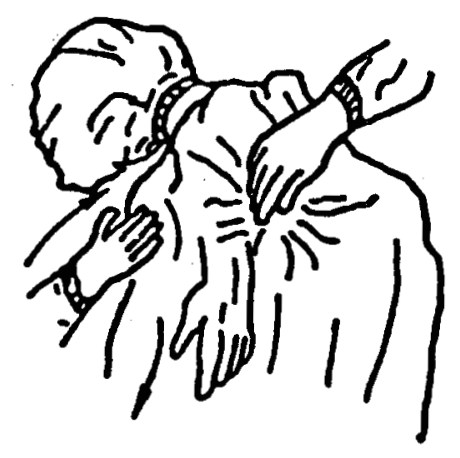

FIGURE 6-B-7

9. Tape the polybag after twisting the top of the bag and folding it over (see Figure 6-B-8).

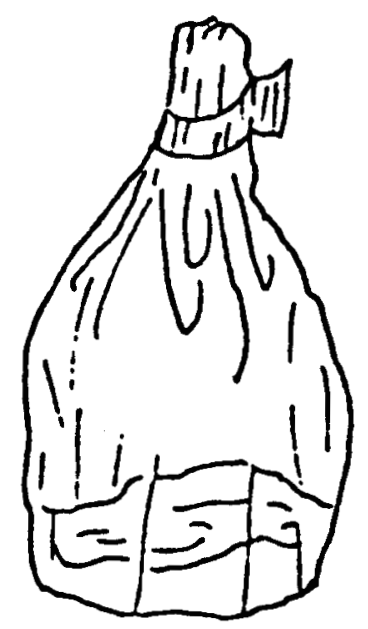

FIGURE 6-B-8

10. One person slips on the replacement glove and inserts it into the containment sleeve. The second person grasps the lip of the glove and folds it over the glove ring (see Figure 6-B-9). 


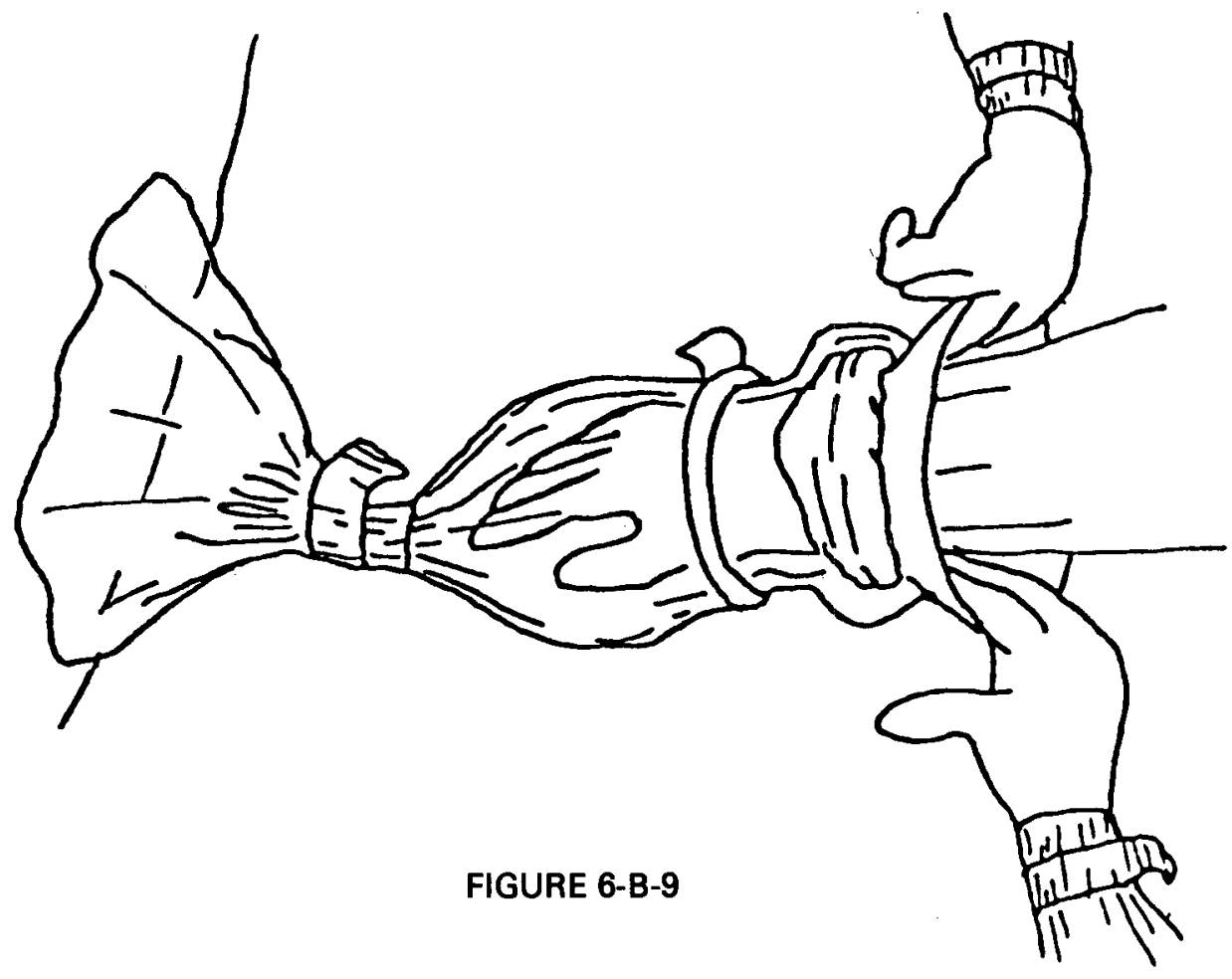

11. Re-install the rubber ring, tape over it and remove the tape from the glove sleeve.

\section{CUT HAND IN A GLOVE BAG}

1. This is a two-man operation: prepare two polybags and gloves.

2. DO NOT PANIC!

3. Lower the hand and turn the palm so that the contaminated and injured area faces down (see Figure 6-C-1). Notify Health Physics personnel.

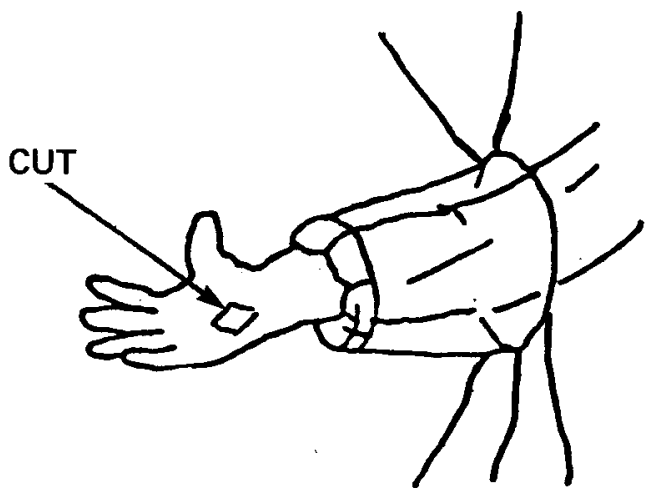

FIGURE 6-C-1 
4. One person inverts a polybag, holds it under the damaged glove and hand while grabbing the sleeve and pinching it tightly. The injured hand is withdrawn into the bag (see Figure $6-c-2$ ).

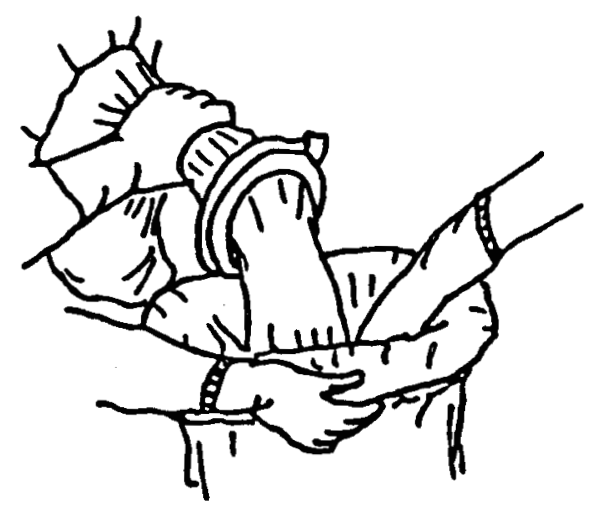

FIGURE 6-C-2

5. Slip the injured hand into another polybag and tape it to the person's arm. Have that person exit the area to be surveyed and receive further instructions from Health Physics personnel (see Figure 6-c-3).

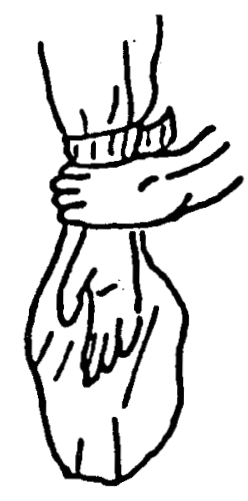

FIGURE 6-C-3

6. Bring the polybag up over the damaged glove and tape it to the sleeve. Have Health Physics personnel swipe the sleeve and cover the replacement of the glove (see Figure 6-C-4). 


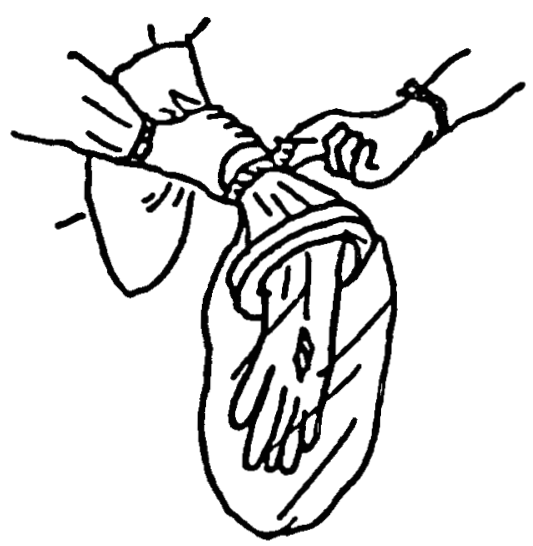

FIGURE 6-C-4

VI-9 


\section{REMOVAL OF CONTAINMENTS}

\section{Precautions}

a. Authorization signatures from User and Health Physics supervisors should be entered in Section $V$ of the Radiological Containment Status Sheet (See Figure 2-A-1).

b. Personnel who remove containments must have their certification current.

c. Health Physics personnel must be notified.

d. Containment Specialists are responsible for removing contaminated items from the glove bag and removing leads.

e. All unnecessary tools and service leads are removed. Use the transfer sleeve.

2. Procedure for removal (primary containments)

a. The Containment Specialist will notify Health Physics personnel when a containment is to be removed.

b. Health Physics personnel should determine the radiological conditions for removal and advise the Containment Specialist, based upon:

- Location and accessibility,

- Potential/actual level of contamination,

- Use of drop cloths and/or absorbent in the work area,

- Use of damp rags to limit the possibility of airborne contamination, and

- Use of CAM (continuous air monitors) or portable air sampler in the immediate area.

c. The information is entered into the Radiological Containment Log (see Figure 2-C-1) and checks the authorization signatures in Section $V$ of the Radiological Containment Status Sheet (see Figure 2-A-1).

d. The Containment Specialist will. drain and decontaminate the containment interior, if necessary.

e. Health Physics personnel will establish the protective clothing requirements.

3. Removal technique (primary containment)

a. Ensure all liquids are removed. Secure and remove the drain hose, starting from the polybottle end.

b. If contamination levels are such that Health Physics personnel considers it necessary, install a HEPA filtered vacuum cleaner. 
- Cut a hole large enough to fit the vacuum hose on the bottom of an $18^{\prime \prime} \times 13^{\prime \prime}$ polybag.

- Insert enough hose so that the hose will touch the HEPA filter on the containment.

- Tape the bag to the hose and install the assembly to the containment HEPA filter.

- Seal with cloth-backed tape. Be sure that the polybag has enough slack so that the vacuum hose can be removed later (see Figure 7-A-1).

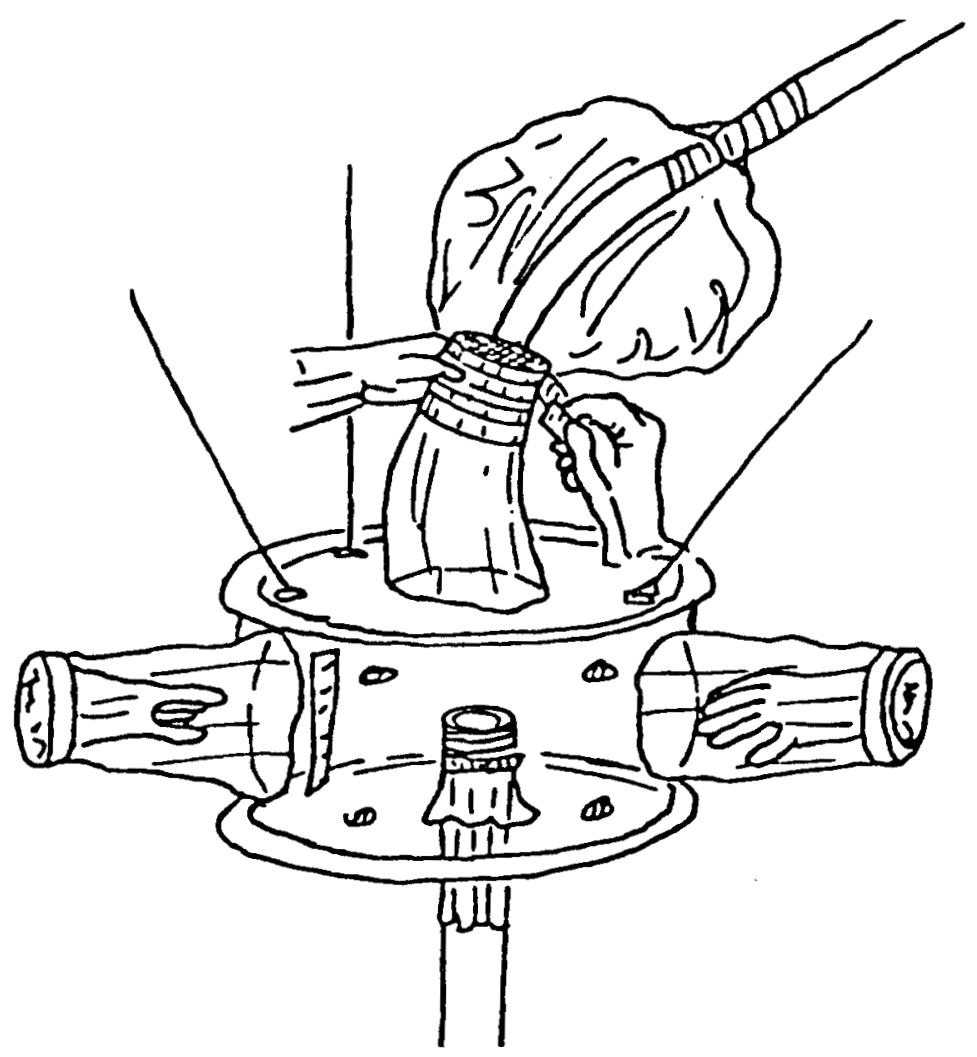

FIGURE 7-A-1

c. Carefully remove the tape covering the hose clamp at the componentcontainment junction. Remove the clamp. Do not remove the tape under the clamp (see Figures $7-A-2$ and $7-A-3$ ). 


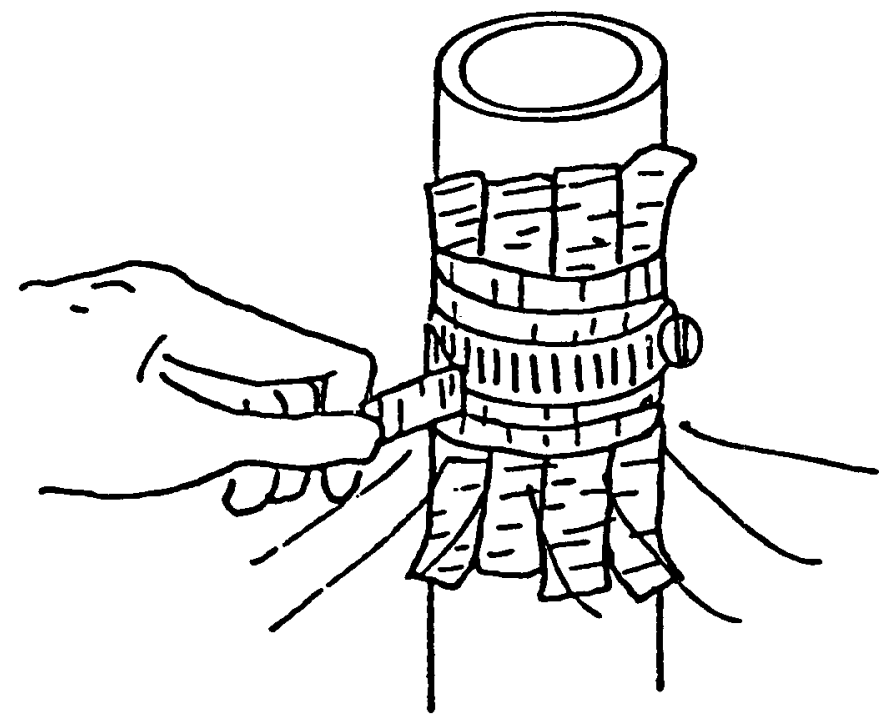

FIGURE 7-A-2

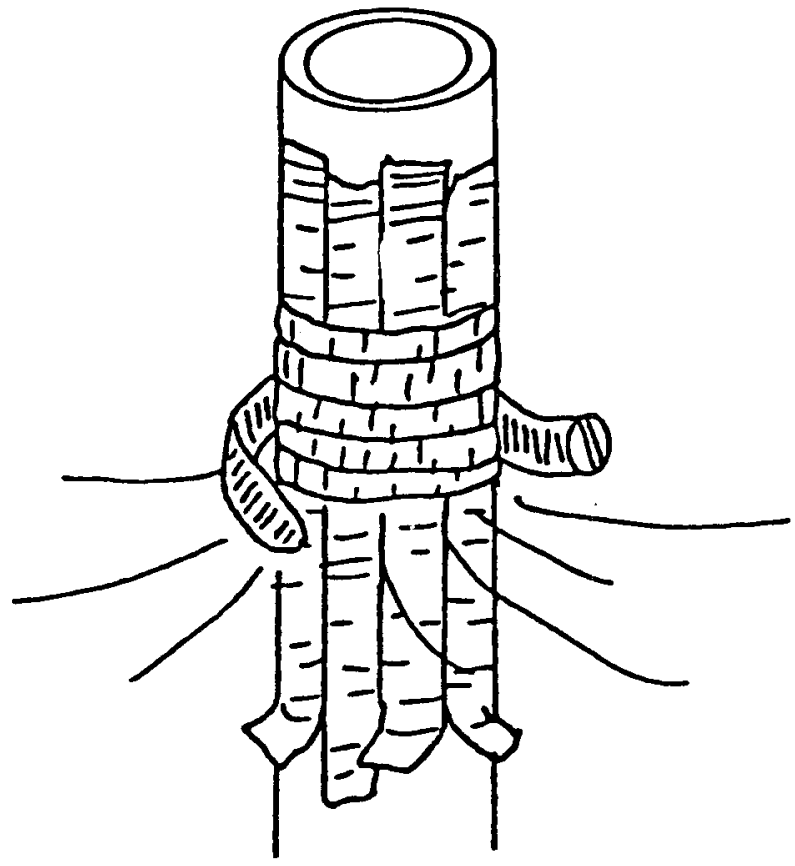

FIGURE 7-A-3 
d. Have a polybag large enough to enclose the containment in the immediate vicinity (see Figure $7-A-4$ ).

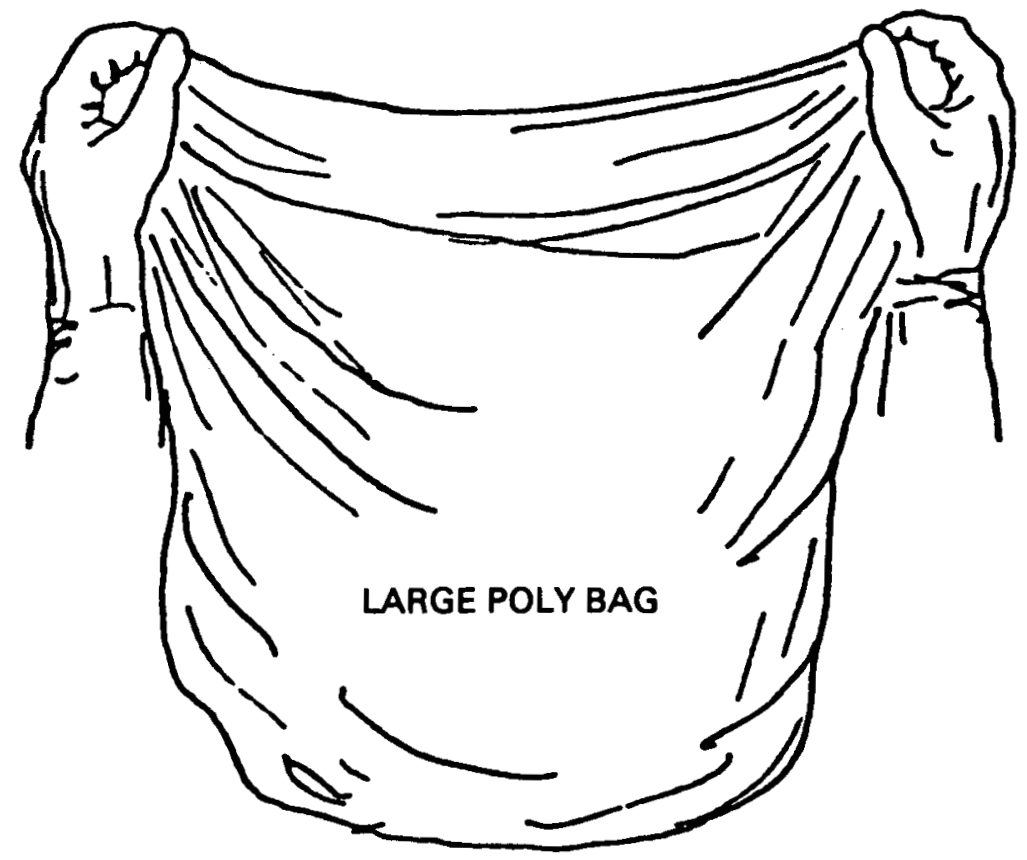

FIGURE 7-A-4

e. Turn on the vacuum cleaner, if used, and allow it to collapse the containment. If no vacuum is used, go to the next step.

f. Sever the containment support cords and let the weight of the containment collapse itself.

g. Using the containment gloves, untape the tape that holds the sleeve to the component. Do not remove the tape covering the component. Remove the containment by pulling it away from the component (see Figure 7-A-5). 


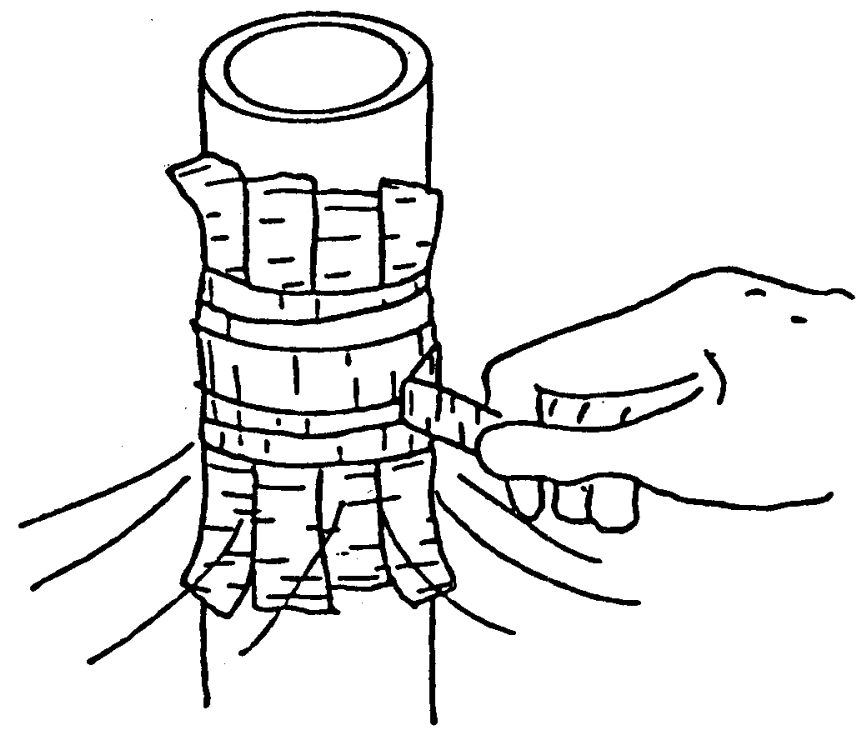

FIGURE 7-A-5

h. Carefully cut it free from the component (see Figure $7-A-6$ ).

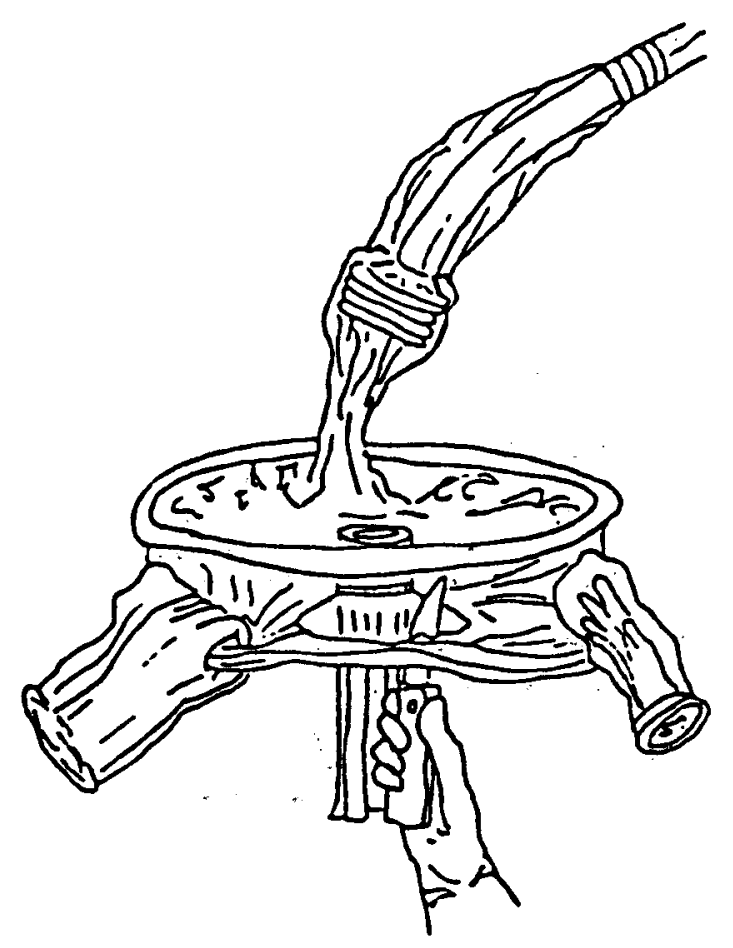

FIGURE 7-A-6 
i. After the containment is removed, place it gently into the large polybag. Seal the bag with cloth-backed tape. If a vacuum cleaner was used, allow it to collapse the polybag. Tape the polybag in the area between the HEPA filter and the vacuum hose (see Figure 7-A-7).

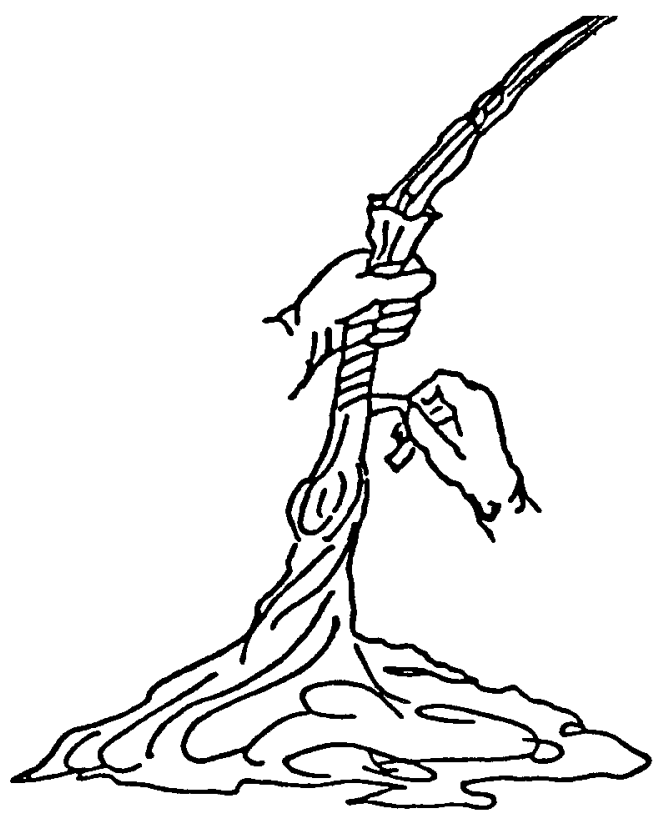

FIGURE 7-A-7

j. Make an umbilical cut below the vacuum hose and tape each end. Bend the top of the polybag over and tape it (see Figures $7-A-8$ and 7-A-9).

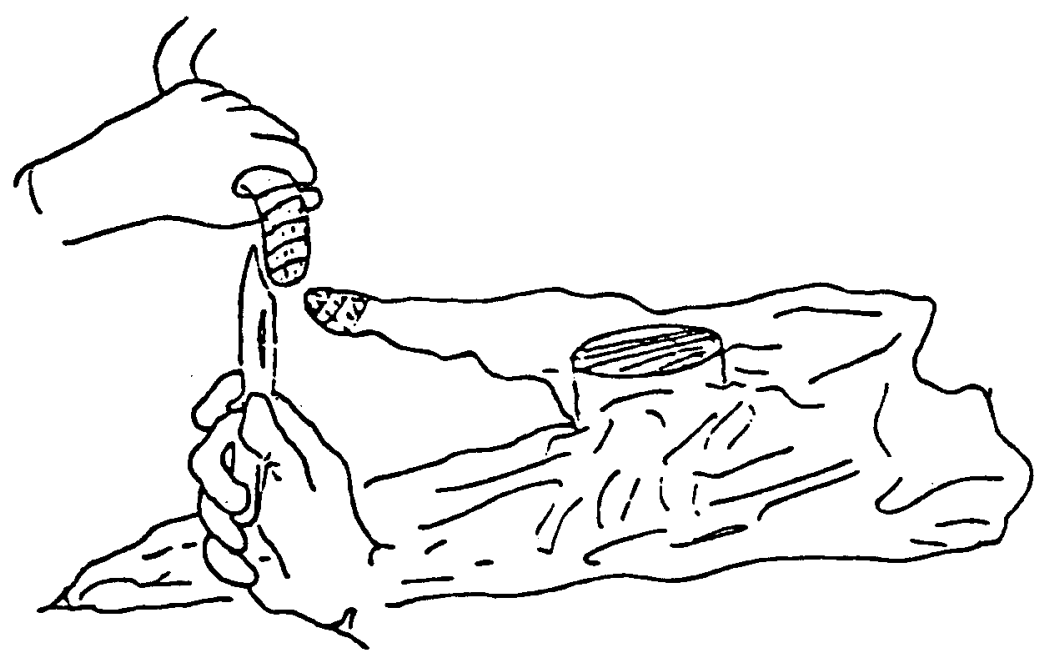

FIGURE 7-A-8 


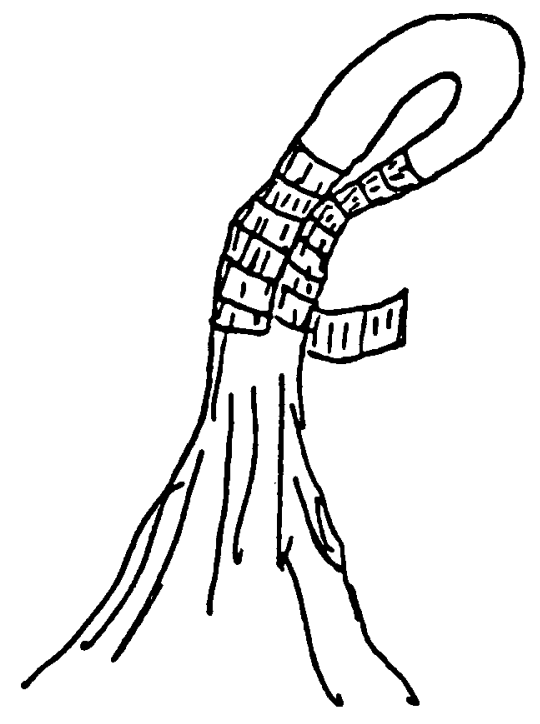

FIGURE 7-A-9

k. Remove the rest of the material used to cover the component. Use care to prevent cross-contamination. Dispose of the materials as radioactive waste. Change gloves as directed by the Health Physics personnel.

1. Cover or contain the component until decontamination and/or swipe survey is made to release the area is complete.

m. Document the glove bag removal in Section VI of the Radiological Containment Status Sheet and the Radiological Containment Log.

n. When the removal is complete, the Health Physics group forwards the Radiological Containment Status Sheet to the responsible management.

3. Removal technique (secondary containments)

a. The Containment Specialist should notify Health Physics personnel prior to the start of removal.

b. After taking a swipe survey to evaluate the radiological conditions, Health Physics personnel will set the protective clothing requirements and make the appropriate signatures with the user manager on Section $V$ of the Radiological Containment Status Sheet.

c. Have a large polybag ready to place the containment in. Remove all support cords. The Containment Specialist should carefully cut the secondary containment away from the component if it has been deconned clean. Otherwise, remove the tape that's holding the containment to the component and then pull it away. 
d. Carefully drop the containment into the polybag. Tape it shut, fold the top over the retape.

e. Health Physics personnel should swipe the component and it will be deconned as necessary. 


$$
\text { TYPE }
$$

1. Machine/work operations in preparation for penetration of system or component. a. - less than release limits on work surfaces.

- No metal removal if fixed contamination or metal activation is suspected.
Catch Containment

Catch Containment
b. - Greater than release limits on work surfaces.
- Metal removal when fixed contamination or metal activa- tion is suspected.

Glove Bag
Containment Tent

............

Catch containment with approval of Radiological Engineering

VENTILATION REQUIRED
2. Machine/work operations to accomplish penetration of system or component. a. - Not expected to exceed release limits internally

- No power grinding

- No process solution water path surfaces to be exposed.

- No process solution expected

- Less than 1 pint residual water expected.

\section{Catch Containment}

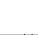




\begin{tabular}{|c|c|c|c|}
\hline WORK OPERATION & RADIOLOGICAL CONSIDERATIONS & $\begin{array}{l}\text { RECOMMENDED CONTAINMENT } \\
\text { (USE MOST APPROPRIATE } \\
\text { TYPE }\end{array}$ & LEVEL \\
\hline $\begin{array}{l}\text { 2. Machine/work operations to } \\
\text { accomplish penetration }\end{array}$ & $\begin{array}{l}\text { b. - Greater than release limits } \\
\text { expected. } \\
\text { - Power Grinding } \\
\text { - Process Solution Path Surfaces } \\
\text { to be exposed } \\
\text { - Process solution expected } \\
\text { - Greater than } 1 \text { pint residual } \\
\text { liquid expected }\end{array}$ & $\begin{array}{l}\text { Glove bag } \\
\quad \text { Containment Tent } \\
\text { Catch containment - with } \\
\text { approval of Radiological } \\
\text { Engineering VENTILATION } \\
\text { REQUIRED }\end{array}$ & Primary \\
\hline $\begin{array}{l}\text { 3. Machine/work operations subse- } \\
\text { quent to penetration of system } \\
\text { or component }\end{array}$ & $\begin{array}{l}\text { a. - Less than release limits } \\
\text { on work surfaces } \\
\text { - No power tool operation } \\
\text { - No liquid expected }\end{array}$ & Catch containment & \\
\hline & $\begin{array}{l}\text { b. - Greater than release limits } \\
\text { on work surfaces } \\
\text { - Power tool operation }\end{array}$ & $\begin{array}{l}\text { Glove bag } \\
\text { Containment Tent } \\
\text { Catch containment - with } \\
\text { approval of Radiological } \\
\text { Engineering VENTILATION } \\
\text { REQUIRED }\end{array}$ & Primary \\
\hline
\end{tabular}


4. Hydrostatic testing of mechanical joints which have been disturbed. Including valve packing both disturbed and undisturbed.

5. Temporary system mechanical joints which have successfully passed hydrostatic testing and operations including valve packing.

6. Temporary system mechanical joints which have successfully passed hydrostatic testing and which do not require manual operations.
Less than release limits on external surfaces and no

Sleeve/bag containment

leakage after reassembly.
LEVEL

Secondary

System internals are exposed to process solution or contaminated liquid

Same as 4 above.

Secondary
System internals are exposed to pro- No containment required None cess solution or contaminated liquid and/or were previously contaminated.

NOTE: When personnel must physically enter a contaminated component, special containment and support systems are required. Containment shall be as specified in operating procedures. 


\section{Appendix B}

\section{GLOSSARY}

CONTAINMENT TENT -

CATCH CONTAINMENT -

DROP CLOTH -

ELECTRONIC SEALING -

GLOVE BAG -

GLOVE BOX -

MECHANICAL JOINT CONTAINMENT -

\section{POLYBOTTLE -}

POLYVINYLCHLORIDE (PVC) -

PRIMARY CONTAINMENT
A large enclosure fabricated from reinforced plastic which allows personnel to physically enter a contaminated environment and perform work.

A partial enclosure used as a backup barrier for the primary containment. Catch containments may be used as primary containments in certain instances.

A flat sheet of reinforced pilastic with absorbent paper applied to one side. Used as a temporary surface protection.

Sealing process used to bond PVC and reinforced plastic.

A flexible containment made of PVC which is used to establish a complete enclosure of minimum size. Personnel accomplish work inside by means of glove sleeves while remaining outside the contaminated environment.

A rigid containment which may be fabricated from stainless steel, polycarbonate, plexiglas, etc. Used in a manner similar to glove bags; however, glove boxes may be decontaminated and reused. Items to be worked on are placed inside and personnel perform work through glove ports.

A secondary containment which is utilized tc wrap mechanical joints to contain any minor leakage.

A polyethylene container (5-15 gallons) used for the collection of small quantities of contaminated liquids. Polybottles are alṣo used as a purge path for contaminated air/gases. Additionally, polybottles used in conjunction with a vacuum cleaner (electric only) may be used for liquid pickup.

Plastic film used in the manufacture of radiological containments. AvaiTable in various colors and thicknesses.

A containment is defined as primary when the containment itself serves as a boundary for contamination control and/or is utilized to contain work operations. A containment is graded as primary when: 
0

RADIOLOGICAL CONTAINMENT -

REINFORCED PLASTIC -
0

0

o

The internal surfaces of the installed containment and/or the external surface of the item being contained is or is expected to become contaminated in excess of release limits;

Contaminated waterpath surfaces will be exposed;

Contaminated solutions will be released within the containment; or

The containment is utilized for the performance of work operations as defined in the Work Chart (see Appendix A).

An enclosure (partial or complete) used as a barrier to control and/or prevent the spread of radioactive contamination.

A strong, durable, laminated vinyl cloth used as wrapping for contaminated material, surface protection in controlled areas and as construction material in the manufacture of tents, glove bags, polybottle containments and catch containments.

SECONDARY CONTAINMENT - A containment is defined as secondary when the system serves as the boundary for contamination control. They are installed to control non-intentional releases from mechanical joints. The internal surfaces of the containment and external surfaces of the component being contained are not contaminated in excess of established limits.

SPECIAL CONTAINMENT - Containment designs which are intended for a specific usage and which are manufactured on an as-required basis (e.g., removal of equipment from waste tanks).

STANDARD CONTAINMENT - Containment designs which are intended for general usage and which are available from stock. 
Appendix C

CONTAINMENT EXAMPLES

Type I Glove Bag, As Built

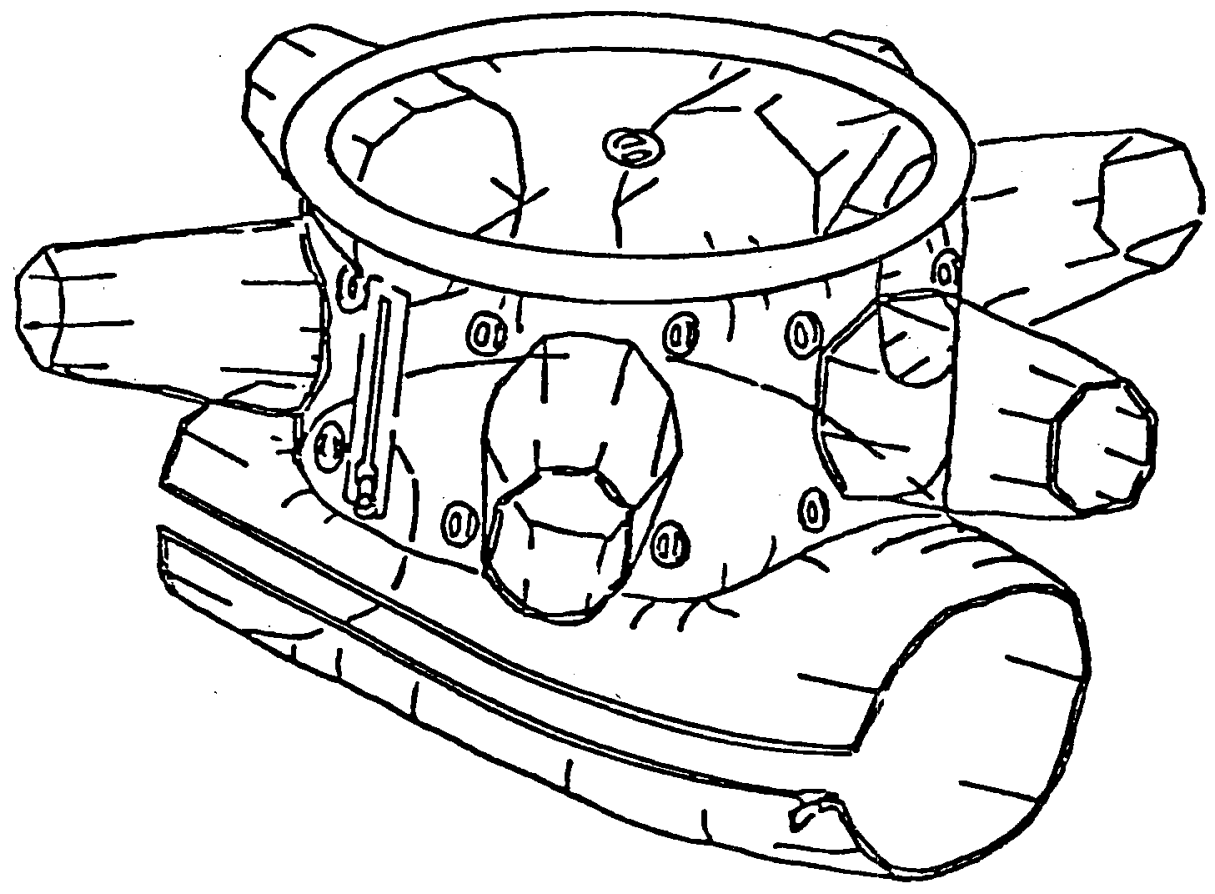

6 Glove Sleeves Around Side

24 Tie-0ffs Around Side

4 Tie-Offs On Top

2 Tie-Offs On Skirt

1 Access Zipper

1 Semi-Rigid Ring

1 Closure Zipper 


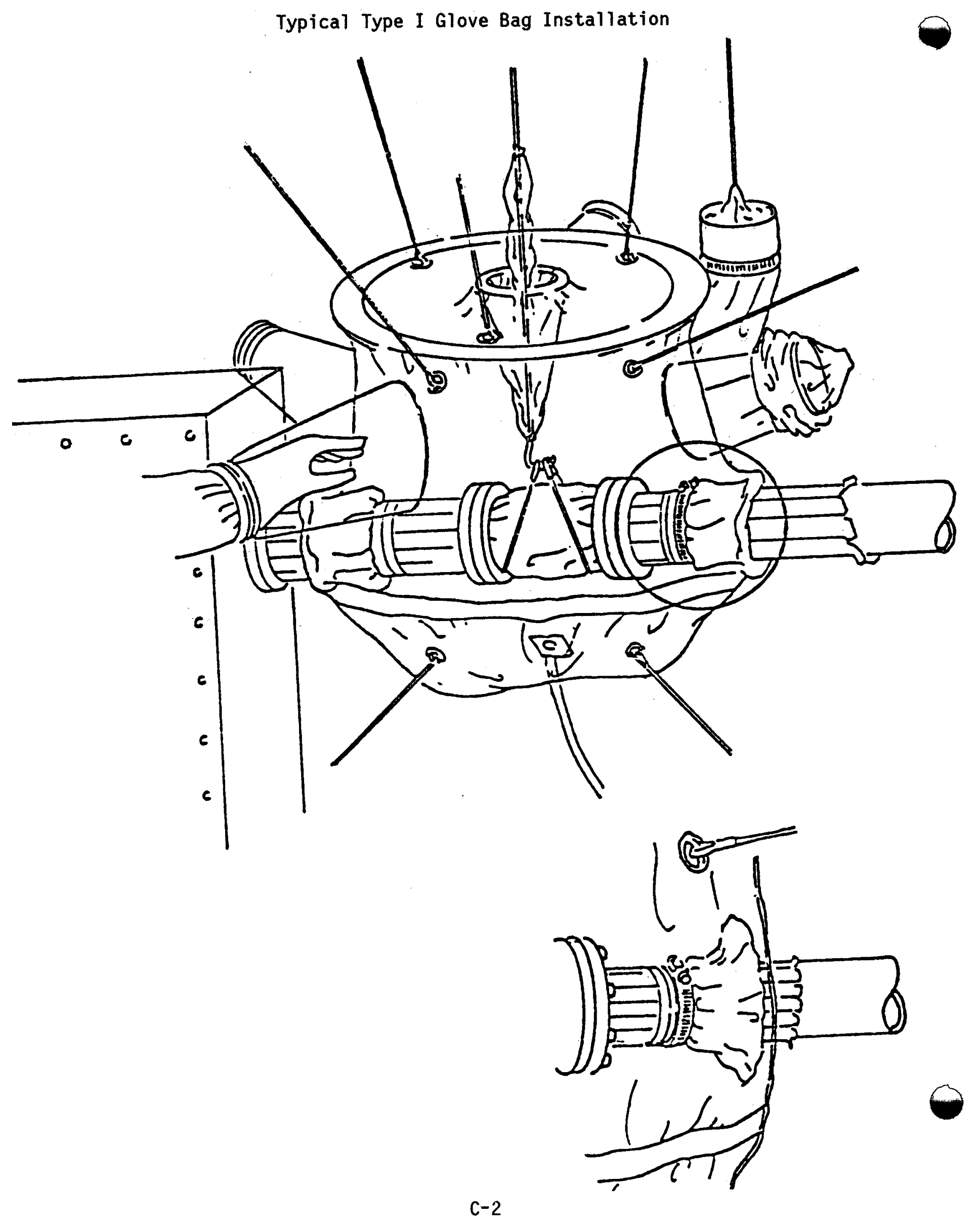




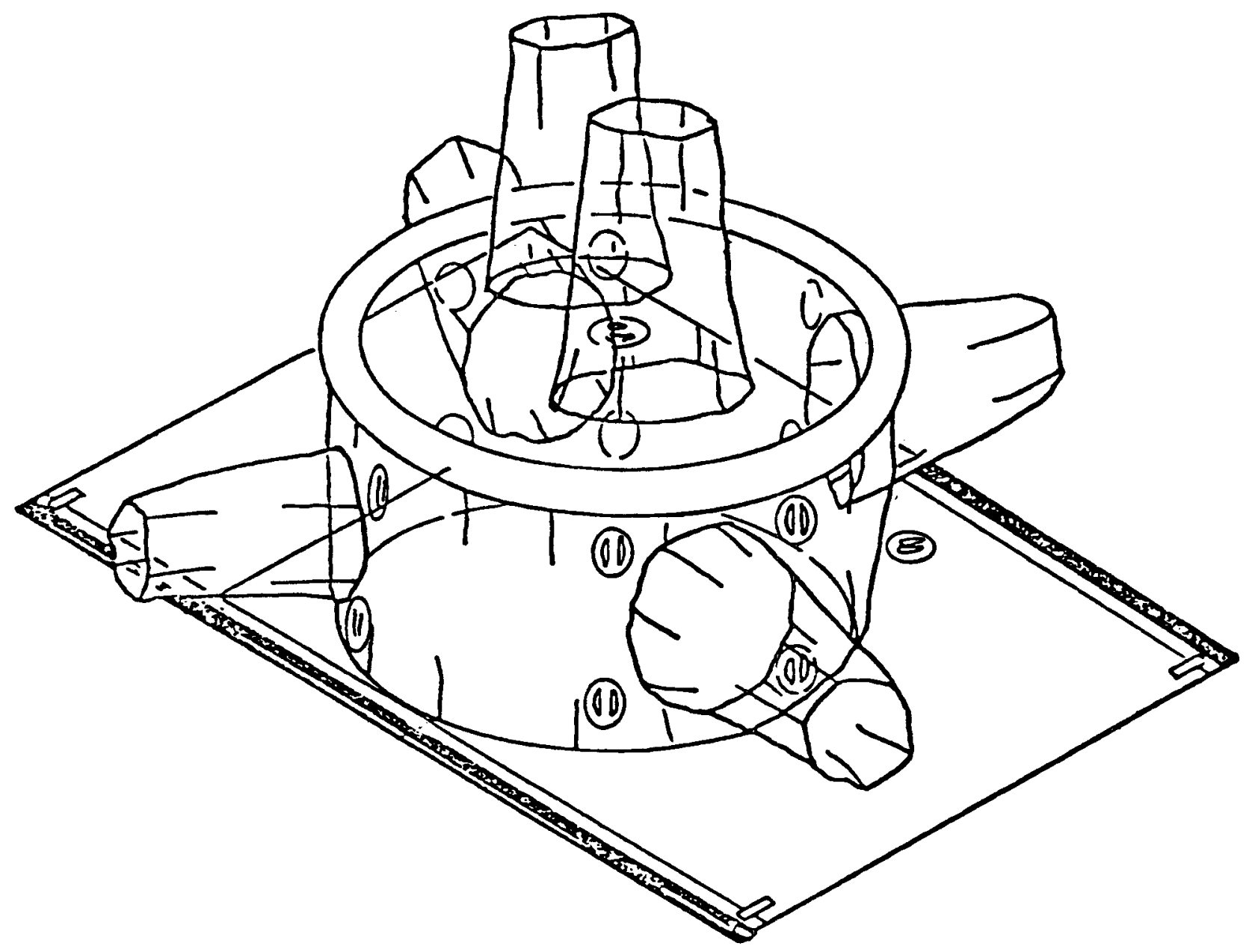

4 Glove Sleeves Around Side

2 Glove Sleeves in Top

1 Access Zipper

1- Semi-Rigid Ring

16 Tie-0ffs Around Side

1 Tie-Off on Flap

1 Closure Zipper 


\section{Typical Type II Glove Bag Installation}

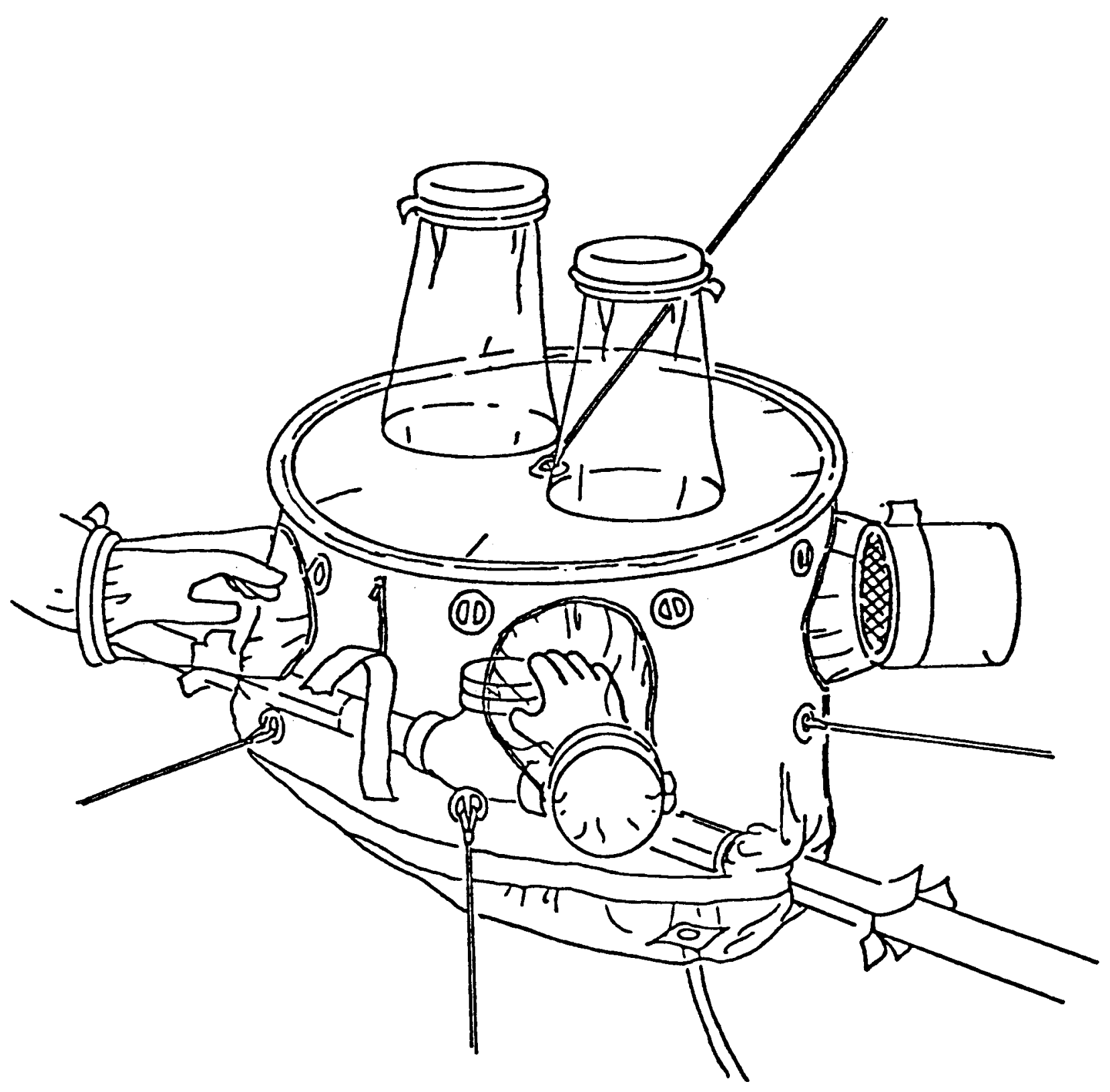




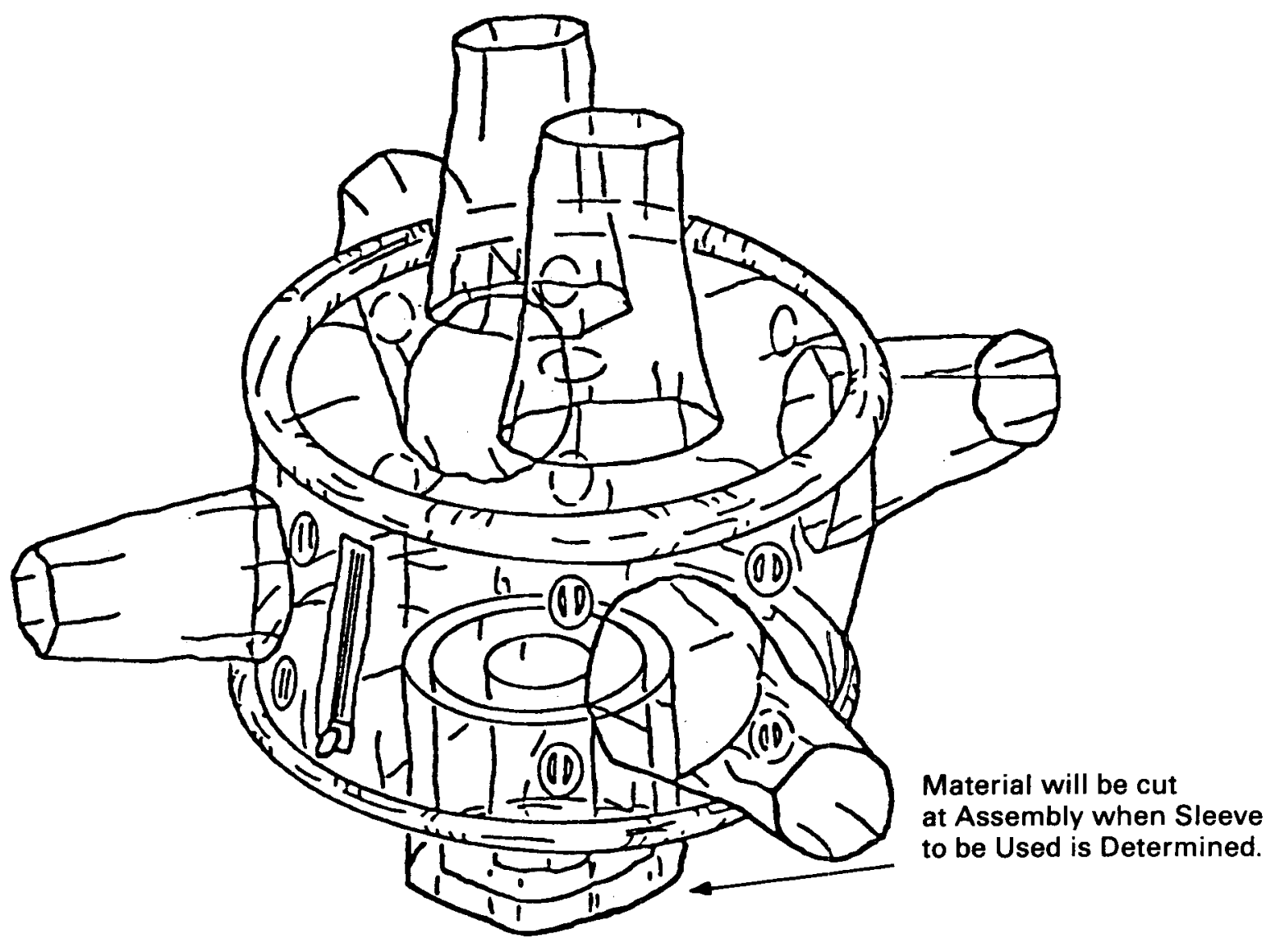

4 Glove Sleeves Around Side

2 Glove Sleeves in Top

1 Access Zipper

16 Tie-0ffs Around Side

2 Semi-Rigid Rings

1 Tie-Off On Top

3 Concentric Sleeves in Bottom

3 Tie-0ffs on Bottom 
Typical Type III Glove Bag Installation

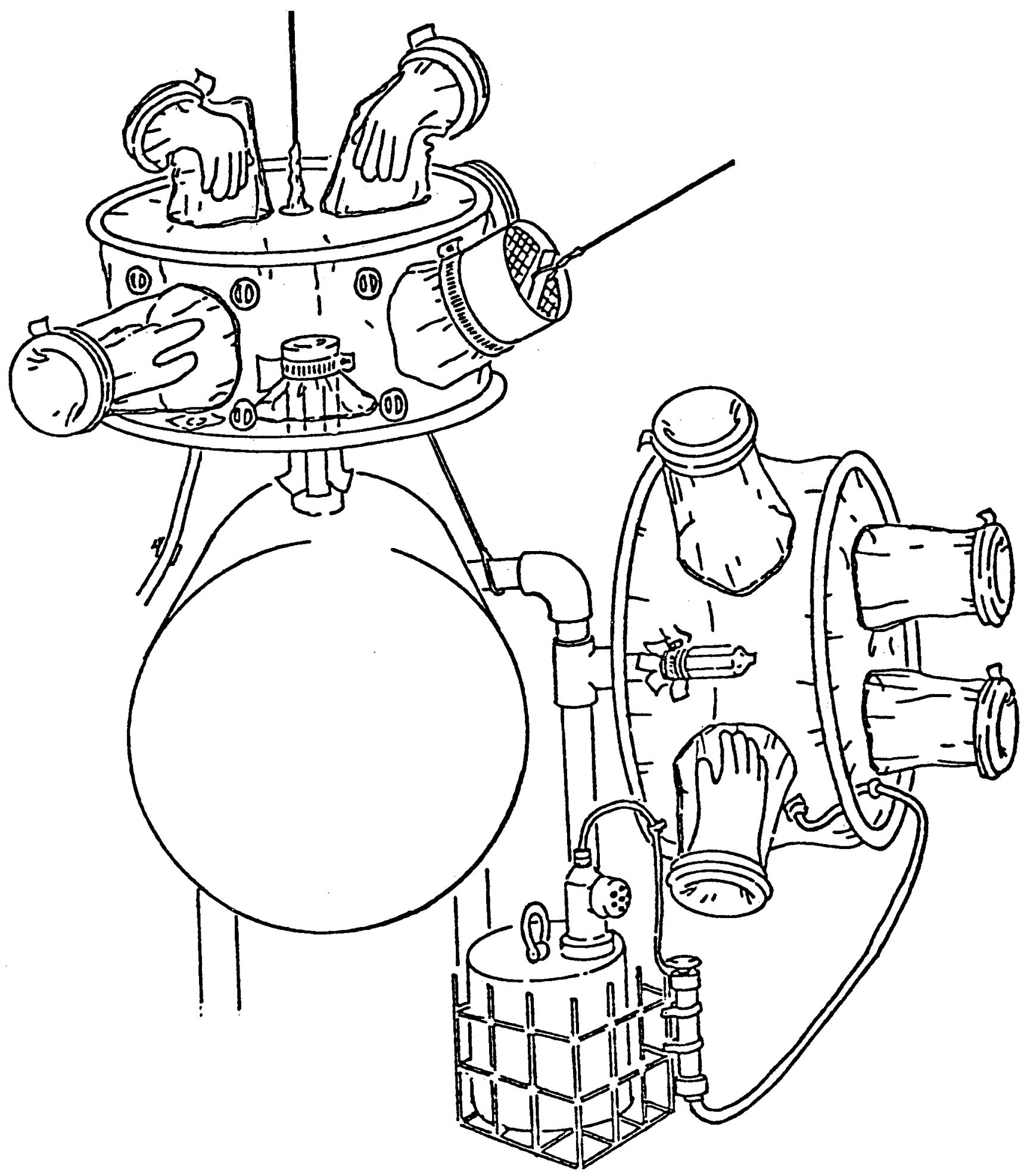


Type IV Containment, As-Built

NOTE: This containment is available with a glove sleeve in addition to the zippered access. This installation includes a Velcro tab to hang the sleeve out of the way when the glove is not in use.

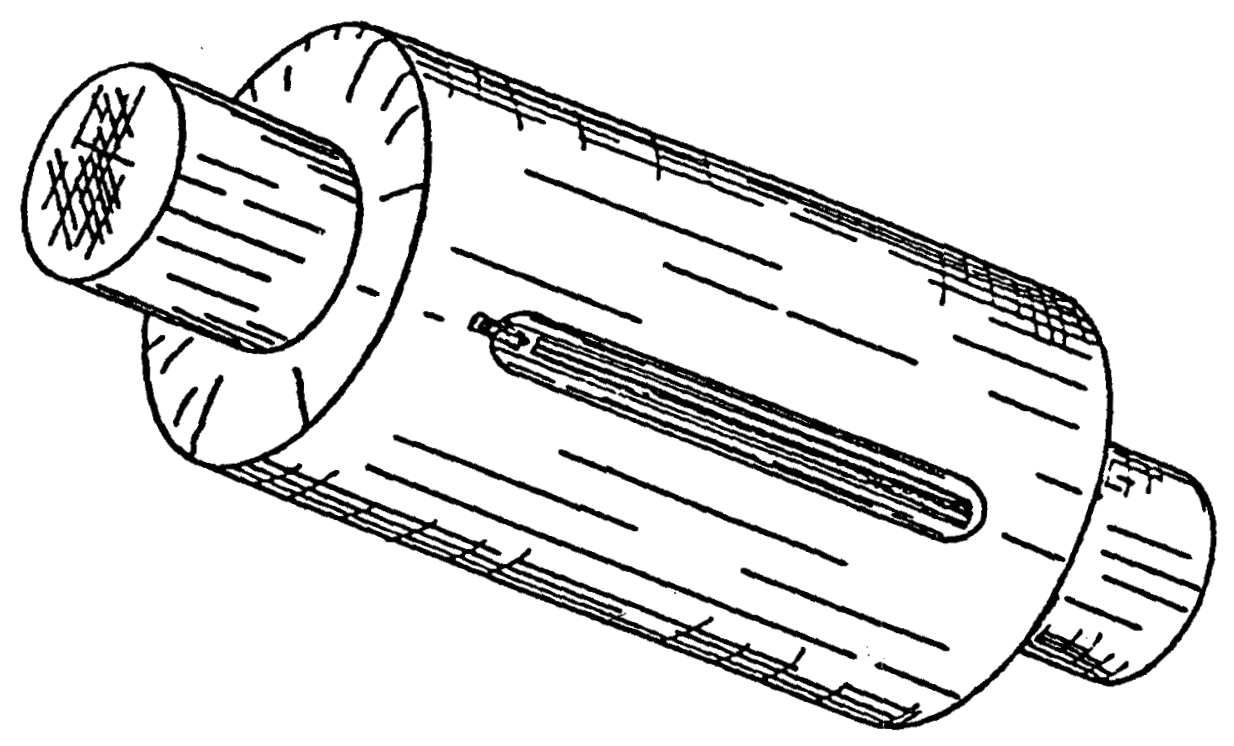

NOTE: Type IV containment also known as "Muff Bag." 


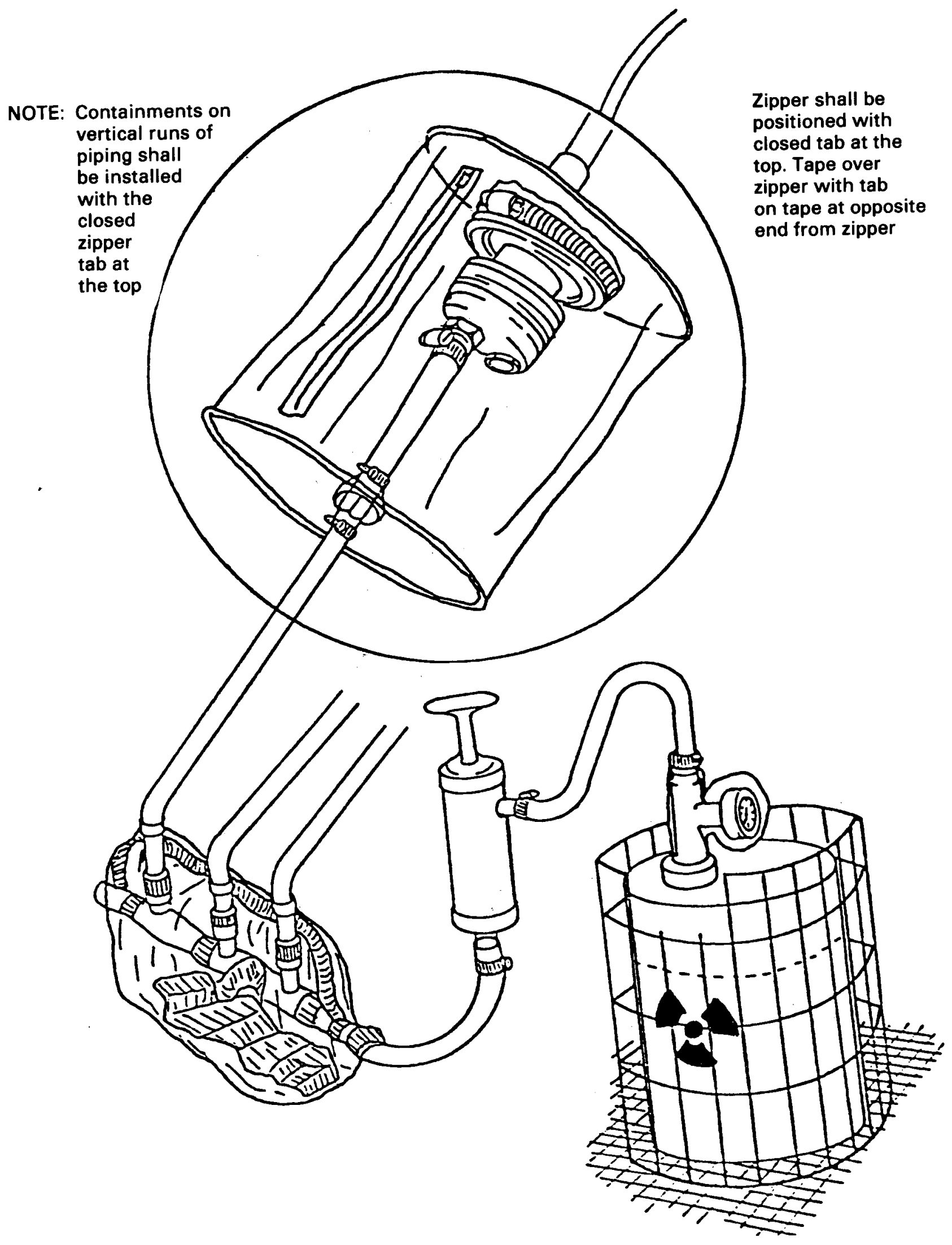




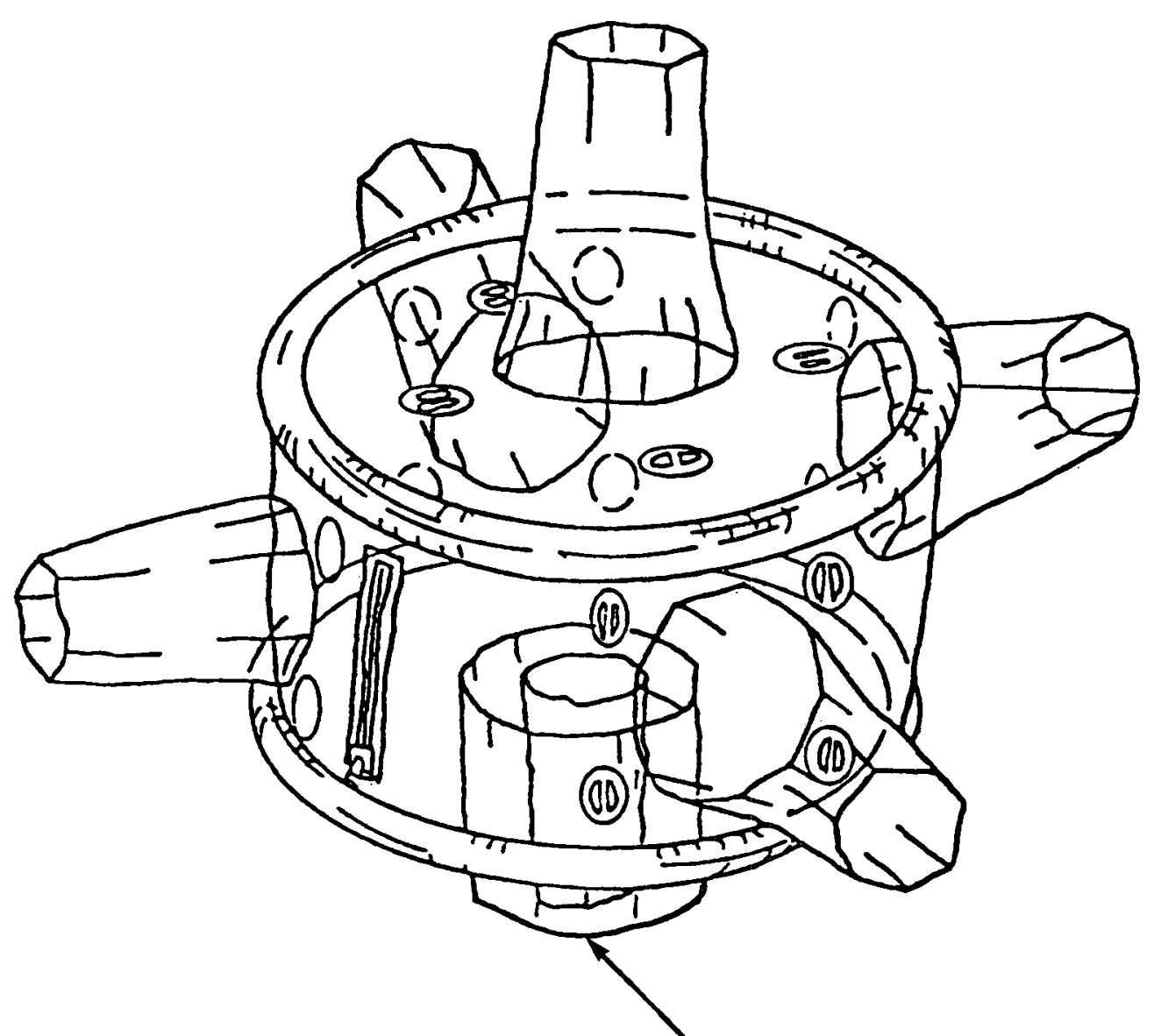

Material will be Cut Out At Assembly

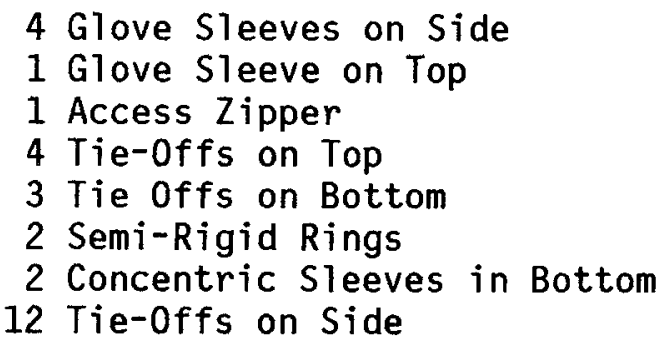


Typical Type $V$ Glove Bag Installed

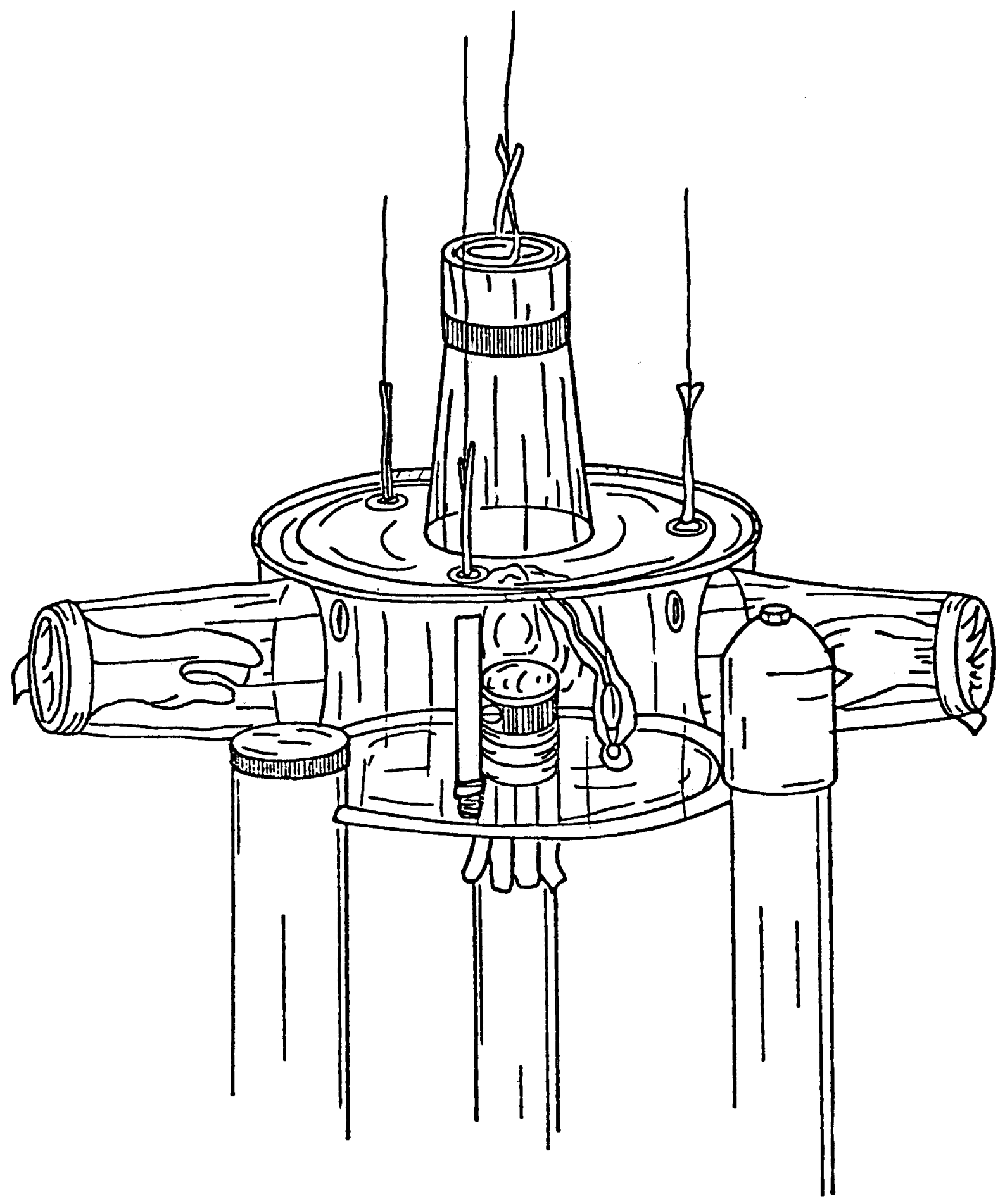


Type VI Glove Bag, As-Built

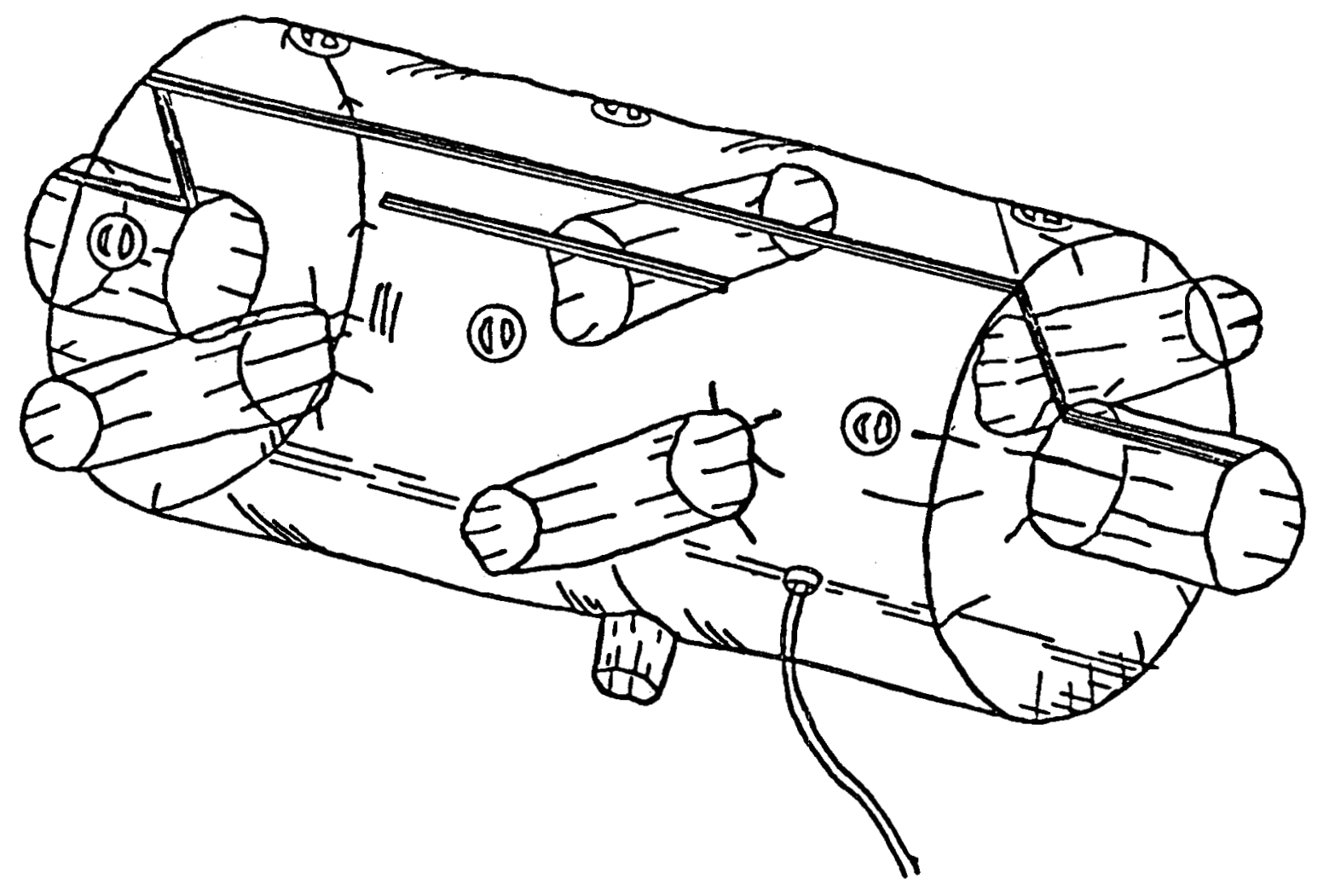

3 Tie-0ffs on Each Side

2 Glove Sleeves on Each Side

1 Access Zipper

1 Closure Zipper

1 Access Port on Bottom 
Type VII Glove Bag, As-Built

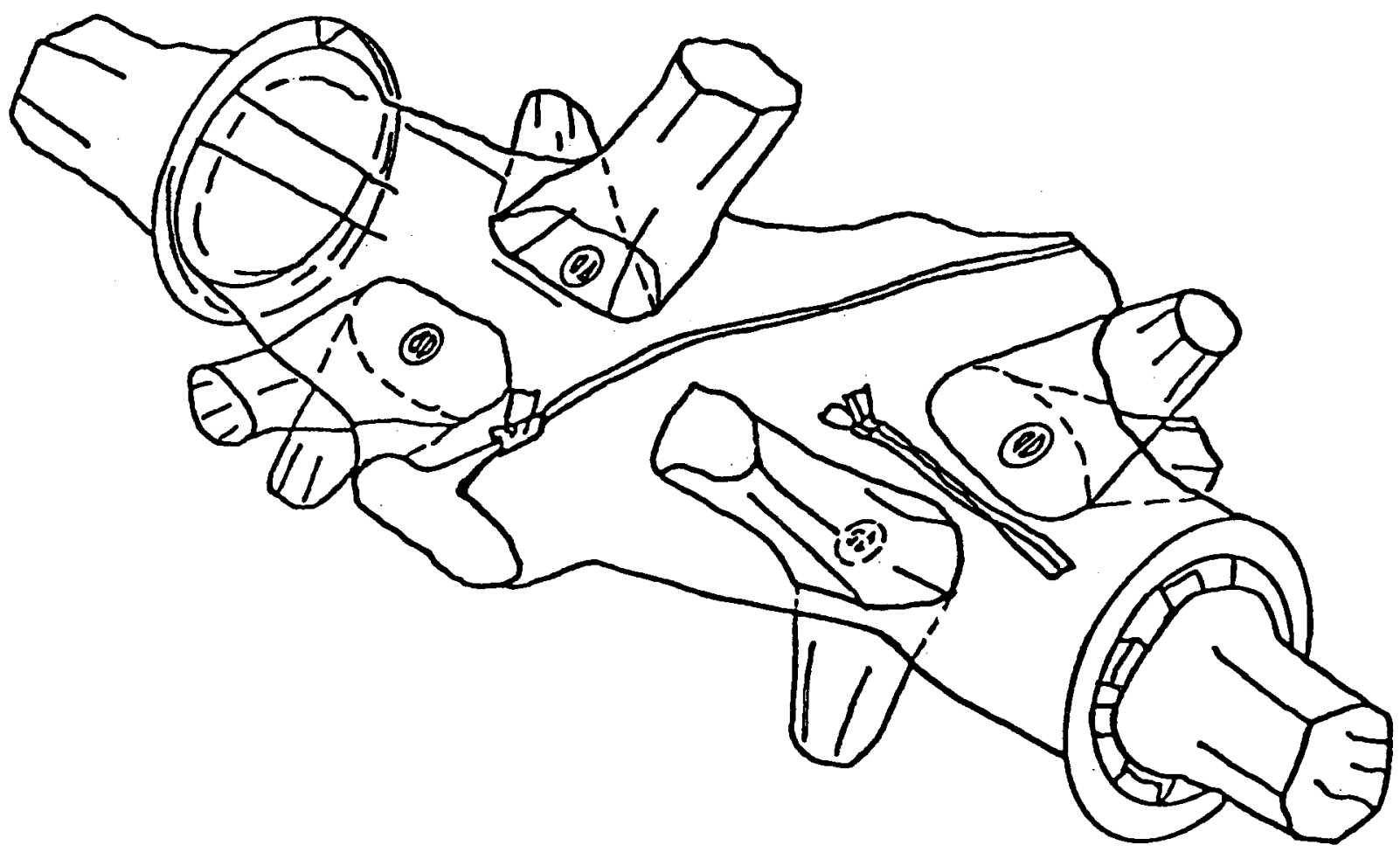

1 Access Zipper

1 Closure Zipper

2 Glove Sleeves (upper surface)

2 Glove Sleeves (lower surface)

I. Glove Sleeve (each end)

1 Semi-Rigid Ring (each end)

4 Tie-Offs (upper and lower surface) 
Typical Type VII Glove Bag Installation

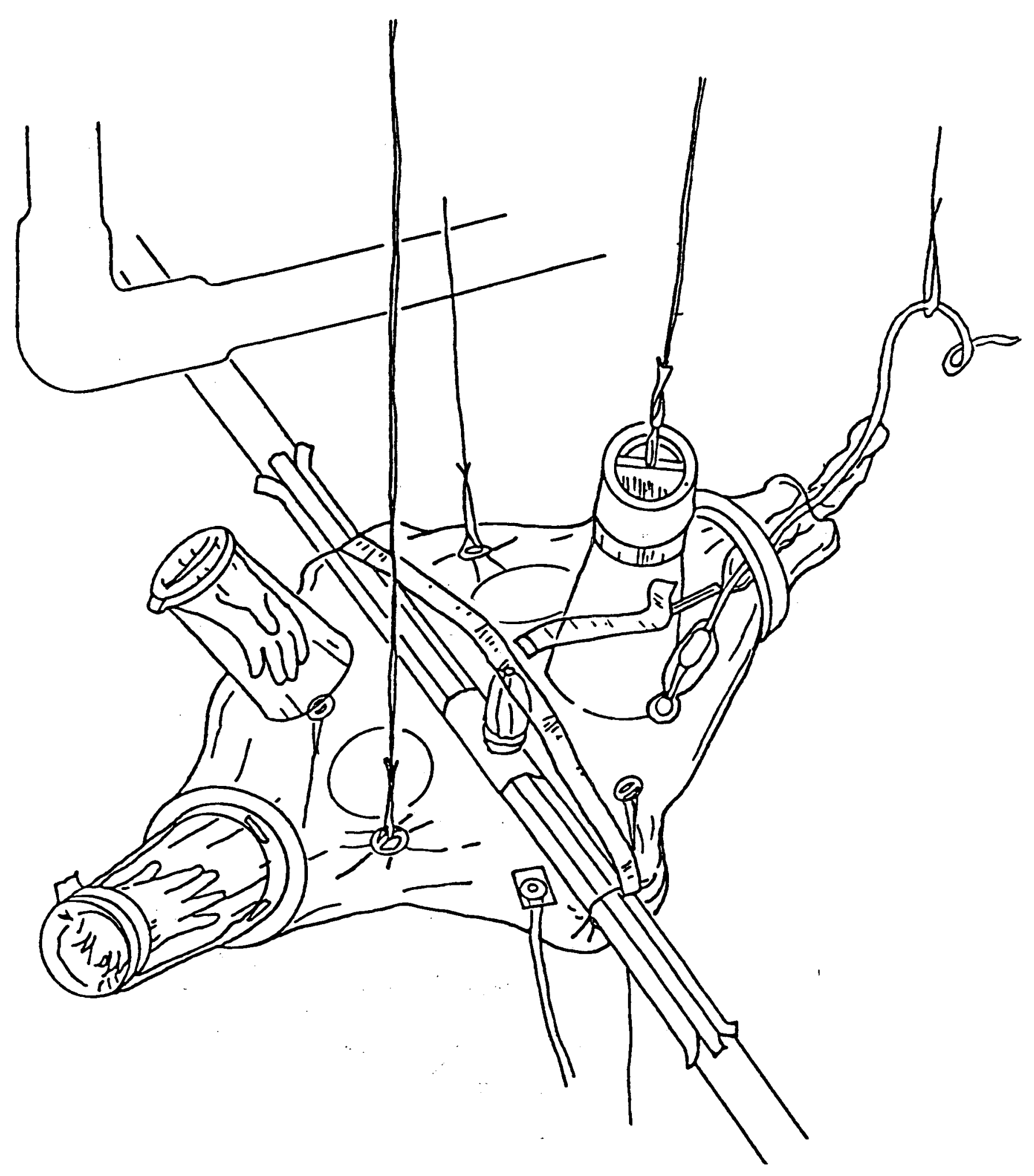




\author{
Catch Containment Typical \\ Arrangement
}

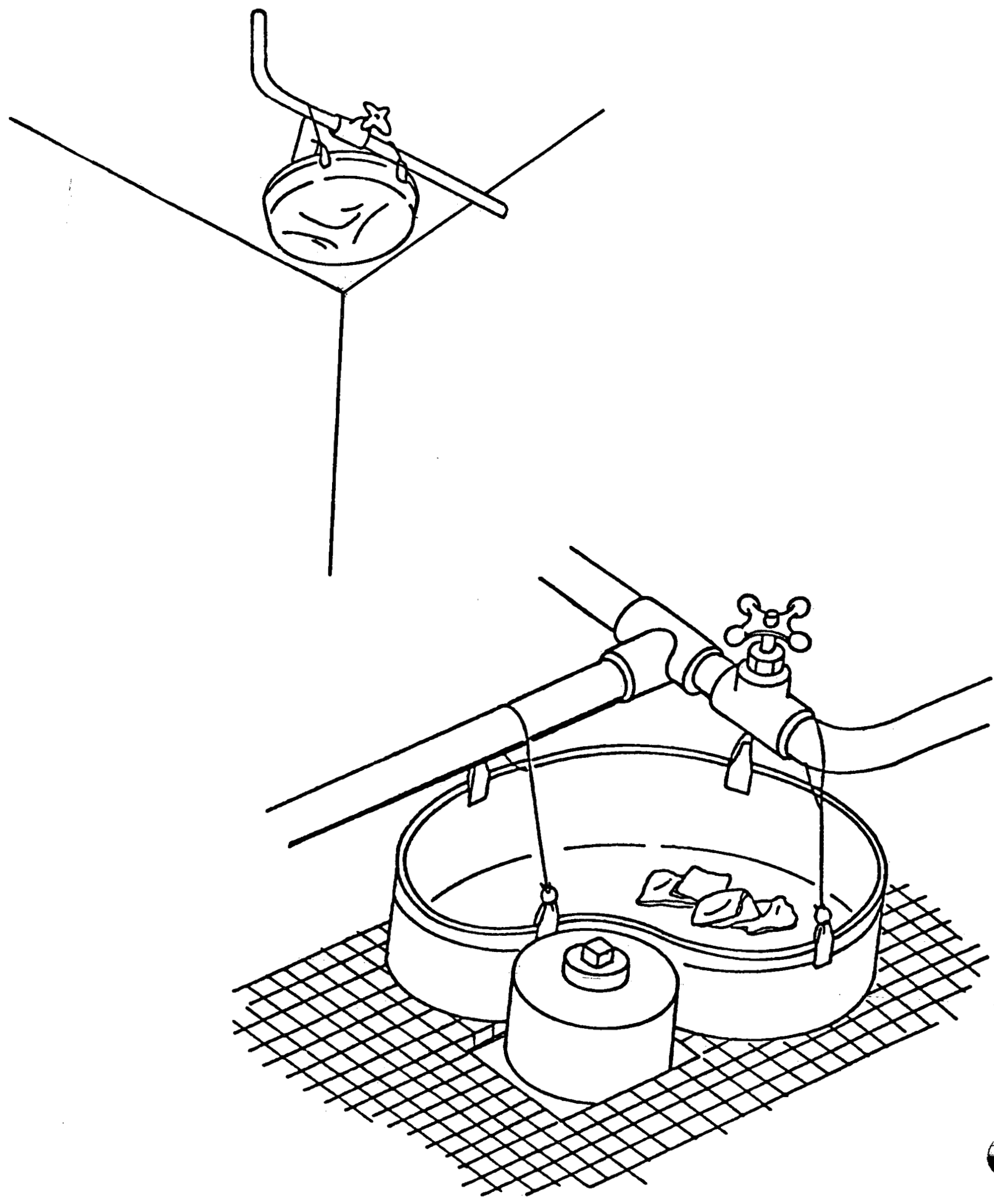

